Synthetic sapphire is a hard, transparent and mostly inert material. Because of its unique physical and chemical properties it is employed in many fields of technology. One of the methods for processing this material is laser processing This PhD thesis studies ultra-short pulsed laser processing and subsequent chemical etching of sapphire for high resolution 3D surface and bulk functionalization. A process is presented and discussed to structure crystalline sapphire substrates using the combination of picosecond or femtosecond pulsed laser irradiation and subsequent chemical etching. This process results in nanometer and micrometer sized structures on the surface and in the bulk of sapphire.

\title{
LASER MICRO/NANOPROCESSING AND SUBSEQUENT CHEMICAL ETCHING OF SAPPHIRE FOR SURFACE AND BULK FUNCTIONALIZATION
}

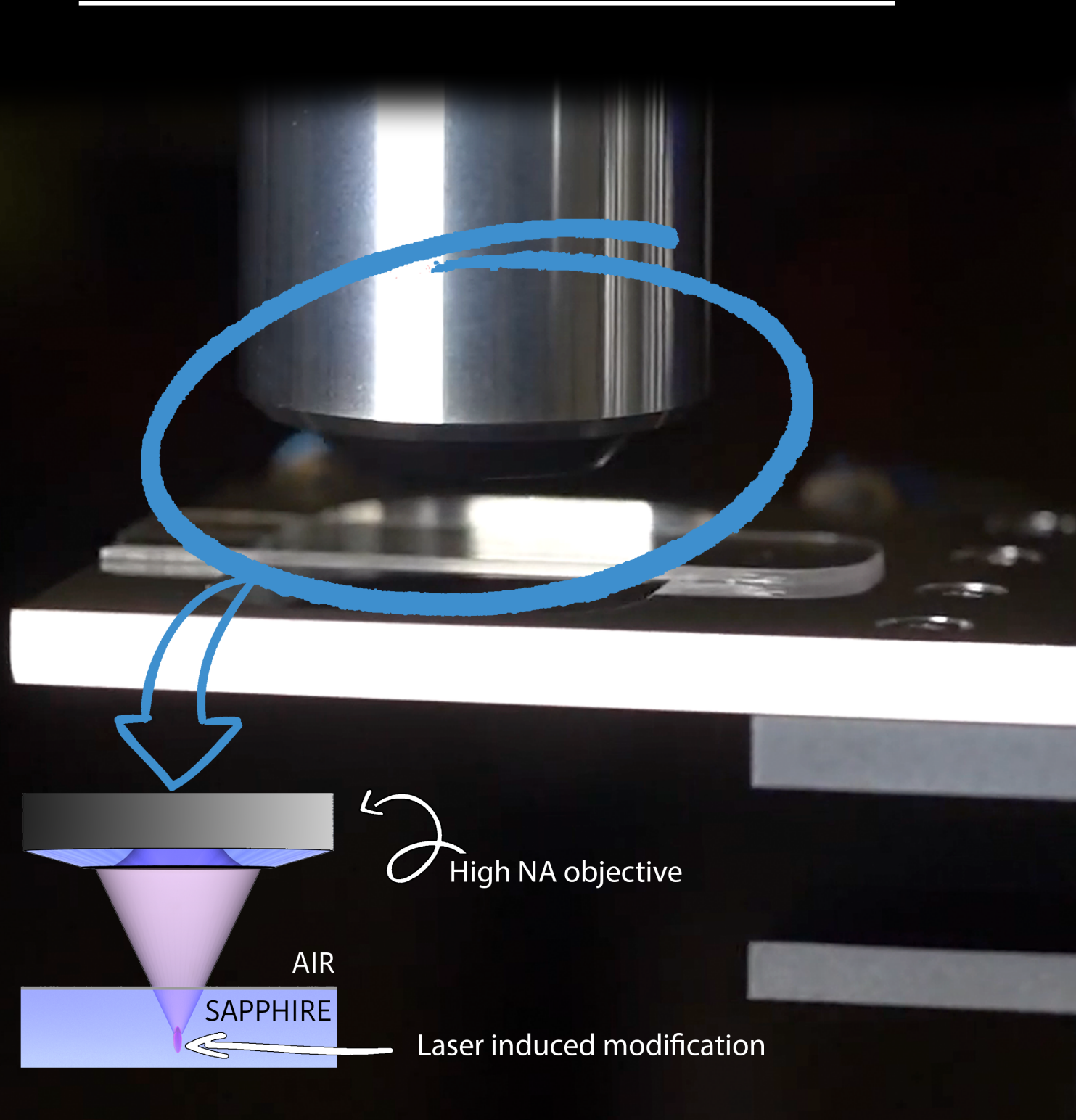


LASER MICRO / NANOPROCESSING AND

SUBSEQUENT CHEMICAL ETCHING OF SAPPHIRE FOR

SURFACE AND BULK FUNCTIONALIZATION

LUIGI CAPUANO 
Composition of the graduation committee:

Chairman and secretary:

Prof. dr. ir. H.F.J.M. Koopman University of Twente, the Netherlands

Promoter:

Prof. dr. ir. G.R.B.E. Römer University of Twente, the Netherlands

Co-promoter:

Dr. M. Feinaeugle

University of Twente, the Netherlands

Members:

Prof. dr. ir. J.G.E. Gardeniers

University of Twente, the Netherlands

Prof. dr. S.M. García Blanco

University of Twente, the Netherlands

Prof. dr. A. Ancona

University West, Sweden

Prof. dr. Sc. N. M. Bulgakova

HiLase Center, Czech Republic

\section{Paranymphs:}

Dr. Federico Califano \& Dr. Hasib Mustafa

The work described in this thesis was performed at the Chair of Laser Processing, Department of Mechanics of Solids, Surfaces \& Systems (MS ${ }^{3}$ ), Faculty of Engineering Technology, University of Twente, P.O. Box 217, 7500 AE Enschede, The Netherlands.

The project Laser4Fun (https:/ / www.laser4fun.eu/), leading to the work described in this thesis, has received funding from the European Union's Horizon 2020 research and innovation programme under the Marie Skłodowska-Curie grant agreement No. 675063.

Layout: This book was typeset with LTEX using the typographical look-andfeel classicthesis in the text editor TeXstudio.

Printed by: Ipskamp Printing, Enschede

ISBN: 978-90-365-5077-2

DOI: $10.3990 / 1.9789036550772$

(C) 2020 Luigi Capuano, The Netherlands. All rights reserved. No parts of this thesis may be reproduced, stored in a retrieval system or transmitted in any form or by any means without the permission of the author. 


\title{
DISSERTATION
}

\author{
to obtain \\ the degree of doctor at the University of Twente, \\ on the authority of the rector magnificus, \\ prof.dr.ir. A. Veldkamp, \\ on account of the decision of the Doctorate Board \\ to be publicly defended \\ on Friday 4 December 2020 at 12.45
}

by

Luigi Capuano

born on 9 November 1989

in Formia, Italy 
This thesis has been approved by the promoter Prof. dr. ir. G.R.B.E. Römer

and the co-promoter

Dr. M. Feinaeugle 
Dedicated to my parents,

Mario Capuano

\&

Antonietta Maria Pero

I could climb up to this point,

for they gave me the ladder.

The inevitability of change might be a universal constant.

- Sheldon Cooper 



\section{SUMMARY}

Synthetic sapphire $\left(\alpha-\mathrm{Al}_{2} \mathrm{O}_{3}\right)$ is a hard, transparent and mostly inert material. Because of its unique physical and chemical properties it is employed in many fields of technology. It is quite common, for example, to find sapphire in modern smartphones and watches.

Crystalline sapphire can be processed using several techniques. Typical processing methods are: mechanical sawing/dicing, dry etching, wet etching and laser processing. In contrast with the other methods, material processing through lasers is fast, precise and flexible in terms of different materials and geometries.

In this thesis, a two-step processing sequence to fabricate microstructures in/on sapphire substrates is presented and discussed. This two-step technique consists of ultra-short (typically picosecond or femtosecond) pulsed laser irradiation and subsequent chemical etching of sapphire. The radiation of focused ultra-short laser pulses can trigger non-linear effects in the material resulting in the material modification of sapphire. In particular, in the affected focal region of the laser beam, the molecular structure can be transformed from crystalline to amorphous. While crystalline sapphire is very inert and resistant to most chemical etchants, amorphous $\mathrm{Al}_{2} \mathrm{O}_{3}$ is reactive and can be selectively etched, permitting to create empty structures in sapphire which may be used for example as microfluidic channels. The method is still not fully exploited in industry due to several unresolved scientific and practical issues. The main objective of this thesis is to address some of these issues in order to achieve an optimized processing technique. To that end, first the physical phenomena governing laser-material interaction of subsurface laser processing of sapphire are studied and analysed. This is needed because, due to the complexity of these phenomena, the effect of processing conditions on the final structures is not yet fully understood. Therefore, a model is presented, which is used to simulate the interaction between the laser light and the sapphire during and directly after the ultrashort laser-pulse duration. The laser absorption phenomena considered in the model are: free electron absorption, multiphoton absorption, tunneling ionization, avalanche ionization, recombination of carriers, diffusion of carriers and heat diffusion. A main discovery from the simulations is that avalanche ionization plays a major role in the modifica- 
tion of the material. In fact, until the avalanche ionization is triggered inside sapphire, the other absorption mechanisms induce only a slight increase in the temperature of the lattice of sapphire. Moreover, a "shielding" effect was identified. That is, locations at which the laser energy is absorbed are also the locations at which free electrons are generated. In turn these free electrons absorb more laser energy, which "shield" lower regions of the material from the laser beam.

To understand the effect of laser-processing conditions and, in order to establish optimized laser parameters (such as: laser pulse energy, laser pulse repetition rate, laser pulse duration and focal depth below the surface) to obtain uniform amorphous structures in sapphire, experimental analysis was performed using a picosecond laser source, as well as a femtosecond laser source. Several structures are presented and discussed produced in the bulk and on the surface of sapphire. It was determined that femtosecond pulses $(230 \mathrm{fs})$ are best suited for the hybrid method of processing. Moreover, it was found that, there is a specific processing window at which the structures obtained show less cracks as well as uniform amorphized sapphire regions. The laser intensity must be high enough $\left(>10^{13}\right.$ to $\left.10^{14} \mathrm{~W} / \mathrm{cm}^{2}\right)$ to amorphize the material but, if an excessive intensity is used, the material cracks. To obtain an uniform and undivided amorphous volume, the laser pulse repetition rate must be at least $100 \mathrm{kHz}$, but, if a repetition rate higher than $1 \mathrm{MHz}$ is used, the material breaks.

Finally, the effect of two different selective etchants on the final morphology of the empty/hollow structures obtained after the etching phase is studied. Hydrofluoric acid (50\% stagnant solution at room temperature) is the most used etchant in this thesis. The hollow / empty structures obtained after etching in this etchant are identical to the shape of the amorphized regions before etching (that is, the crystalline material is not noticeably etched). The use of a mixture of sulphuric acid and phosphoric acid $\left(\mathrm{H}_{2} \mathrm{SO}_{4}+\mathrm{H}_{3} \mathrm{PO}_{4}\right)$ at $180{ }^{\circ} \mathrm{C}$ to etch the structures obtained with this technique, results not only in the fast etching of the amorphized material, but also in anisotropic etching of crystalline sapphire. A series of different structures were fabricated on the surface and in the bulk of sapphire to demonstrate the potential of the anisotropic etching of sapphire. The structures were analysed before etching and after several etching periods. The anisotropic etching of the crystalline sapphire of the modifications revealed structures showing well-defined geometrical shapes (trapezohedrons and tetrahedrons) and an etching-induced periodic pattern. 


\section{S A MENVATTING}

Synthetisch saffier $\left(\alpha-\mathrm{Al}_{2} \mathrm{O}_{3}\right)$ is een hard, transparant materiaal dat in hoge mate inert is. Vanwege deze unieke fysische en chemische eigenschappen wordt het in veel technologiegebieden toegepast. Saffier wordt bijvoorbeeld veel toegepast in moderne smartphones en horloges.

Kristallijn saffier kan met verschillende technieken worden bewerkt. Typische bewerkingsmethoden zijn: mechanisch zagen, droog etsen, nat etsen en laserbewerken. In tegenstelling tot de andere methoden is materiaal bewerking met lasers snel, nauwkeurig en flexibel in termen van materiaalkeuze als ook qua bewerkingsgeometrieën.

In dit proefschrift wordt een tweestaps laser-bewerkingstechniek om microstructuren in en op saffiersubstraten te fabriceren geïntroduceerd en onderzocht. Deze tweestaps-techniek bestaat uit het blootstellen van saffier aan ultrakort laser pulsen (met een pulsduur in het bereik van femtoseconden tot picoseconden) en daaropvolgend chemisch etsen van saffier. De straling van de gefocuste ultrakorte laserpulsen kan niet-lineaire effecten in het materiaal teweegbrengen, wat resulteert in modificatie van saffier. Indien de intensiteit van de laserbundel hoog genoeg is, kan de moleculaire structuur van saffier worden getransformeerd van kristallijn naar amorf. Terwijl kristallijn saffier zeer inert is en bestand is tegen de meeste chemische etsmiddelen, is amorf $\mathrm{Al}_{2} \mathrm{O}_{3}$ reactief en kan het selectief worden geëtst, waardoor "open structuren" in saffier kunnen worden gecreëerd. De methode wordt nog steeds niet volledig uitgebuit in de industrie vanwege een aantal nog onopgeloste wetenschappelijke en praktische problemen. Het belangrijkste doel van dit proefschrift is om een aantal van deze problemen aan te pakken om zo tot een geoptimaliseerde bewerkingstechniek te komen. Daartoe worden eerst de fysische verschijnselen, die de interactie tussen het laserlicht en het materiaal onder de oppervlakte van het saffier bepalen, bestudeerd en geanalyseerd. Dit is nodig omdat, vanwege de complexiteit van deze verschijnselen, het effect van bewerkingsparameters op de uiteindelijke structuren nog niet volledig wordt begrepen. Daarom wordt in dit proefschrift een model gepresenteerd dat wordt gebruikt om de interactie tussen het laserlicht en het saffier tijdens en direct na de ultrakorte laserpuls te simuleren. De laserabsorptieverschijnselen die in het model worden beschouwd zijn: vrije elektronenabsorptie, 
multifotonabsorptie, tunnelingsionisatie, lawine-ionisatie, recombinatie van ladings-dragers, diffusie van ladings-dragers en klassieke warmtediffusie. Een belangrijke bevinding uit de simulaties is dat lawine-ionisatie een cruciale rol speelt bij de modificatie van het materiaal. Dat wil zeggen, totdat lawineionisatie zich in saffier manifesteert, veroorzaken de andere absorptiemechanismen slechts een lichte stijging van de temperatuur van het kristalrooster van saffier. Bovendien werd een "afschermend" effect gevonden, d.w.z. locaties waar de laserenergie wordt geabsorbeerd, zijn ook de locaties waar vrije elektronen worden gegenereerd. Deze vrije elektronen absorberen op hun beurt meer laserenergie, die de lagergelegen delen van het materiaal "afschermen" van de laserstraal.

Pico- en femtoseconde laserbronnen zijn gebruikt om experimenteel optimale laserparameters (zoals puls-energie, pulsfrequentie en pulsduur) vast te stellen voor het maken van uniforme amorfe structuren in saffier. Verschillende structuren die werden gevonden in de bulk en op het oppervlak van saffier worden gepresenteerd en besproken. Het blijkt dat femtoseconde laser pulsen $(230 f s$ ) het meest geschikt zijn voor de tweestaps bewerkingsmethode. Bovendien blijkt dat er een specifieke set van bewerkingsparameters is waarbij de verkregen structuren relatief weinig scheuren vertonen, evenals uniforme geamorfiseerde saffiergebieden. De laserintensiteit moet hoog genoeg zijn (> $10^{13}$ tot $10^{14} \mathrm{~W} / \mathrm{cm}^{2}$ ) om het materiaal te amorfiseren, maar bij toepassing van een te hoge intensiteit verschijnen er scheuren in het materiaal. Om een uniform amorf volume te verkrijgen, moet de pulsfrequentie van de laser ten minste $100 \mathrm{kHz}$ zijn, maar als een pulsfrequentie hoger dan $1 \mathrm{MHz}$ wordt toegepast scheurt het materiaal.

Ten slotte wordt het effect van twee verschillende selectieve etsmiddelen op de uiteindelijke morfologie van de holle structuren, die na de ets fase worden verkregen gepresenteerd en onderzocht. Fluorwaterstofzuur $(50 \%$ stagnerende oplossing bij kamertemperatuur) is het meest toegepaste etsmiddel in dit proefschrift. De holle/lege structuren verkregen na het etsen in dit etsmiddel zijn identiek aan de vorm van de laser-geamorfiseerde gebieden vóór het etsen (dat wil zeggen, het kristallijne materiaal wordt niet, tot verwaarloosbaar geëtst). Het gebruik van een etsmengsel van zwavelzuur en fosforzuur $\left(\mathrm{H}_{2} \mathrm{SO}_{4}+\mathrm{H}_{3} \mathrm{PO}_{4}\right)$ bij $180{ }^{\circ} \mathrm{C}$, resulteert niet alleen in het snel etsen van het geamorfiseerde materiaal, maar ook in het anisotroop etsen van het naburige kristallijne saffier. Een reeks verschillende structuren werden zowel op het oppervlak als in saffier vervaardigd om het potentieel van het anisotrope etsen van saffier aan te tonen. $\mathrm{Na}$ het anisotrope etsen van het 
kristallijne saffier van de modificaties werden structuren goed gedefinieerde geometrische vormen gevonden als ook een "ets-geïnduceerd periodiek patroon". 

- L. Capuano, D. de Zeeuw, and G. R. B. E. Römer. "Towards a numerical model of picosecond laser-material interaction in bulk sapphire." Journal of laser micro nanoengineering 13, no. 3 (2018): 166-177.(Chapter 3 of this thesis)

- L. Capuano, R. Pohl, R. M. Tiggelaar, J. W. Berenschot, J. G. E. Gardeniers, and G. R. B. E. Römer. "Morphology of single picosecond pulse subsurface laser-induced modifications of sapphire and subsequent selective etching." Optics express 26, no. 22 (2018): 29283-29295.(Chapter 4 of this thesis)

- L. Capuano, R. M. Tiggelaar, J. W. Berenschot, J. G. E. Gardeniers, and G. R. B. E. Römer. "Fabrication of millimeter-long structures in sapphire using femtosecond infrared laser pulses and selective etching." Optics and Lasers in Engineering 133 (2020): 106114. (Chapter 5 of this thesis)

- L. Capuano, M. Feinaeugle, R. M. Tiggelaar, J. W. Berenschot, J. G. E. Gardeniers, and G. R. B. E. Römer. "Fabrication of microstructures in and on sapphire by anisotropic selective wet etching of femtosecond infrared laser affected volumes" In preparation. (Chapter 6 of this thesis)

OTHER JOURNAL PUBLICATIONS

- N. Ur Rahman, L. Capuano, A. van der Meer, M. B. De Rooij, D. T. A. Matthews, G. Walmag, M. Sinnaeve, A. Garcia-Junceda, M. Castillo, and G. R. B. E. Römer. "Development and characterization of multilayer laser cladded high speed steels." Additive manufacturing 24 (2018): 76-85.

- N. Ur Rahman, L. Capuano, M. B. De Rooij, D. T. A. Matthews, A. GarciaJunceda, M. A. Mekicha, L. Cordova, G. Walmag, M. Sinnaeve, and G. R. B. E. Römer. "Laser metal deposition of vanadium-rich high speed steel: Microstructural and high temperature wear characterization." Surface and coatings technology 364 (2019): 115-126. 
- N. Ur Rahman, L. Capuano, S. Cabeza, M. Feinaeugle, A. Garcia-Junceda, M. B. de Rooij, D. T. A. Matthews, G. Walmag, I. Gibson, and G. R. B. E. Römer. "Directed energy deposition and characterization of high-carbon high speed steels." Additive manufacturing 30 (2019): 100838.

- H. Mustafa, M. P. Aarnts, L. Capuano, D. T. A. Matthews, and G. R. B. E. Römer. "Data on laser induced preferential crystal (re) orientation by picosecond laser ablation of zinc in air." Data in brief 24 (2019): 103922.

CONFERENCE CONTRIBUTIONS

- L. Capuano, D. de Zeeuw, and G. R. B. E. Römer. "Towards a numerical model of picosecond laser-material interaction in bulk sapphire." The 19th International Symposium on Laser Precision Microfabrication (LPM 2018), Edinburgh, UK, 2018.

- L. Capuano, G. R. B. E. Römer, "Double-step processing of sapphire", Poster presented at Photonics Event 2018, Enschede, The Netherlands, 2018.

OUTREACH TO THE GENERAL PUBLIC

- Video Youtube: "Micromachining of sapphire, a material of the future", 07 Oct 2019. https: / / www.youtube.com/watch?v=55MPFJi8sM0

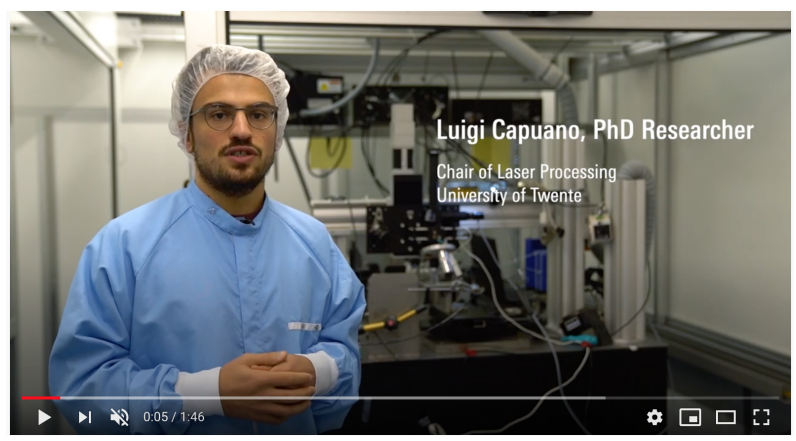

Screenshot from the Youtube video. 


\section{Roman symbols}

\begin{tabular}{lll}
\hline Symbol & Description & Unit \\
\hline$B$ & Magnetic flux density & $\mathrm{T}$ \\
$C_{e}$ & Specific heat capacity electron subsystem & $\mathrm{kJ} / \mathrm{kg}$ \\
$C_{l}$ & Specific heat capacity lattice & $\mathrm{kJ} / \mathrm{kg}$ \\
$D$ & Electric displacement field & $\mathrm{C} / \mathrm{m}^{2}$ \\
$E$ & Electric field strength & $\mathrm{V} / \mathrm{m}$ \\
$E_{e}$ & Energy electron subsystem & $\mathrm{eV}$ \\
$E_{g}$ & Bandgap energy & $\mathrm{eV}$ \\
$E_{p}$ & Pulse energy & $\mathrm{J}$ \\
$H$ & Magnetic field strength & $\mathrm{A} / \mathrm{m}$ \\
$H V$ & Hardness Vickers & $\mathrm{kN} / \mathrm{mm}^{2}$ \\
$I$ & Optical intensity & $\mathrm{W} / \mathrm{m}^{2}$ \\
$J$ & Current & $\mathrm{A}$ \\
\hline$L$ & Loss terms & $\mathrm{W} / \mathrm{m}^{3}$ \\
$P$ & Power & $\mathrm{W}$ \\
$Q$ & Thermal source & $\mathrm{W} / \mathrm{m}^{3}$ \\
$S$ & Source term & $\mathrm{W} / \mathrm{m}^{3}$ \\
$T_{e}$ & Temperature of electron subsystem $(\mathrm{gas})$ & $\mathrm{Kor} \mathrm{eV}$ \\
$T_{l}$ & Temperature of lattice & $\mathrm{K}$ \\
$W_{\text {source }}$ & Electron ionization rate & $1 /\left(\mathrm{m}^{3} \mathrm{~s}\right)$ \\
$W_{l o s s}$ & Electron reduction rate & $1 /\left(\mathrm{m}^{3} \mathrm{~s}\right)$ \\
$c_{0}$ & Speed of light in vacuum $(299792458)$ & $\mathrm{m} / \mathrm{s}$ \\
$e$ & Electron charge $\left(1.60217662 \cdot 10^{-19}\right)$ & $\mathrm{C}$ \\
$h$ & Planck constant $\left(6.6260700 \cdot 10^{-34}\right)$ & $\mathrm{Js}$ \\
\hline & & \\
\hline$H$ & & \\
\hline & & \\
\hline
\end{tabular}




\begin{tabular}{lll}
$\hbar$ & Reduced Planck constant $\left(1.054571800 \cdot 10^{-34}\right)$ & $\mathrm{Js} / \mathrm{rad}$ \\
\hline$k$ & Wavenumber & $\mathrm{m}^{-1}$ \\
$k_{0}$ & Reference wave number & $\mathrm{m}^{-1}$ \\
$k_{b}$ & Boltzmann constant $\left(1.38064852 \cdot 10^{-23}\right)$ & $\mathrm{W} / \mathrm{mK}$ \\
$k_{e}$ & Electron thermal conductivity & $\mathrm{m}^{2} \mathrm{~K} / \mathrm{s}^{2} \mathrm{k}$ \\
$k_{l}$ & Thermal conductivity & $\mathrm{W} / \mathrm{mK}$ \\
$m_{e}$ & Electron mass $\left(9.10938356 \cdot 10^{-31}\right)$ & $\mathrm{kg}$ \\
$m_{e}^{*}$ & Effective electron mass & $\mathrm{kg}$ \\
$m_{h}^{*}$ & Effective hole mass & $\mathrm{kg}$ \\
\hline$n$ & Refractive index & - \\
\hline$n_{c r}$ & Critical electron density & $\mathrm{m}^{-3}$ \\
$n_{e}$ & Free electron density & $\mathrm{m}^{-3}$ \\
$n_{p h}$ & Number of photons & - \\
\hline$n_{v b}$ & Valence band electron density & $\mathrm{m}^{-3}$ \\
$t$ & Time & $\mathrm{s}$ \\
\hline$t_{p}$ & Pulse duration & $\mathrm{s}$ \\
$w_{0}$ & Beam radius in focus & $\mathrm{m}^{2}$ \\
\hline
\end{tabular}

\section{Greek symbols}

\begin{tabular}{lll}
\hline Symbol & Description & Unit \\
\hline$\Gamma$ & Electron phonon coupling coefficient & $\mathrm{J} /(\mathrm{kgKs})$ \\
$\gamma$ & Keldish parameter & - \\
$\delta$ & Impact ionization coefficient & - \\
$\epsilon_{o}$ & Vacuum permittivity $\left(8.854187817 \cdot 10^{-12}\right)$ & $\mathrm{F} / \mathrm{m}$ \\
$\eta$ & Electrical impedance & $\Omega$ \\
$\lambda$ & Wavelength & $\mathrm{m}$ \\
$\mu_{e}$ & Electron mobility & $\mathrm{m}^{2} / \mathrm{Vs}$ \\
$\mu_{h}$ & Hole mobility & $\mathrm{m}^{2} / \mathrm{Vs}$ \\
$\nu_{e}$ & Electron collision frequency & $1 / \mathrm{s}$ \\
$\rho$ & Density & $\mathrm{g} / \mathrm{cm}^{3}$
\end{tabular}




\begin{tabular}{lll}
$\sigma$ & Electrical conductivity & $\mathrm{S} / \mathrm{m}$ \\
$\sigma_{a b}$ & Absorption cross-section & $\mathrm{m}$ \\
$\sigma_{c}$ & Ultimate compressive strength & $\mathrm{N} / \mathrm{m}^{2}$ \\
$\sigma_{n}$ & N-photon absorption coefficient & $\mathrm{m}^{2}$ \\
$\sigma_{t}$ & Ultimate tensile strength & $\mathrm{N} / \mathrm{m}^{2}$ \\
$\tau_{c}$ & Mean electron-electron collision time & $\mathrm{s}$ \\
$\tau_{e}$ & Mean electron-hole recombination time & $\mathrm{S}$ \\
$\tau_{r}$ & Characteristic electron lattice relaxation time & $\mathrm{s}$ \\
$\chi$ & Electic susceptability & - \\
$\omega$ & Frequency of light & $\mathrm{rad} / \mathrm{s}$ \\
$\omega_{p}$ & Electron plasma frequency & $\mathrm{rad} / \mathrm{s}$ \\
\hline
\end{tabular}





\section{CONTENTS}

Summary

Nomenclature

1 INTRODUCTION

1.1 Laser modification of bulk transparent materials . . . . . . . . 1

1.2 Natural and synthetic sapphire: characteristics and uses . . . . . 3

1.3 Problem definition and Research objectives . . . . . . . . . 6

1.3.1 Problem definition . . . . . . . . . . . . . 6

1.3.2 Research objectives . . . . . . . . . . . . . 7

1.4 Thesis outline . . . . . . . . . . . . . . 9

2 LASER MODIFICATION OF SAPPHIRE AND SELECTIVE ETCH-

ING: THEORETICAL BACKGROUND AND EXPERIMENTAL METH-

ODS 15

2.1 Laser modification of the crystallinity of sapphire . . . . . . 15

2.2 Selective etching of sapphire . . . . . . . . . . . . . . 17

2.3 Complex structures inside the bulk of sapphire . . . . . . . . 18

2.4 Experimental methods . . . . . . . . . . . . . . . . 21

2.4.1 Experimental set-up for laser modification and selective etching of sapphire . . . . . . . . . . . . . . 21

2.5 Materials . . . . . . . . . . . . . . . . . . . 24

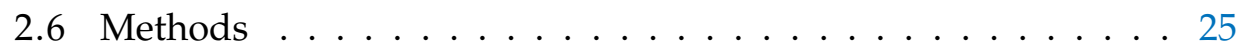

2.7 Analysis tools . . . . . . . . . . . . . . 26

3 TOWARDS A NUMERICAL MODEL OF PICOSECOND LASERMATERIAL INTERACTION IN BULK SAPPHIRE 29

3.1 Introduction $\ldots \ldots \ldots \ldots \ldots \ldots \ldots \ldots \ldots \ldots \ldots$

3.2 Model description and governing equations . . . . . . . . . . 31

3.2.1 Free electron density . . . . . . . . . . . . . 32

3.2 .2 Free electron temperature . . . . . . . . . . . 36

3.2 .3 Lattice temperature . . . . . . . . . . . . . . . . 38

3.2 .4 Beam propagation . . . . . . . . . . . 38

3.3 Model Implementation . . . . . . . . . . . . . . . . . . . . . . 39

3.3.1 Initial and boundary conditions . . . . . . . . . 39

3.4 Results . . . . . . . . . . . . . . . . . . . 40

3.4 .1 Electron Density . . . . . . . . . . . . . 41

3.4.2 Electron and lattice temperatures . . . . . . . . . . 43 
3.4.3 Laser intensity spatial distribution . . . . . . . . . . . 45

3.4.4 Electron density distribution . . . . . . . . . . . . 45

3.4.5 Temperature and energy distribution in the electron sub-

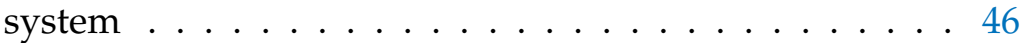

3.5 Limitations of the model . . . . . . . . . . . . . . . . . 46

3.5.1 Phase transformation and material properties . . . . . 46

3.5.2 Beam propagation and focusing optics . . . . . . . . . 48

3.5.3 Free electron temperature . . . . . . . . . . . . 48

3.5.4 Self-Focusing and Kerr effect . . . . . . . . . . . . . 48

3.6 Conclusions . . . . . . . . . . . . . . . . . . . . . . . . 49

3.7 Additional results . . . . . . . . . . . . . . . . . . . . . . 49

3.7.1 Electron density, electron temperature and lattice temperature in overcritical conditions . . . . . . . . . 49

3.7.2 Energy balance . . . . . . . . . . . . . . 52

4 MORPHOLOGY OF SINGLE PICOSECOND PULSE SUBSURFACE LASER-INDUCED MODIFICATIONS OF SAPPHIRE AND SUBSEQUENT SELECTIVE ETCHING 57

4.1 Introduction . . . . . . . . . . . . . . 57

4.2 Materials and methods . . . . . . . . . . . . . . . . 61

4.2.1 Materials . . . . . . . . . . . . . . 61 61

4.2 .2 Laser set-up . . . . . . . . . . . . . . . . 6 . . . . . . . . . . . 61

4.2 .3 Analysis tools . . . . . . . . . . . . . . . . 6 62

4.2 .4 Methods . . . . . . . . . . . . . . . . 62

4.2 .5 Simulations . . . . . . . . . . . . . . . 63

4.3 Results and discussion . . . . . . . . . . . . . . . . 64

4.3.1 The effect of pulse energy on morphology of modifications 64

4.3.2 The effect of focus depth on morphology of modifications 66

4.3 .3 Cracks . . . . . . . . . . . . . . . 67

4.3.4 Simulation and experimental validation . . . . . . . . 67

4.3.5 Morphology of etched amorphous sapphire . . . . . . 71

4.4 Conclusions . . . . . . . . . . . . . . . 72

5 FABRICATION OF MILLIMETER-LONG STRUCTURES IN SAPPHIRE USING FEMTOSECOND INFRARED LASER PULSES AND SELECTIVE ETCHING 77

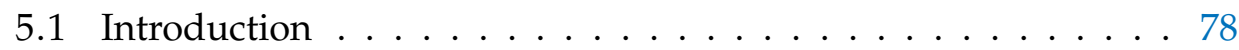

5.2 Experimental set-up and analysis tools . . . . . . . . . . . 80

5.3 Materials and methods . . . . . . . . . . . . . . . 81

5.3 .1 Materials . . . . . . . . . . . . . . . . . 81 
5.3 .2 Methods . . . . . . . . . . . . . . . . . 81

5.4 Results and discussion . . . . . . . . . . . . . . . 84

5.4.1 Structures parallel or perpendicular to the polarization of the laser light . . . . . . . . . . . . . . 85

5.4.2 Effect of pulse repetition rate on lines and stacks of lines 89

5.4 .3 Effect of energy per pulse . . . . . . . . . . . 990

5.4 .4 Overlapping of the modified lines . . . . . . . . . 92

5.5 Conclusions .......................... 95

6 FABRICATION OF MICROSTRUCTURES IN AND ON SAPPHIRE BY ANISOTROPIC SELECTIVE WET ETCHING OF FEMTOSECOND INFRARED LASER AFFECTED VOLUMES 101

6.1 Introduction . . . . . . . . . . . . . . . . 102

6.2 Crystallographic structure and anisotropic etching of sapphire . 103

6.3 Experimental section . . . . . . . . . . . . . . . 106

6.3 .1 Materials . . . . . . . . . . . . . . . 106

6.3 .2 Laser set-up . . . . . . . . . . . . . . . . . . . . . . . . . . . . . . . . . . .

6.3 .3 Methods . . . . . . . . . . . . . . . . . . 107

6.3 .4 Analysis tools . . . . . . . . . . . . . . . 108

6.4 Results and discussion . . . . . . . . . . . . . . . . . . . . . . . . . . . . . . . . . . . . . . .

6.4 .1 Subsurface processing . . . . . . . . . . . . . . . . . . . . . . . . . . . . .

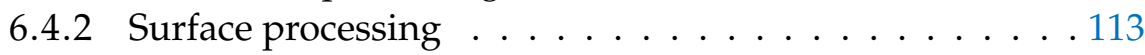

6.5 Conclusions . . . . . . . . . . . . . . . . 117

7 CONCLUSIONS AND RECOMMENDATIONS 123

7.1 Conclusions . . . . . . . . . . . . . . . . 123

7.2 Recommendations . . . . . . . . . . . . . . . 128

ACKNOWLEDGEMENTS 131 



\section{1}

\section{INTRODUCTION}

\subsection{LASER MODIFICATION OF BULK TRANSPARENT MATERIALS}

Thanks to their unique properties, laser sources are employed in many fields including sensors and measurement equipment, surgery, telecommunications and material processing. In contrast with many traditional processing methods, laser-material processing is fast, precise and flexible in terms of different materials and geometries [1]. Therefore, laser-material processing is, not only replacing multiple conventional manufacturing methods, but it also creates new possibilities in terms of processing techniques and/or new products [1].

Subsurface ultrashort pulsed laser 3D processing of transparent materials is one of the flourishing applications of laser micromachining. Its growing popularity is due to the fact that the technique allows the fabrication of unique textures and structures unachievable with other methods like mechanical processing, dry and wet etching or laser surface machining [2-5]. Laser processing of transparent materials allows for example to produce channels and reservoirs directly inside the material, to be used for microfluidic applications [6-8]. Although laser ablation/vaporization can be employed to remove material and produce structures on the surface of transparent materials [9; 10], direct 3D structuring requires nonlinear absorption of the laser light directly inside the bulk.

The use of laser energy to produce subsurface modifications derives from the possibility to modify the transparent material directly in the bulk, leaving the surface unaffected [4]. To do so, the laser energy is to be absorbed in a confined volume below the surface. This implies that the material has to be sufficiently transparent for the wavelength of the laser beam to reach the bulk of the material. Transparent dielectrics have a wide optical band gap [4;5] implying a high transparency in the visible or near infrared part of the spectrum of light at low intensity. Of course, this requirement is in direct competition with the necessity of absorption of laser energy in the volume that is to be modified. At laser intensities in excess of $10^{14} \mathrm{~W} / \mathrm{cm}^{2}$, most dielectrics are ionized [11-14]. To achieve such high intensities, tightly focused ultrashort laser pulses, with pulse durations in the femto- to picosecond regime [15] can 
be employed. The laser energy absorbed in the material eventually causes a modification (Figure 1.1 (a)) resulting in a change of optical and structural properties only in the focal region, leaving the surface of the specimen and the surroundings of the modified area unaffected. By overlapping single laserpulse induced modifications, it is possible to produce a large variety of 3D shapes inside the bulk [12; 16-23].
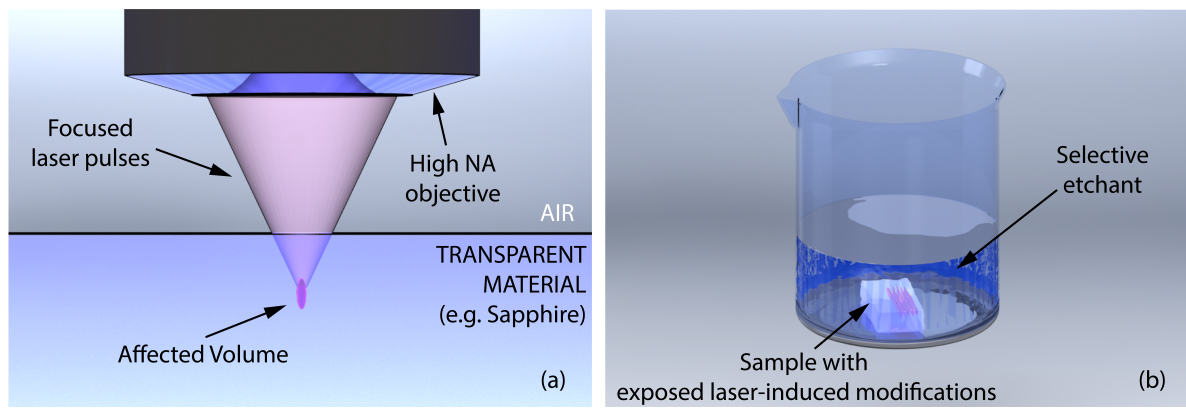

Figure 1.1: 3D schematic showing the subtractive processing method based on laser modification and selective etching. (a) The transparent material is irradiated with ultra-short laser pulses and a modified volume is formed. (b) The sample is submerged in a selective etchant for the removal of the laser-modified material.

A limiting factor in this process is that, since the solid modified material is embedded inside the bulk of the transparent material, it is not possible to directly produce empty/hollow structures. However, by combining ultrashort pulsed laser irradiation (Figure 1.1 (a)) with a subsequent selective etching step (Figure $1.1(\mathrm{~b})$ ), it is feasible to process transparent materials in a subtractive manufacturing method .

Such a "hybrid" technique of laser-induced material modification, and subsequent chemical selective etching of the modified material, allows the creation of surface and bulk 3D microstructures to be used in a wide range of applications. Although very appealing, this method is still at an early stage of its development and several scientific challenges need to be overcome for the technique to be fully exploited. Many issues characteristic of the process, in fact, are still unresolved.

This is especially the case for sapphire. 
1.2 NATURAL AND SYNTHETIC SAPPHIRE: CHARACTERISTICS AND USES

Natural sapphire is one of the mineral forms of corundum, which is a form of aluminium oxide $\left(\alpha-\mathrm{Al}_{2} \mathrm{O}_{3}\right)$. Inclusions of elements such as iron, titanium, chromium, copper or magnesium can give the mineral corundum a wide range of colours. Red corundum is typically referred to as ruby [24].

Sapphire can be produced artificially for industrial purposes. Synthetic sapphire is also referred to as sapphire glass. The production of synthetic sapphire at industrial scale started in the early twentieth century thanks to the discoveries of French chemist Auguste Verneuil who published the homonymous synthesis process [25] in 1904. This technique was for many years the only industrial production method of synthetic corundum. Starting from the 1960s new methods of production were invented with the objective of increasing the purity of ruby and sapphire. In this framework new synthesis methods such as the Czochralski crystal growth, the edge-defined film-fed growth (EFG) by LaBelle, the heat exchanger method (HEM) by Shmid and Viechnicki replaced Verneuil's process [26]. To date, these techniques are still the main methods for producing synthetic sapphire.

Synthetic sapphire is chemically inert, it has a high melting point, low friction coefficient, and it is a good thermal and electrical insulator, see table 1.1. Moreover, the material is not only highly transparent to wavelengths in the electromagnetic spectrum between $150 \mathrm{~nm}$ (UV) and $5500 \mathrm{~nm}$ (IR) [27] (the human eye can discern wavelengths from about $380 \mathrm{~nm}$ to $750 \mathrm{~nm}$ [28]), but due to its hardness ( 9 in the Mohs scale), also highly scratch-resistant.

Table 1.1 shows an overview of the main physical and chemical properties of sapphire [29]. This unique combination of physical, chemical properties allows single crystal sapphire to withstand high temperatures, high pressure, thermal shock, water or sand erosion and chemical etching. In addition, its radiation resistance makes it an excellent material for use in optical windows for space applications [29; 30].

Sapphire substrates are produced by slicing pure boules grown, following a specific crystal orientation (normally along the optical c-axis for minimum birefringence). The substrates are then polished to the desired surface roughness [31]. Sapphire is an anisotropic hexagonal crystal; implying that its properties depend on crystallographic direction relative to the optical c-axis (see figure 1.4 and table 1.1). Figures 1.2 and 1.3, and Table 1.1 show some physical and optical properties of sapphire. 


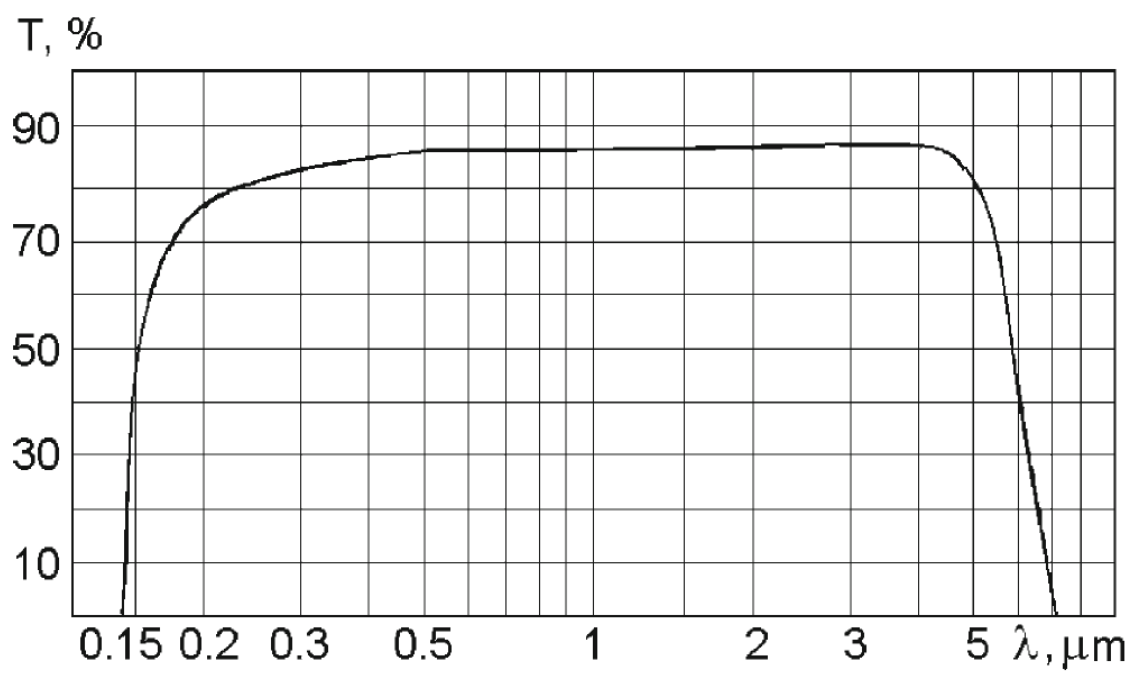

Figure 1.2: Dependence of transmission T (\%) on wavelength [29].

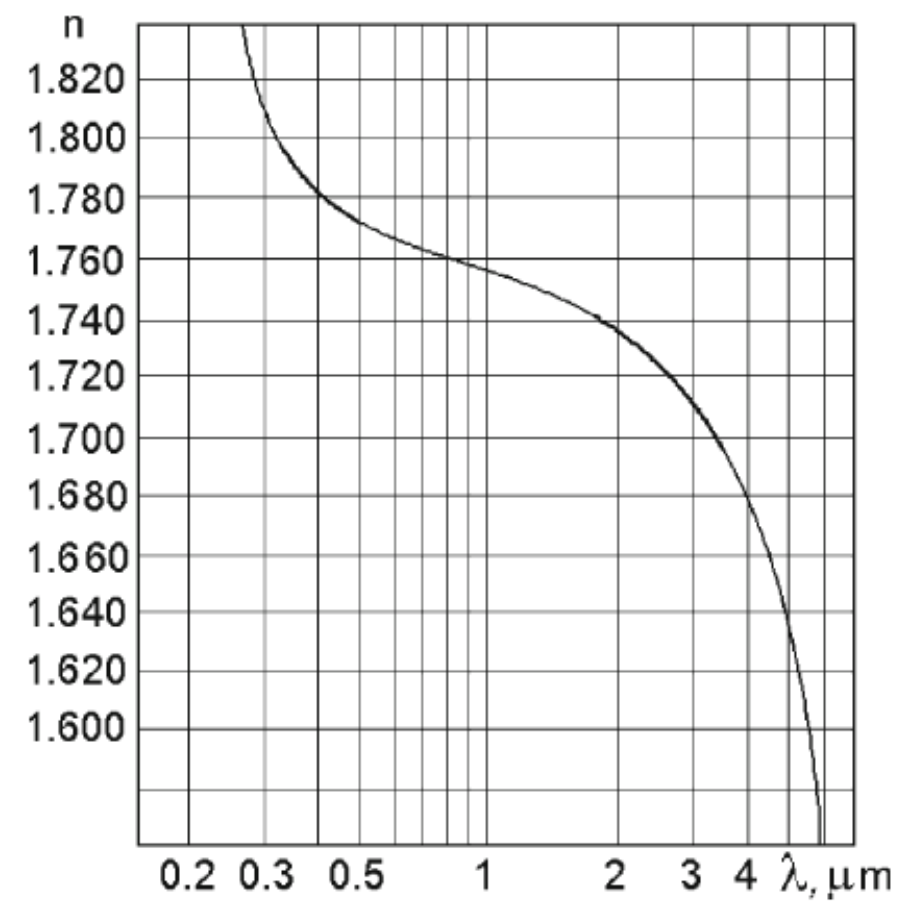

Figure 1.3: Variation of the refractive index $n$ of sapphire with wavelength [29]. 
Table 1.1: Chemical and physical properties of synthetic sapphire [29].

\begin{tabular}{ll}
\hline Chemical formula & $\mathrm{Al}_{2} \mathrm{O}_{3}$ \\
\hline Crystal class & Trigonal \\
\hline Molecular weight & 101.94 \\
\hline Density (at 298 $\mathrm{K}), \mathrm{g} / \mathrm{cm}^{3}$ & 3.98 \\
\hline Dielectric constant for $10^{3}-10^{9} \mathrm{~Hz}($ at $298 \mathrm{~K})$ & \\
$\quad$ Parallel to C-axis & 11.5 \\
$\quad$ Perpendicular to C-axis & 9.3 \\
\hline Dielectric strength, $\mathrm{V} / \mathrm{m}$ & $48 \cdot 10^{6}$ \\
\hline Resistivity (at 298 $\mathrm{K}), \Omega \cdot \mathrm{cm}$ & \\
$\quad$ Parallel to C-axis & $5.0 \cdot 10^{18}$ \\
$\quad$ Perpendicular to C-axis & $1.3-2.9 \cdot 10^{19}$ \\
\hline Melting temperature, $\mathrm{K}$ & 2300 \\
\hline Thermal conductivity $(300 \mathrm{~K}), \mathrm{W} /(\mathrm{m} \cdot \mathrm{K})$ & \\
$\quad$ Parallel to C-axis & 35.1 \\
$\quad$ Perpendicular to C-axis & 33.0 \\
\hline Thermal expansion (at $298 \mathrm{~K}), \mathrm{K}-1$ & \\
$\quad$ Parallel to C-axis & $5.6 \times 10^{-6}$ \\
Perpendicular to C-axis & $5.0 \times 10^{-6}$ \\
\hline Specific heat (at $298 \mathrm{~K}), \mathrm{cal} /(\mathrm{g} \cdot \mathrm{K})$ & 0.18 \\
\hline Bandgap, $\mathrm{eV}$ & 9.9 \\
\hline Mohs hardness & 9 \\
\hline Knoop hardness, $\mathrm{kg} / \mathrm{mm}{ }^{2}$ & 1370 \\
\hline Young's modulus, $\mathrm{GPa}$ & 335 \\
\hline Shear modulus, $\mathrm{GPa}$ & 240 \\
\hline Bulk modulus, $\mathrm{GPa}$ at $273 \mathrm{~K}$ & 0.25 \\
\hline Apparent elastic limit, $\mathrm{MPa}$ & \\
\hline Poisson's ratio & \\
\hline & \\
\hline
\end{tabular}




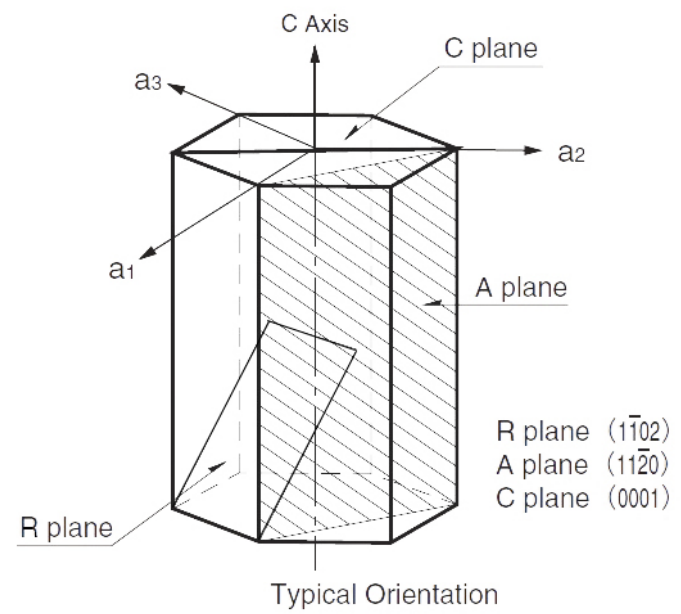

Figure 1.4: The main crystal planes of sapphire [32].

Depending on the orientation of the crystal, sapphire is used in several industrial fields. For example C-plane sapphire substrates are used to grow compounds such as gallium nitride for LED and laser diodes; A-plane oriented substrates assure uniform dielectric constant and high insulation for hybrid microelectronic applications; R-plane are used for deposition of silicon for microelectronic integrated circuits applications [33; 34]. As the number of its uses increases, sapphire is more affordable and more readily available.

\subsection{PROBLEM DEFINITION AND RESEARCH OBJECTIVES}

\subsubsection{Problem definition}

Due to its mechanical and chemical properties, which were discussed in the previous section, machining of sapphire is challenging. Although bulk and surface machining of sapphire by mechanical techniques [35], dry etching [36-38] and wet etching techniques [39-42] have been demonstrated, the latter techniques are only suitable for $2 \mathrm{D}$ or $2.5 \mathrm{D}$ processing. This is due to the fact that these techniques require that material removal must start and proceed from an open surface of the substrate. 
When ultra-short laser pulses, with a pulse duration in the range of femtoseconds to picoseconds, are tightly focused inside the bulk of sapphire, the crystalline state of the material can be changed to amorphous [12]. That is, if the laser intensity is over $10^{14} \mathrm{~W} / \mathrm{cm}^{2}$ the laser energy causes a "microexplosion", which, in turn, results in an amorphous or partially amorphous voxel, in and near the focal spot of the laser beam, surrounded by crystalline material [43]. Amorphous $\mathrm{Al}_{2} \mathrm{O}_{3}$ can be selectively etched using specific etchants. The most employed etchant, for this purpose, is hydrofluoric acid (HF) $[8 ; 12 ; 20 ; 23 ; 43-$ 45]. The ratio of the etch rate of $\mathrm{HF}$ with respect to crystalline and amorphous $\mathrm{Al}_{2} \mathrm{O}_{3}$ is $1: 10^{5}$ [12]. Hence, $\mathrm{HF}$ is a highly selective etchant for the amorphous material.

Laser processing and subsequent selective etching of sapphire has been investigated since the early 2000s [12]. This method allows the fabrication of subsurface structures embedded in the bulk of sapphire. However, when compared to other transparent materials such as fused silica, the technique for sapphire is still not widespread. That is, still several scientific and technical challenges are impeding industrial exploitation of the technique for sapphire. These challenges include, but are not limited to: the formation of undesired laser-induced cracks around the amorphous material, the irregular and inhomogeneous distribution of amorphous material in the laser focal interaction zone and, last but not least, the chemical wet etching of the channels which can be hard to control.

\subsubsection{Research objectives}

To address the challenges described in the previous section, the phenomena and parameters governing laser-material interaction of subsurface processing of sapphire, as well as the effect of etchants on both crystalline and amorphized material need to be understood. In this regard, this thesis addresses three research objectives.

The non-linear phenomena governing the absorption of laser energy in the material, at high laser intensity levels, include, but are not limited to free electron absorption, multiphoton absorption, tunneling ionization, avalanche ionization [46]. Once absorbed, the energy is transferred from the electron system to the lattice of sapphire. This energy transfer is usually described by the so-called Two Temperature Model (TTM) [47]. The laser conditions at which the above phenomena are triggered, and which phenomena are dominant during laser processing are still not fully understood. The latter is required to 
allow optimization of the laser processing parameters. Experimental investigation of the phenomena is challenging due to the small temporal (femtoseconds to nanoseconds) and spatial ((sub)micrometer) scale at which these phenomena occur. Therefore, several authors developed simplified (numerical) models describing the absorption phenomena [48; 49]. However, the studies mostly consider semiconductors instead of large bandgap dielectric materials, such as sapphire and no model is available in literature suitable for the application on sapphire allowing to calculate the temperatures in sapphire as a result of the laser pulse. Therefore, the first research objective of this thesis is formulated as:

1. Develop a (numerical) model describing both laser energy absorption and thermal phenomena in bulk sapphire, which allows to determine at what laser conditions the (non-linear) absorption phenomena are triggered, which phenomena are dominant during laser processing, and how these affect the morphology of the laser affected volume in sapphire.

Due to the high non-linearity of the physical phenomena governing lasermaterial interaction of sapphire, as well as due to the lack of reliable material parameters of sapphire at high laser intensities, (numerical) modelling necessarily involves several simplifying assumptions. Optimized laser parameters to obtain uniform amorphous structures in sapphire can therefore not be fully based on modelling, but must be supported by experimental analysis. Therefore, the second research objective is formulated as:

2. Establish the influence of laser processing parameters on the morphology of the amorphized volume and cracking inside bulk sapphire. In particular, establish the influence of the:

- pulse duration-i.e. the influence of femtosecond and picosecond pulses,

- laser pulse energy,

- laser pulse repetition rates-i.e. the influence of a single laser pulse and multiple laser pulses at pulse rates as high as $\mathrm{MHz}$,

- spherical aberration, induced by the combined effect of the focusing objective to focus the laser beam, the depth of the focal spot below the surface of the sapphire substrate,

- the geometrical pulse-to-pulse overlap (pitch) in order to create amorphous volumes in sapphire, which are larger than the volume induced by a single laser pulse/spot. 
Etching of (amorphized) sapphire, leading to the final (void) structure in the bulk, is a critical step of the two-step processing technique. Hence, studying the effect of etching parameters, including the type of etchant, is necessary to predict the final etched morphology. As was mentioned above, hydrofluoric acid is most frequently employed to etch amorphous $\mathrm{Al}_{2} \mathrm{O}_{3}$. Other etchants, such as a mix of sulphuric acid and phosphoric acid $\left(\mathrm{H}_{2} \mathrm{SO}_{4}\right.$ $+\mathrm{H}_{3} \mathrm{PO}_{4}$ ) etch the material anisotropically, faster along some crystal planes rather than along other planes. To analyse the impact of the mentioned etchants on the processing technique, the third and last research objective is formulated as:

3. Establish experimentally the influence of hydrofluoric acid, as well as a mixture of sulphuric acid and phosphoric acid on the morphology of the laser-induced etched structures in sapphire.

\subsection{THESIS OUTLINE}

This thesis consists of 7 chapters. Chapter 2 presents a detailed overview of the state-of-the art of laser processing and subsequent chemical etching of sapphire, including a theoretical background. This chapter also presents an overview of the experimental setups and experimental approach employed in this thesis. Chapters 3 through 6 address the three research objectives as defined in the previous section, see also Table 1.2.

In Chapter 3 the absorption and thermal phenomena governing lasermaterial interaction of sapphire are introduced in detail, as well as the equations describing these phenomena. On the basis of these equations a timedependent 2D axisymmetric numerical model is developed, which is employed to simulate the electron density, electron temperature and lattice temperature during ultrashort pulsed subsurface laser processing of sapphire. As such, this chapter addresses research objective 1, as defined in section 1.3.

Chapter 4 presents the results of an experimental study into the effects of picosecond pulsed laser processing parameters on the morphology of subsurface modifications induced by single infrared (IR) picosecond pulses in sapphire and their selective etching in hydrofluoric acid. The size and shape of the amorphized regions are compared to simulated laser intensity profiles inside the bulk in order to establish experimentally the intensity threshold that creates a modification in sapphire. As such, this chapter addresses research objective 2 and 3 , as defined in section 1.3. 
Table 1.2: Outline of the thesis.

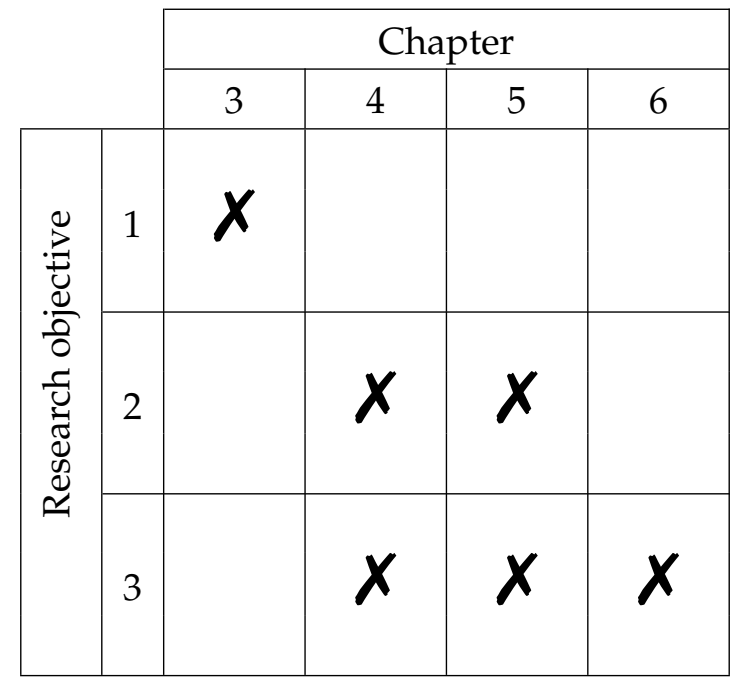

Chapter 5 presents and discusses the results of an experimental investigation of the influence of laser and etching parameters to fabricate open and continuous microchannels and stacks of such microchannels in the bulk of crystalline sapphire. As such, this chapter addresses research objectives 2 and 3 as defined in section 1.3.

Chapter 6 explores the use a mix of sulphuric and phosphoric acid $\left(\mathrm{H}_{2} \mathrm{SO}_{4}\right.$ $+\mathrm{H}_{3} \mathrm{PO}_{4}$ ) as an anisotropic etchant to modify the morphology of single laser pulse-induced modifications, single channels, stacks of channels in the bulk of sapphire, as well as on the surface of the substrate. As such, this chapter addresses research question 3 as defined in section 1.3.

Finally, Chapter 7 concludes results and findings of this thesis and relates these to the research objectives. It also provides recommendations for future research. It should be pointed out that this thesis work is based on 3 published peer-reviewed scientific publications, and 1 paper prepared for submission to a peer-reviewed scientific journal. That is, the content of Chapters 3 to 6 is identical to the content of the papers or has small variations. Therefore, it is unavoidable that a few repetitions are found in the chapters, as typical academic articles need introductory sections. However, this also has the advantage that each chapter can be read independently from the others. 
BIBLIOGRAPHY

[1] J. D. Majumdar and I. Manna, "Laser processing of materials," Sadhana, vol. 28, no. 3-4, pp. 495-562, 2003.

[2] W. Watanabe, Y. Li, and K. Itoh, "Ultrafast laser micro-processing of transparent material," Optics and Laser Technology, vol. 78, pp. 52 - 61, 2016.

[3] S. S. Mao, F. Quéré, S. Guizard, X. Mao, R. E. Russo, G. Petite, and P. Martin, “Dynamics of femtosecond laser interactions with dielectrics," Applied Physics A: Materials Science and Processing, vol. 79, no. 7, pp. 1695-1709, 2004.

[4] R. Osellame, G. Cerullo, and R. Ramponi, Femtosecond Laser Micromachining. Topics in Applied Physics, Berlin Heidelberg: Springer-Verlag, 1st ed., 2012.

[5] H. Misawa and S. Juodkazis, 3D laser microfabrication: principles and applications. John Wiley \& Sons, 2006.

[6] R. Taylor, C. Hnatovsky, and E. Simova, "Applications of femtosecond laser induced self-organized planar nanocracks inside fused silica glass," Laser $\mathcal{E}$ Photonics Reviews, vol. 2, no. 1-2, pp. 26-46, 2008.

[7] C. Hnatovsky, R. Taylor, E. Simova, V. Bhardwaj, D. Rayner, and P. Corkum, "Polarizationselective etching in femtosecond laser-assisted microfluidic channel fabrication in fused silica," Optics letters, vol. 30, no. 14, pp. 1867-1869, 2005.

[8] D. Wortmann, J. Gottmann, N. Brandt, and H. Horn-Solle, "Micro- and nanostructures inside sapphire by fs-laser irradiation and selective etching," in proceedings of 2008 Conference on Quantum Electronics and Laser Science Conference on Lasers and Electro-Optics, CLEO/QELS, 2008.

[9] J. Ihlemann, B. Wolff, and P. Simon, "Nanosecond and femtosecond excimer laser ablation of fused silica," Applied Physics A, vol. 54, no. 4, pp. 363-368, 1992.

[10] B. Chimier, O. Utéza, N. Sanner, M. Sentis, T. Itina, P. Lassonde, F. Légaré, F. Vidal, and J. Kieffer, "Damage and ablation thresholds of fused-silica in femtosecond regime," Physical Review B, vol. 84, no. 9, p. 094104, 2011.

[11] D. von der Linde and H. Schüler, "Breakdown threshold and plasma formation in femtosecond laser-solid interaction," Journal Optical Society America B, vol. 13, no. 1, pp. 216222, 1996.

[12] S. Juodkazis, K. Nishimura, H. Misawa, T. Ebisui, R. Waki, S. Matsuo, and T. Okada, "Control over the crystalline state of sapphire," Advanced Materials, vol. 18, no. 11, pp. 13611364, 2006.

[13] C. B. Schaffer, A. Brodeur, and E. Mazur, "Laser-induced breakdown and damage in bulk transparent materials induced by tightly focused femtosecond laser pulses," Measurement Science and Technology, vol. 12, no. 11, p. 1784, 2001.

[14] S. K. Sundaram and E. Mazur, "Inducing and probing non-thermal transitions in semiconductors using femtosecond laser pulses," Nature materials, vol. 1, no. 4, pp. 217-224, 2002.

[15] W. Kaiser and D. H. Auston, Ultrashort laser pulses: generation and applications. Springer, 1993.

[16] S. Juodkazis, K. Nishimura, S. Tanaka, H. Misawa, E. G. Gamaly, B. Luther-Davies, L. Hallo, P. Nicolai, and V. T. Tikhonchuk, "Laser-induced microexplosion confined in the bulk of a sapphire cystal: Evidence of multimegabar pressures," Physical Review Letters, vol. 96, no. 16, p. 166101, 2006. 
[17] E. Gamaly, B. Luther-Davies, A. Rode, S. Joudkazis, H. Misawa, L. Hallo, P. Nicolai, and V. Tikhonchuk, "Laser-matter interaction in the bulk of transparent dielectrics: Confined micro-explosion," in Journal of Physics: Conference Series, vol. 59, p. 002, IOP Publishing, 2007.

[18] E. G. Gamaly, S. Juodkazis, K. Nishimura, H. Misawa, and B. Luther Davies, "Lasermatter interaction in the bulk of a transparent solid: Confined microexplosion and void formation," Physical review. B, vol. 73, no. 21, p. 214101, 2006.

[19] Y. Bellouard, A. Said, M. Dugan, and P. Bado, "Fabrication of high-aspect ratio, microfluidic channels and tunnels using femtosecond laser pulses and chemical etching," Optics Express, vol. 12, no. 10, p. 2120, 2004.

[20] M. Hörstmann-Jungemann, J. Gottmann, and M. Keggenhoff, "3D-microstructuring of sapphire using fs-laser irradiation and selective etching," Journal of Laser Micro Nanoengineering, vol. 5, no. 2, pp. 145-149, 2010.

[21] J. Gottmann, D. Wortmann, and M. Horstmann-Jungemann, "Fabrication of subwavelength surface ripples and in-volume nanostructures by fs-laser induced selective etching," Applied surface science, vol. 255, no. 10, pp. 5641-5646, 2009.

[22] S. Matsuo, Y. Shichijo, T. Tomita, and S. Hashimoto, "Laser fabrication of ship-in-a-bottle microstructures in sapphire," JLMN, vol. 2, pp. 114-116, 2007.

[23] S. Matsuo, K. Tokumi, T. Tomita, and S. Hashimoto, “Three-dimensional residue-free volume removal inside sapphire by high-temperature etching after irradiation of femtosecond laser Pulses," Laser Chemistry, vol. 2008, 2008.

[24] M. Bauer, Precious stones, vol. 1. Courier Corporation, 2012.

[25] A. V. L. Verneuil, "Process of producing synthetic sapphires.," Mar. 28 1911. US Patent 988,230 .

[26] D. C. Harris, "A peek into the history of sapphire crystal growth," in Window and Dome Technologies VIII (R. W. Tustison, ed.), vol. 5078, p. 1, sep 2003.

[27] Kyocera, "Single crystal sapphire datasheet - Kyocera," 2011.

[28] S. Hecht, J. C. Peskin, and M. Patt, "Intensity discrimination in the human eye: Ii. the relation between $\delta \mathrm{i} / \mathrm{i}$ and intensity for different parts of the spectrum," The Journal of general physiology, vol. 22, no. 1, pp. 7-19, 1938.

[29] E. R. Dobrovinskaya, L. A. Litvinov, and V. V. Pishchik, Sapphire : material, manufacturing, applications. New York: Springer, 2009.

[30] M. E. Tobar, J. G. Hartnett, E. N. Ivanov, D. Cros, P. Blondy, and P. Guillon, “Cryogenically cooled sapphire-rutile dielectric resonators for ultrahigh-frequency stable oscillators for terrestrial and space applications," IEEE Transactions on Microwave Theory and Techniques, vol. 48, no. 7, pp. 1265-1269, 2000.

[31] J. Grandia and J. C. Hill, "Process for slicing boules of single crystal material," Apr. 18 1978. US Patent $4,084,354$.

[32] F. J. Bruni, "Crystal growth of sapphire for substrates for high-brightness, light emitting diodes," Crystal Research and Technology, vol. 50, no. 1, pp. 133-142, 2015.

[33] W. Wang, W. Yang, H. Wang, Y. Zhu, M. Yang, J. Gao, and G. Li, “A comparative study on the properties of c-plane and a-plane gan epitaxial films grown on sapphire substrates by pulsed laser deposition," Vacuum, vol. 128, pp. 158 - 165, 2016.

[34] Q. Wen, P. Zhang, G. Cheng, F. Jiang, and X. Lu, "Crystalline orientation effects on material removal of sapphire by femtosecond laser irradiation," Ceramics International, vol. 45, no. 17, Part B, pp. 23501 - 23508, 2019. 
[35] K. Matsumaru, A. Takata, and K. Ishizaki, "Advanced thin dicing blade for sapphire substrate," Science and Technology of Advanced Materials, vol. 6, no. 2, pp. 120-122, 2005.

[36] Y. P. Hsu, S. J. Chang, Y. K. Su, J. K. Sheu, C. H. Kuo, C. S. Chang, and S. C. Shei, "ICP etching of sapphire substrates," Optical Materials, vol. 27, no. 6, pp. 1171-1174, 2005.

[37] C. H. Jeong, D. W. Kim, H. Y. Lee, H. S. Kim, Y. J. Sung, and G. Y. Yeom, "Sapphire etching with $\mathrm{BCl} 3 / \mathrm{HBr} /$ Ar plasma," Surface and Coatings Technology, vol. 171, no. 1-3, pp. 280-284, 2003.

[38] H. Furuya, N. Okada, and K. Tadatomo, "Growth of $\{11-22\}$ GaN on shallowly etched r -plane patterned sapphire substrates," Physica Status Solidi (C) Current Topics in Solid State Physics, vol. 9, no. 3-4, pp. 568-571, 2012.

[39] T. V. Cuong, H. S. Cheong, H. G. Kim, H. Y. Kim, C. H. Hong, E. K. Sun, H. K. Cho, and B. H. Kong, "Enhanced light output from aligned micropit InGaN-based light emitting diodes using wet-etch sapphire patterning," Applied Physics Letters, vol. 90, no. 13, 2007.

[40] Y. J. Lee, J. M. Hwang, T. C. Hsu, M. H. Hsieh, M. J. Jou, B. J. Lee, T. C. Lu, H. C. Kuo, and S. C. Wang, "Enhancing the output power of GaN-based LEDs grown on wet-etched patterned sapphire substrates," IEEE Photonics Technology Letters, pp. 1152-1154, 2006.

[41] D. S. Wuu, W. K. Wang, K. S. Wen, S. C. Huang, S. H. Lin, R. H. Horng, Y. S. Yu, and M. H. Pan, "Fabrication of pyramidal patterned sapphire substrates for high-efficiency InGaN-based light emitting diodes," Journal of The Electrochemical Society, vol. 153, no. 8, pp. G765-G770, 2006.

[42] J. Wang, L. Guo, H. Jia, Y. Wang, Z. Xing, W. Li, H. Chen, and J. Zhou, “Fabrication of patterned sapphire substrate by wet chemical etching for maskless lateral overgrowth of gan," Journal of the Electrochemical Society, vol. 153, no. 3, p. C182, 2006.

[43] L. Capuano, R. Pohl, R. M. Tiggelaar, J. W. Berenschot, J. G. E. Gardeniers, and G. R. B. E. Römer, "Morphology of single picosecond pulse subsurface laser-induced modifications of sapphire and subsequent selective etching," Optics Express, vol. 26, no. 22, 2018.

[44] S. Juodkazis and H. Misawa, "Forming tiny 3D structures for micro- and nanofluidics," SPIE Newsroom, pp. 4-6, 2007.

[45] L. Capuano, R. M. Tiggelaar, J. W. Berenschot, J. G. E. Gardeniers, and G. R. B. E. Römer, "Fabrication of millimeter-long structures in sapphire using femtosecond infrared laser pulses and selective etching," Optics and Lasers in Engineering, vol. 133, p. 106114, 2020.

[46] L. Capuano, D. de Zeeuw, and G. R. B. E. Römer, "Towards a numerical model of picosecond laser-material interaction in bulk sapphire," Journal of Laser Micro Nanoengineering, vol. 13, no. 3, 2018.

[47] P. C. Verburg, G. R. Römer, and A. J. Huis In 'T Veld, “Two-temperature model for pulsedlaser-induced subsurface modifications in Si," Applied Physics A: Materials Science and Processing, pp. 1135-1143, 2014.

[48] N. M. Bulgakova, “Theoretical Models and Qualitative Interpretations of Fs Laser Material Processing," Journal of Laser Micro/Nanoengineering, 2007.

[49] K. I. Popov, C. McElcheran, K. Briggs, S. Mack, and L. Ramunno, “Morphology of femtosecond laser modification of bulk dielectrics," Optics Express, pp. 271-282, 2011. 



\section{2}

LASER MODIFICATION OF SAPPHIRE AND

SELECTIVE ETCHING: THEORETICAL BACKGROUND AND EXPERIMENTAL METHODS

When an ultra-short pulsed laser beam is tightly focused inside the bulk of crystalline sapphire, the transparent material can be amorphized [1-8]. The amorphized region, confined in the crystalline bulk, can be etched faster than crystalline sapphire when exposed to specific etchants. The most used etchants for this etching step are hydrofluoric acid (HF) and potassium hydroxide (KOH). The two-step method, based on laser irradiation and subsequent selective etching, allows the fabrication of subsurface structures embedded in the bulk of sapphire.

\subsection{LASER MODIFICATION OF THE CRYSTALLINITY OF SAPPHIRE}

The laser processing method described in this thesis is based on the nonlinear absorption of light into sapphire (see Figure 2.1). The intensity threshold necessary for such nonlinear absorption to occur is $10^{13}$ to $10^{14} \mathrm{~W} / \mathrm{cm}^{2}[1$; 911] and can be reached by focusing ultrashort laser pulses below the surface using objectives with a high numerical aperture (NA) $[1 ; 3 ; 5 ; 7 ; 8 ; 12-15]$.

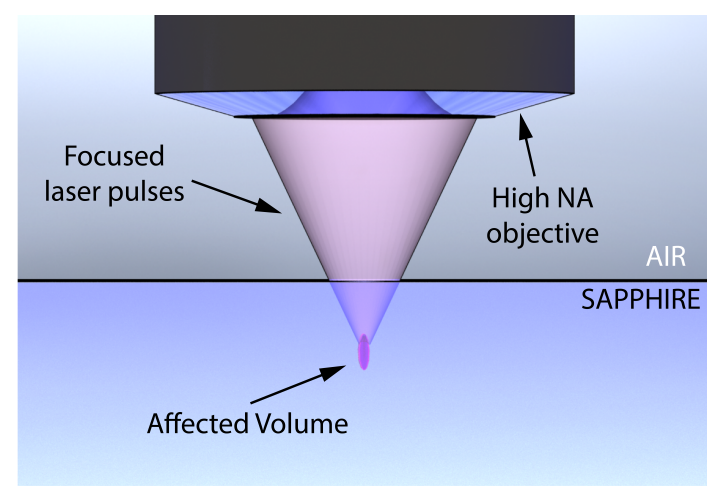

Figure 2.1: Schematic of the laser modification of sapphire. By focusing an ultrashort laser beam below the surface with a high numerical aperture (NA) objective, the sapphire in the focal volume is modified. 
The required laser pulse durations for the process reported in literature are in the femtosecond $[1 ; 5 ; 8 ; 14 ; 16-18]$ or picosecond regime $[19 ; 20]$. Heat transmission phenomena inside the lattice of sapphire occur on a time scale in the order of tens of picoseconds [11]. Hence, the ultrashort pulse duration in the femto- to picosecond range limits the heat transmission inside the sample during the laser pulse.

Optical electronic excitation can cause crystalline transitions in solid state materials [1]. Through ultrashort focused laser pulses, it is possible to ionize the material contained in the laser-focal volume of sapphire by multiphoton absorption, tunneling ionization and avalanche ionization [21-25]. In chapter 3 of this thesis these and other mechanisms of absorption will be described in more detail. After the ionization of the material, the absorbed energy causes a shock wave and superfast thermal quenching (thermalization phase) which, in turn, lead to transitions of crystalline sapphire into several material phases with different chemical properties [1]. One of those phases is an amorphous state of $\mathrm{Al}_{2} \mathrm{O}_{3}$, with high chemical reactivity, embedded inside the crystalline phase.

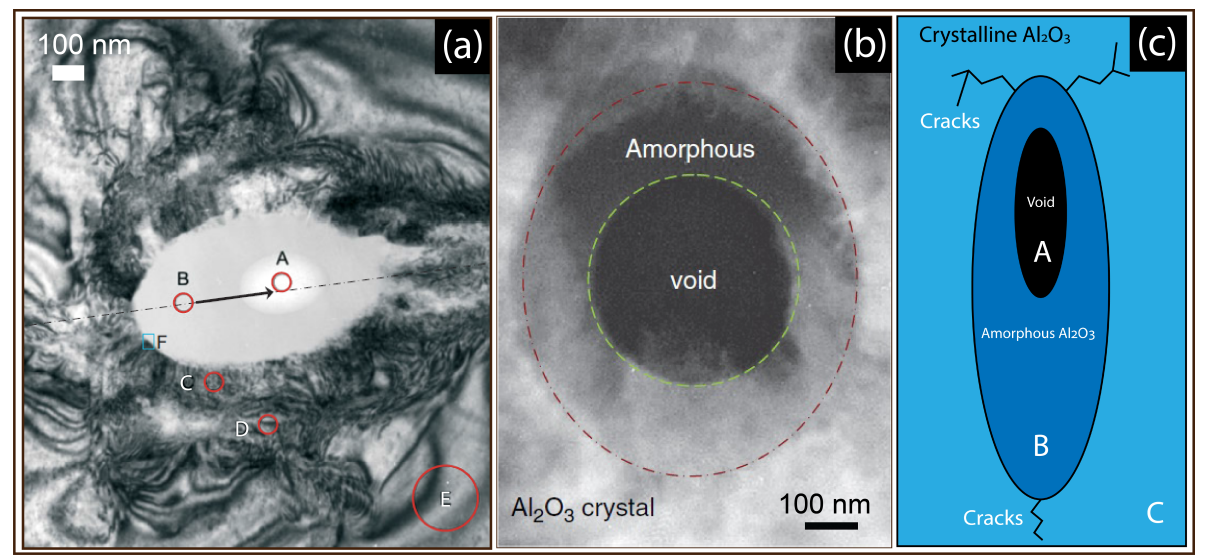

Figure 2.2: (a) TEM micrograph showing the different phases of a single laser pulse induced modification: A is a void, B is amorphous material, C, D, E, F show various states of stress-affected crystalline material. Reproduced from [1] (b) TEM micrograph showing a void in the center, amorphous material and crystalline $\mathrm{Al}_{2} \mathrm{O}_{3}$. Reproduced from [2]. (c) Schematic of the single modification inside the bulk of sapphire: $\mathrm{A}$ is the void, $\mathrm{B}$ is the amorphous $\mathrm{Al}_{2} \mathrm{O}_{3}, \mathrm{C}$ the crystalline material. Adapted from [19] 
Figure 2.2 ( $a$ and b) show TEM micrographs of a single pulse induced photomodified region inside sapphire with its different regions with a schematic (Figure 2.2, (c)) [19] of the various phases. In this Figure, region A shows the presence of a void (laser-induced, not caused by etching) induced by the rarefaction front of the pressure wave in the laser-material interaction zone. However, Juodkazis et al. demonstrated that, using low pulse energies, void formation (region A) can be avoided [16]. Region B typically consists of amorphous sapphire, while region $C$ typically consists of polycrystalline or crystalline phases, which will be hardly etched. Depending on the laser pulse energy used and the stress caused by the shock wave, this polycrystalline phase can show a different refractive index than the unaffected crystalline material. Due to the compression of the material caused by the shock wave, the amorphous material can have a different density, as compared to the polycrystalline and crystalline phase. In particular, the density of this region is "similar to that of the crystalline phase when there were no voids at region A, and higher when the central void was present" [1]. The dimension of the laser-modified zone can be controlled on a micrometer scale by tuning the processing parameters, while the surrounding material stays unaffected by the laser.

\subsection{SELECTIVE ETCHING OF SAPPHIRE}

After the laser irradiation, the amorphized phase can be subsequently etched selectively by specific chemical etchants (see Figure 2.3).

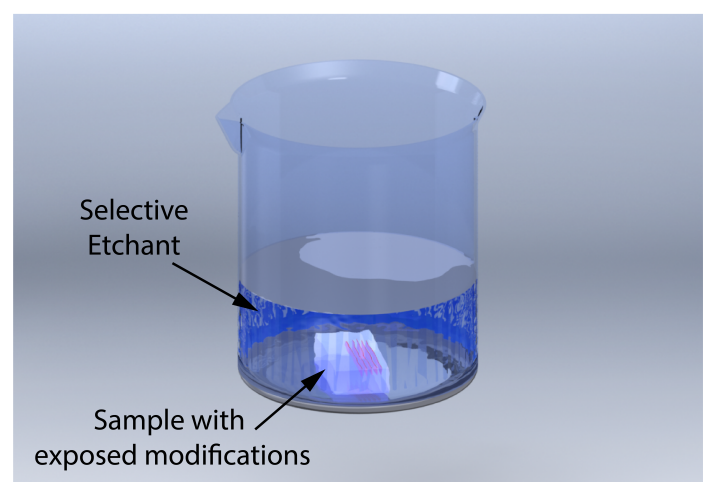

Figure 2.3: After the laser irradiation, the modified part is exposed to specific selective chemical etchants by submerging the substrate in the solution. 
Aqueous solutions of hydrofluoric acid (HF) or potassium hydroxide $(\mathrm{KOH})$ show much higher selectivity towards amorphous sapphire (HF etches amorphous material $10^{5}$ times faster than crystalline [1]) relative to that of the crystalline and polycrystalline phases. Juodkazis et al. [1] atribute the high etch rate of amorphous $\mathrm{Al}_{2} \mathrm{O}_{3}$ (region $\mathrm{B}$ in Figure 2.2), when using HF, to a decrease of the average angle, in the $\mathrm{Al}_{2} \mathrm{O}_{3}$ molecule, between aluminum and oxygen atoms. That implies the formation of a more basic (Lewis-base) material with a higher reactivity to acidic solutions. After the etching, the amorphized material is dissolved, leaving hollow or void shapes in the bulk of sapphire, see Figure 2.4.

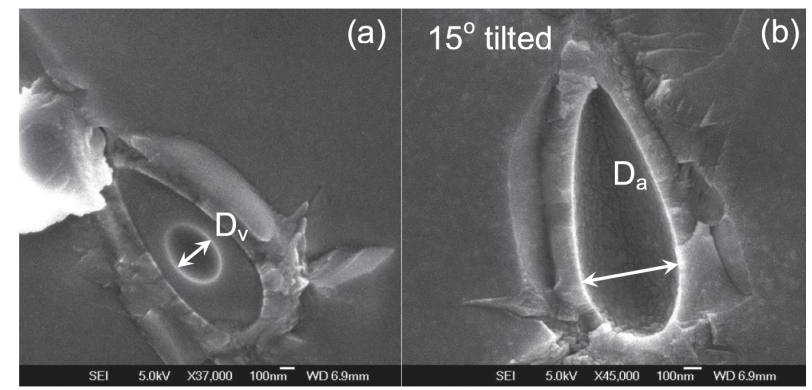

Figure 2.4: SEM micrograph of a single pulse modification (a) before etching and (b) after 15 mins etching in a 10\% solution of HF. Reproduced from [16].

\subsection{COMPLEX STRUCTURES INSIDE THE BULK OF SAPPHIRE}

S. Juodkazis et al. [1] demonstrated complex 3D networks (see Figure 2.5) of channels inside the bulk of sapphire using the two-step technique based on laser irradiation and selective etching. The 3D laser patterning of sapphire was carried out using an objective lens with a numerical aperture NA= 1.35. The length of the channel was $40 \mu \mathrm{m}$, the diameter $0.5 \mu \mathrm{m}$. HörstmannJungemann et al. [5], using a similar approach, fabricated channels (see Figure 2.6, (a)) inside the bulk of sapphire studying the etching speed of HF for amorphous $\mathrm{Al}_{2} \mathrm{O}_{3}$. Moreover, the authors demonstrated that, by modifying several overlapping tracks in the volume of sapphire (Figure 2.6, (b) and (c)) and subsequent etching, wide micro channels composed of arrays of parallel modified lines can be produced. The dimension of the microchannels can be modified by changing the number of tracks next to each other, see Figure 2.6, (b). Applying the same method also to vertical stacked tracks, vertical cuts 


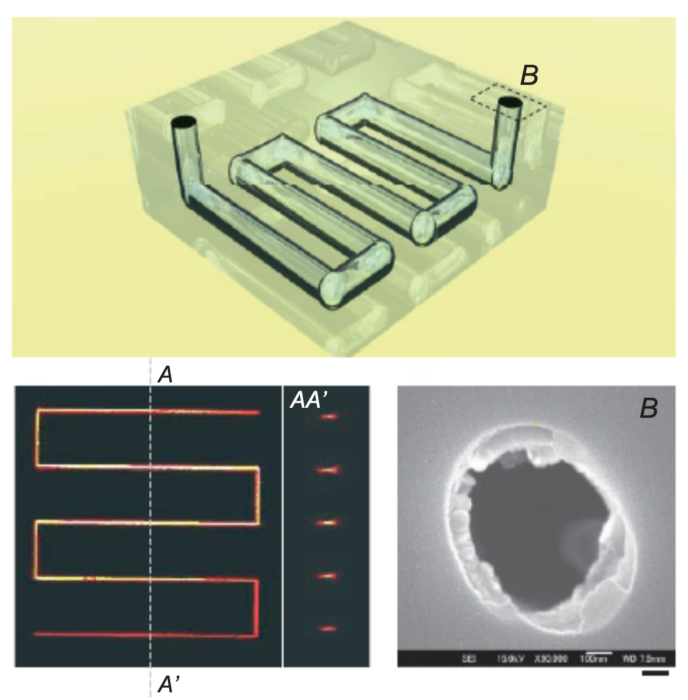

Figure 2.5: Example of a complex 3D network of channels inside the bulk of sapphire created by the two-step laser and etching technique. Reproduced from [1].

can be fabricated, see Figure 2.6, (c). This type of vertical processing was also exploited to cut 3D microparts out of sapphire and to fabricate microholes. For example, Figure 2.7 (a) shows a cut-out cylinder as well as the hole left in a sapphire substrate. Finally, combining the irradiation strategies used for the fabrication of wide microchannels and vertical cuts, the authors fabricated hollow volumes inside the bulk of sapphire. For example, in Figure 2.7 (b), a hollow reservoir and the irradiation strategy to produce it are shown.

Although such structures have been demonstrated, when large amorphized structures are created, a series of phenomena can influence the formation of a uniform and continuous block of amorphous sapphire. The latter, in turn, affects the solubility of the formed material. Several publications on etched channels in sapphire, often report cross-sections in which, after the wet chemical etching, the obtained structure is not completely hollow [6; 7; 26; 27]. In 2008, Juodkazis et al. [26] studied this phenomenon and showed that overlapping single laser pulse induced modifications may cause recrystallization of the amorphized material, which is not etched by an acid like HF (see Figure 2.8 (a)). Gottmann et al. [6] and Horstmann et al. [28] showed that, within a range of parameters (mainly numerical aperture and energy per pulse) the crosssection of channels either show a series of amorphized parallel nanochannels (see Figure 2.8 (b)), or hollow channels (see Figure 2.8 (c)). 

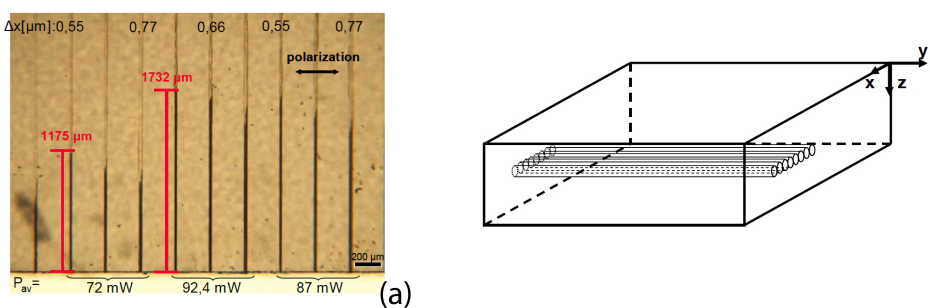

(a)

(b)

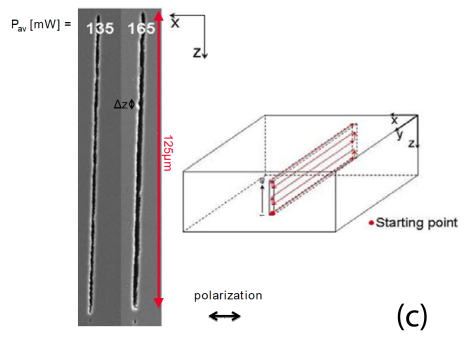

Figure 2.6: (a) Optical microscopy image of single modified lines partially etched inside the bulk of sapphire. (b) Schematic of overlapping single lines to form large structures. (c) SEM micrographs of the cross section with the schematic of vertical cuts made inside the bulk of sapphire by overlapping several tracks. Reproduced from [5]
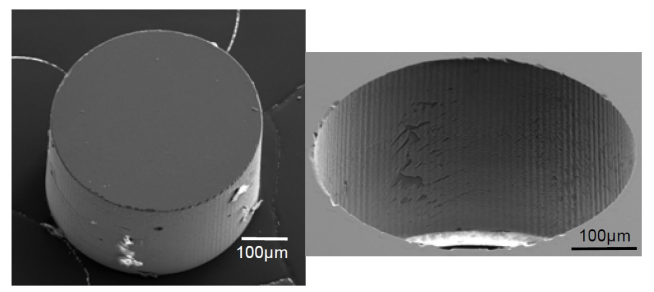

(a)
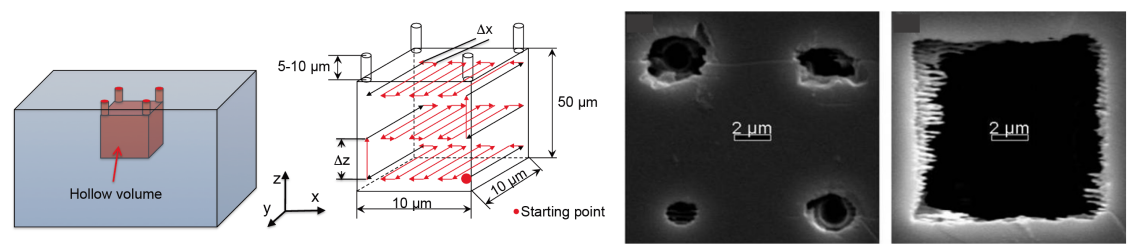

(b)

Figure 2.7: (a) Cylinder cut out of sapphire and the hole left in the sample (b) A cubic reservoir with inlets/outlets and the irradiation strategy. Reproduced from [5]. 

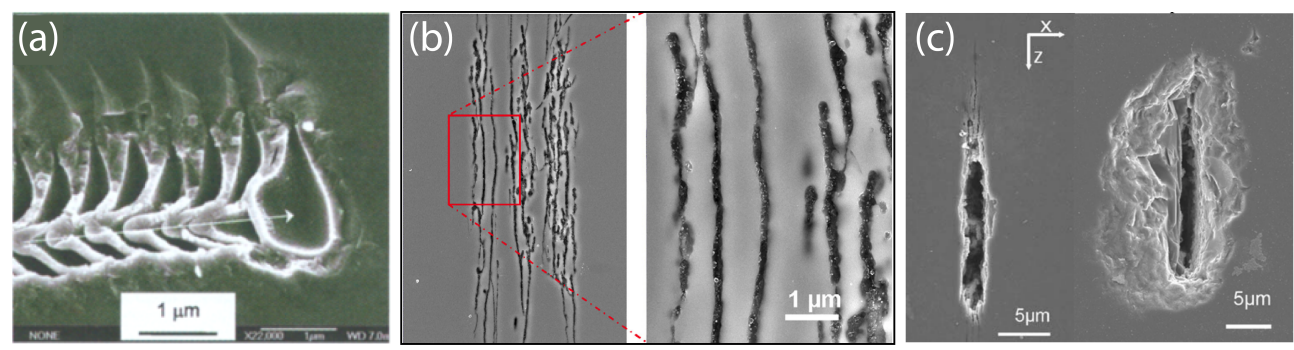

Figure 2.8: (a) SEM micrograph of a longitudinal-section of a structure formed by overlapping single laser femtosecond pulses inside the bulk of sapphire. Reproduced from [26]. (b) SEM micrograph of a cross section of a channel (etched) composed of nanolines produced inside the bulk of sapphire by highly overlapping femtosecond laser pulses using low numerical aperture (0.55). Reproduced from [6]. (c) SEM micrograph of a cross section of a single channel (etched) produced inside the bulk of sapphire by highly overlapping femtosecond laser pulses using high numerical aperture (0.7). Reproduced from [28].

In chapter 5 of this thesis, the specific conditions are analysed which determine the final shape and appearance of the amorphized sapphire and how to tune the laser and etching parameters to obtain exact and distinct types of structures using the two-step method.

\subsection{EXPERIMENTAL METHODS}

\subsubsection{Experimental set-up for laser modification and selective etching of sapphire}

To design the experimental set-up(s) and methods used for carrying out the experiments described in this study, a literature review was performed of experimental parameters for laser modification and selective etching of sapphire. Table 2.1 shows the main parameters found in literature.

Based on the parameters in this table, two laser-setups were designed and implemented. One setup includes a picosecond pulsed laser source, whereas the second setup incudes a femtosecond pulsed laser source.

In the first setup (in Figure 2.9), a Yb:YAG laser source (TruMicro5050 of Trumpf, Germany) emitting pulses of 7 ss of linearly polarized light at a central wavelength of $1030 \mathrm{~nm}$ is employed, see 1 in Fig. 2.9. The power density profile of the laser beam is nearly Gaussian $\left(M^{2}<1.3\right)$. The laser source has a range of repetition rate from $40 \mathrm{~Hz}$ to $400 \mathrm{kHz}$. A $\lambda / 2$ wave plate (2 in 
Table 2.1: Experimental parameters for laser modification and selective etching of sapphire found in literature.

\begin{tabular}{|l|l|}
\hline \multicolumn{1}{|c|}{ PARAMETER } & \multicolumn{1}{c|}{ VALUES FOUND IN LITERATURE } \\
\hline Laser pulse energy, $E_{p}$ & $10 \mathrm{~nJ}[1], 45 \mathrm{~nJ}[7], 140 \mathrm{~nJ}[13], 1 \mu J[14], 24 \mu J[5]$ \\
\hline Laser pulse duration, $\tau$ & $150 \mathrm{fs}[1 ; 13], 400 \mathrm{fs}[14], 450 \mathrm{fs}[5]$ \\
\hline Laser pulse repetition rate, $f$ & $20 \mathrm{~Hz}[13], 1 \mathrm{kHz}[1], 500 \mathrm{kHz}[5]$ \\
\hline Laser wavelength, $\lambda$ & $800 \mathrm{~nm}[1 ; 13], 1045 \mathrm{~nm}[5 ; 14]$ \\
\hline Microscope objective, $N A$ & $0.55[14], 0.6[5], 1.35[1 ; 7], 1.4[13]$ \\
\hline Etchant & $10 \% \mathrm{HF}[1 ; 7], 47 \% \mathrm{HF}[13], 48 \% \mathrm{HF}[5], 1-2 \mathrm{M} \mathrm{KOH} \mathrm{[13]}$ \\
\hline
\end{tabular}

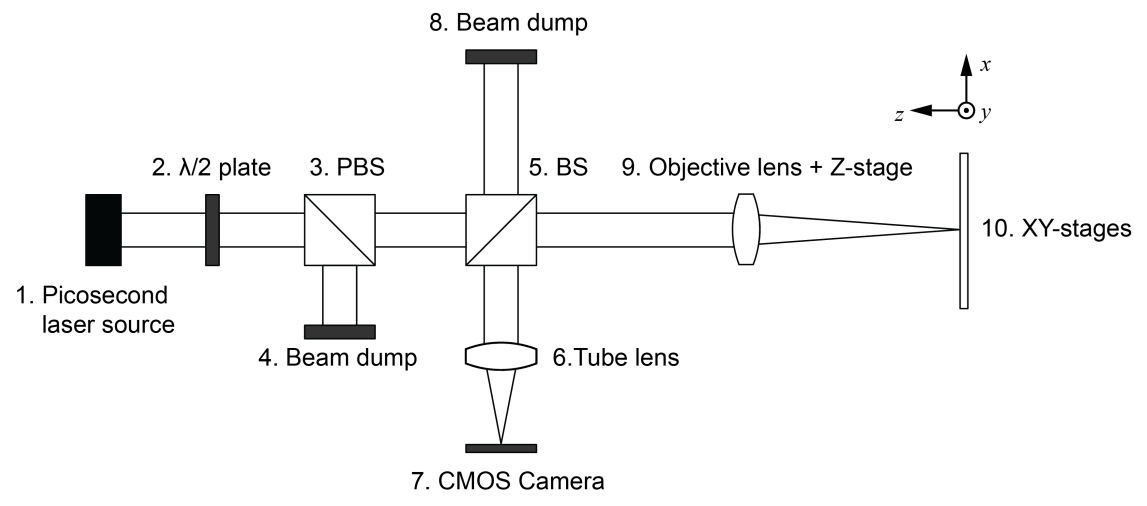

Figure 2.9: Schematic of the picosecond laser set-up used in chapter 4 of this thesis.

Fig. 2.9), a polarizing beam splitter ( 3 in Fig. 2.9), and a beam dump (4 in Fig. 2.9) are used as an attenuator, allowing to vary the pulse energy impinging the substrate. A microscope objective (type 11101666 of Leica Microsystems, Germany), corrected for a $100 \mu m$ thick coverslip of silicon (refractive index $n=3.55$ ) and with a numerical aperture of 0.7 is used to focus the laser beam to a diameter of $0.9 \mu \mathrm{m}$ (calculated), see 9 in Fig. 2.9. It should be noted that 


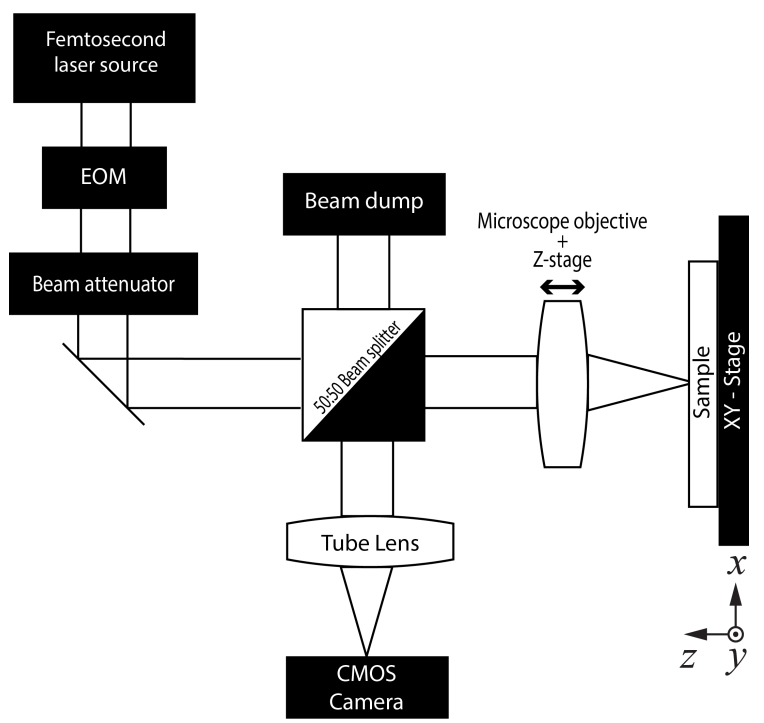

Figure 2.10: Schematic of the femtosecond laser set-up used in chapter 5 and 6 of this thesis.

in the experiments no coverslip was employed. The medium between the objective and the sample is air. A beam splitter ( $50 \%-50 \%, 5$ in Fig. 2.9) and a tube lens (focal length $75 \mathrm{~mm}, 6$ in Fig. 2.9) are used to image light, originating from the substrate, on a CMOS camera (DCC1545M of Thorlabs, Germany, 7 in Fig. 2.9). These components allow to accurately position the focus of the laser beam relative to the surface of the substrate. The sample is mounted on a vacuum chuck, which is positioned in the $x y$-plane by servo-controlled stages (10 in Fig. 2.9, UPS-150 of Physik Instrumente, Germany) with a resolution (minimum incremental motion) of $15 \mathrm{~nm}$ and bidirectional repeatability of $\pm 35 \mathrm{~nm}$. The objective (9 in Fig. 2.9) is also positioned by a servo-controlled stage (M-511 of Physik Instrumente, Germany) with a resolution of $50 \mathrm{~nm}$ and bidirectional repeatability of $\pm 200 \mathrm{~nm}$.

To study the effects of femtosecond pulse duration on the modification of sapphire and selective etching, a femtosecond laser set-up was designed and implemented, see Figure 2.10. This set-up includes a fiber laser source (Y-Fi of KMLabs, USA) which emits a linearly polarized laser beam at a central wavelength of $\lambda=1035 \mathrm{~nm}$. The pulse duration of this source is $230 \mathrm{fs}$, which was measured with an autocorrelator (APE Berlin Pulse Check, Germany). The power density profile of the laser beam is nearly Gaussian $\left(\mathrm{M}^{2}<1.2\right)$. Since 
the laser source does not offer the option of changing the repetition rate to less than $1 \mathrm{MHz}$, an electro-optic modulator (EOM, Model 360-80 by Conoptics, USA) is positioned in the beam path after the laser source for pulse picking. In this setting, the range of repetition rate of the setup is $1 \mathrm{~Hz}$ to $15 \mathrm{MHz}$. A beam attenuator (Ultrafast Version, Altechna, Lithuania) is used to set the pulse energy of the laser pulses. The same microscope objective as in the picosecond setup (11101666, Leica Microsystems, Germany, NA = 0.7) is used to focus the beam to a spot of about $0.9 \mu \mathrm{m}$ diameter (calculated). The microscope objective is mounted on a linear stage (ATS100, Aerotech USA), which moves the lens in the z-direction, allowing the focal spot of the laser beam to be positioned relative to the surface of the sample. The sample is fixed with a vacuum chuck on xy-stages (ALS130-150, Aerotech USA). As in the picosecond laser setup, the microscope objective is also used as magnifying element for imaging, that is, the light reflected by the sample passes again through the objective and a tube lens to arrive finally on a CMOS camera (DCC1545, Thorlabs, USA). This alignment facilitates the positioning of the focal spot in the bulk (z-direction) of the sample as well as in the xy-plane. It also allows to observe the progress and quality of the irradiation during machining.

All the laser experiments are carried out in a cleanroom environment (class ISO 8 , air exchange rate of 6 times per hour, temperature of $21^{\circ} \mathrm{C}$, relative humidity of $40 \%$ ).

\subsection{MATERIALS}
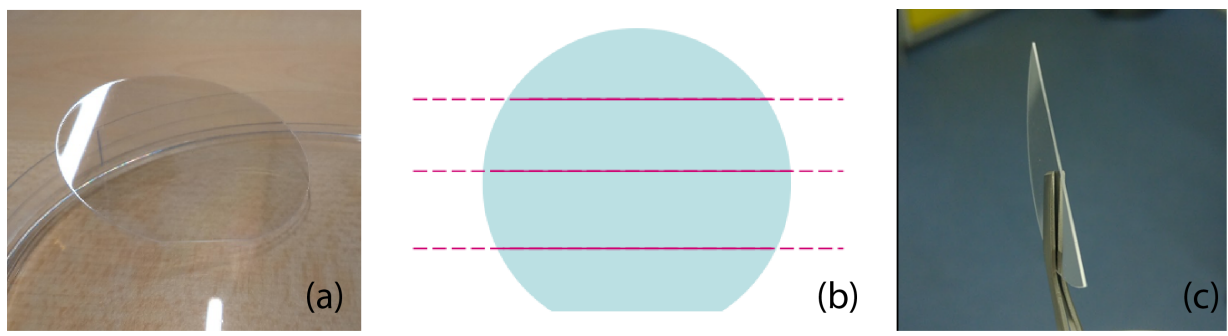

Figure 2.11: (a) Circular sapphire wafers used for the experiments. (b) The samples were cut along the red lines to create smaller strips. (c) Single sapphire strip used for the experiments.

Circular sapphire wafers, 2 inches in diameter and with a thickness of $430 \mu \mathrm{m}$ and crystal orientation (0001), supplied by Crystech GmbH, Germany, were 
used throughout the whole study (Figure 2.11). For most experiments, the circular samples were cut into smaller strips (of various sizes), see Figure 2.11 (b) and (c) with the help of a diamond scribe for easier handling. The etchants used for the etching of laser-treated samples are a stagnant 50\% hydrofluoric acid aqueous solution (BASF, Germany) at room temperature and a mixture of $96 \% \mathrm{H}_{2} \mathrm{SO}_{4}+85 \% \mathrm{H}_{3} \mathrm{PO}_{4}(\mathrm{vol} \%)$ in a volume ratio of $3: 1$ at a temperature of $180^{\circ} \mathrm{C}$.

\subsection{METHODS}
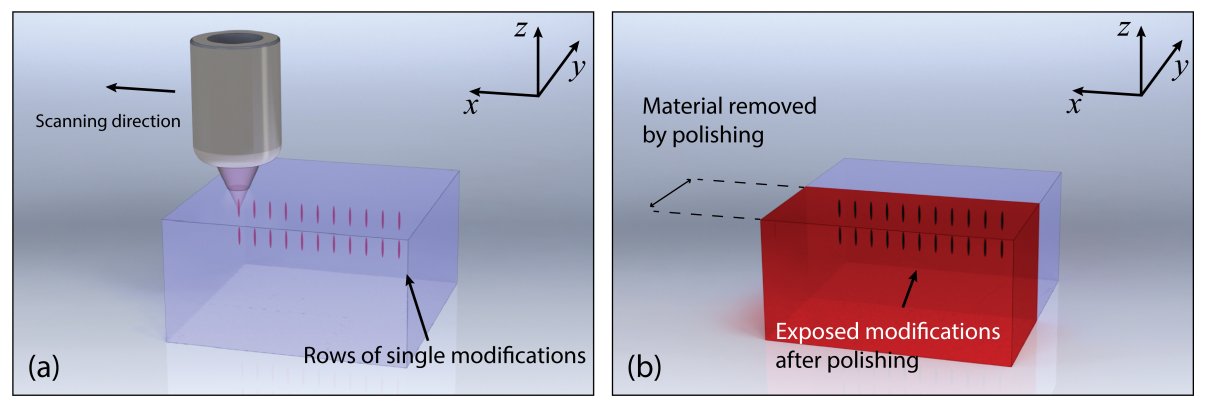

Figure 2.12: Schematic process sequence: (a) first, the sample is irradiated with the laser beam to form modifications below the surface of the sapphire substrate. (b) after laser processing, the substrate is polished to remove bulk material (red in the representation) in order to "expose" cross-sections of the modifications for etching and analysis.

Modifications were produced by focusing the laser beam at different depths (ranging from $0 \mu \mathrm{m}$ to $400 \mu \mathrm{m}$ ) below the surface (z-direction in Fig. 2.12 (a)) of the substrate and at different pulse energies (ranging from $94.7 \mathrm{~nJ}$ to $18 \mu \mathrm{J}$ ). To prevent optical effects induced by laser processing too close to the edge of the sapphire substrate, the laser beam was focused at least at a distance $5 \mathrm{~mm}$ from the edges of the substrate. Moreover, in order to avoid optical "disturbances" originating from modifications produced above, the modified lines were produced proceeding from bottom to top.

When cross-sections were to be analyzed, the edge of the substrate was polished, using a Struers Tegramin (Netherlands) polishing device, to approximately the centre of the single modifications in the $z x$-plane (or $z y$-plane), see Fig. 2.12 (b). Best polishing results were obtained by using the following a 3-steps recipe: 
1. lapping using silicon carbide sandpapers in subsequent steps of: 320p, 500p, 1000p, 2000p, and 4000p

2. polishing steps using diamond suspensions on polishing cloth with the following grain sizes: $9 \mu \mathrm{m}, 3 \mu \mathrm{m}, 1 \mu \mathrm{m}$

3. polishing using alumina suspension $(0.1 \mu \mathrm{m})$

After polishing, the samples were cleaned in an ultrasonic bath with isopropanol. A first characterization was performed after the cleaning, then the substrates were immersed in the etchant for the etching phase. Finally, the samples were inspected again, often at the same locations, to study the effects of the etching.

\subsection{ANALYSIS TOOLS}

The analysis tools used in this thesis to characterize the laser-induced modifications and the obtained final (etched) structures include:

- Scanning Electron Microscopy (SEM), using a JSM-7200F SEM (JEOL, Japan),

- Optical microscopy, using a VHX 5000 (Keyence, Japan),

- Polarized microscopy, using a VHX 5000 (Keyence, Japan),

- Confocal microscopy, using a S-Neox (Sensofar Metrology, Spain),

- Atomic force microscopy (AFM), using a FlexAFM (Nanosurf AG, Switzerland).

\section{BIBLIOGR A PHY}

[1] S. Juodkazis, K. Nishimura, H. Misawa, T. Ebisui, R. Waki, S. Matsuo, and T. Okada, "Control over the crystalline state of sapphire," Advanced Materials, vol. 18, no. 11, pp. 1361$1364,2006$.

[2] S. Juodkazis, S. Kohara, Y. Ohishi, N. Hirao, A. Vailionis, V. Mizeikis, A. Saito, and A. Rode, "Structural Characterization of Femtosecond Laser Modified Regions Inside Sapphire," Journal of Nanoscience and Nanotechnology, vol. 11, pp. 2931-2936, apr 2011.

[3] E. G. Gamaly, S. Juodkazis, K. Nishimura, H. Misawa, and B. Luther Davies, “Lasermatter interaction in the bulk of a transparent solid: Confined microexplosion and void formation," Physical review. B, vol. 73, no. 21, p. 214101, 2006. 
[4] Y. Bellouard, A. Said, M. Dugan, and P. Bado, "Fabrication of high-aspect ratio, microfluidic channels and tunnels using femtosecond laser pulses and chemical etching," Optics Express, vol. 12, no. 10, p. 2120, 2004.

[5] M. Hörstmann-Jungemann, J. Gottmann, and M. Keggenhoff, "3D-microstructuring of sapphire using fs-laser irradiation and selective etching," Journal of Laser Micro Nanoengineering, vol. 5, no. 2, pp. 145-149, 2010.

[6] J. Gottmann, D. Wortmann, and M. Hörstmann-Jungemann, "Fabrication of subwavelength surface ripples and in-volume nanostructures by fs-laser induced selective etching," Applied surface science, vol. 255, no. 10, pp. 5641-5646, 2009.

[7] S. Matsuo, Y. Shichijo, T. Tomita, and S. Hashimoto, "Laser fabrication of ship-in-a-bottle microstructures in sapphire," JLMN, vol. 2, pp. 114-116, 2007.

[8] S. Matsuo, K. Tokumi, T. Tomita, and S. Hashimoto, "Three-dimensional residue-free volume removal inside sapphire by high-temperature etching after irradiation of femtosecond laser Pulses," Laser Chemistry, vol. 2008, 2008.

[9] D. von der Linde and H. Schüler, "Breakdown threshold and plasma formation in femtosecond laser-solid interaction," Journal Optical Society America B, vol. 13, no. 1, pp. 216$222,1996$.

[10] C. B. Schaffer, A. Brodeur, and E. Mazur, "Laser-induced breakdown and damage in bulk transparent materials induced by tightly focused femtosecond laser pulses," Measurement Science and Technology, vol. 12, no. 11, p. 1784, 2001.

[11] S. K. Sundaram and E. Mazur, "Inducing and probing non-thermal transitions in semiconductors using femtosecond laser pulses," Nature materials, vol. 1, no. 4, pp. 217-224, 2002.

[12] S. Juodkazis, K. Nishimura, H. Okuno, Y. Tabuchi, S. Matsuo, S. Tanaka, and H. Misawa, "Three-dimensional laser microfabrication of metals, semiconductors, and dielectrics art. no. 67320B," International Conference on Lasers, Applications, and Technologies 2007: Laser-Assisted Micro- and Nanotechnologies, vol. 6732, pp. B7320-B7320, 2007.

[13] S. Juodkazis, Y. Nishi, and H. Misawa, "Femtosecond laser-assisted formation of channels in sapphire using KOH solution," Physica Status Solidi - Rapid Research Letters, 2008.

[14] D. Wortmann, J. Gottmann, N. Brandt, and H. Horn-Solle, "Micro- and nanostructures inside sapphire by fs-laser irradiation and selective etching," in proceedings of 2008 Conference on Quantum Electronics and Laser Science Conference on Lasers and Electro-Optics, CLEO/QELS, 2008.

[15] E. Gamaly, B. Luther-Davies, A. Rode, S. Joudkazis, H. Misawa, L. Hallo, P. Nicolai, and V. Tikhonchuk, "Laser-matter interaction in the bulk of transparent dielectrics: Confined micro-explosion," in Journal of Physics: Conference Series, vol. 59, p. 002, IOP Publishing, 2007.

[16] S. Juodkazis, K. Nishimura, S. Tanaka, H. Misawa, E. G. Gamaly, B. Luther-Davies, L. Hallo, P. Nicolai, and V. T. Tikhonchuk, "Laser-induced microexplosion confined in the bulk of a sapphire cystal: Evidence of multimegabar pressures," Physical Review Letters, vol. 96, no. 16, p. 166101, 2006.

[17] S. Juodkazis and H. Misawa, "Forming tiny 3D structures for micro- and nanofluidics," SPIE Newsroom, pp. 4-6, 2007.

[18] L. Capuano, R. M. Tiggelaar, J. W. Berenschot, J. G. E. Gardeniers, and G. R. B. E. Römer, "Fabrication of millimeter-long structures in sapphire using femtosecond infrared laser pulses and selective etching," Optics and Lasers in Engineering, vol. 133, p. 106114, 2020. 
[19] L. Capuano, R. Pohl, R. M. Tiggelaar, J. W. Berenschot, J. G. E. Gardeniers, and G. R. B. E. Römer, "Morphology of single picosecond pulse subsurface laser-induced modifications of sapphire and subsequent selective etching," Optics Express, vol. 26, no. 22, 2018.

[20] R. Moser, N. Ojha, M. Kunzer, and U. T. Schwarz, "Sub-surface channels in sapphire made by ultraviolet picosecond laser irradiation and selective etching," Optics Express, vol. 19, no. 24, p. 24738, 2011.

[21] H. Misawa and S. Juodkazis, 3D laser microfabrication: principles and applications. John Wiley \& Sons, 2006.

[22] R. Osellame, G. Cerullo, and R. Ramponi, Femtosecond Laser Micromachining. Topics in Applied Physics, Berlin Heidelberg: Springer-Verlag, 1st ed., 2012.

[23] L. V. Keldysh, "Ionization in the field of a strong electromagnetic wave," Soviet Physics JETP, vol. 20, no. 5, pp. 1307-1314, 1965.

[24] N. Bloembergen, "Laser-induced electric breakdown in solids," IEEE Journal of Quantum Electronics, vol. 10, pp. 375-386, 1974.

[25] M. Sparks, D. L. Mills, R. Warren, T. Holstein, A. A. Maradudin, L. J. Sham, E. Loh, and D. F. King, "Theory of electron-avalanche breakdown in solids," Physical Review B, vol. 24, no. 6, pp. 3519-3536, 1981.

[26] S. Juodkazis and H. Misawa, "Laser processing of sapphire by strongly focused femtosecond pulses," Appl. Phys. A, vol. 93, pp. 857-861, 2008.

[27] M. Kaiser, M. Kumkar, R. Leute, J. Schmauch, R. Priester, J. Kleiner, M. Jenne, D. Flamm, and F. Zimmermann, "Selective etching of ultrafast laser modified sapphire," in Laser Applications in Microelectronic and Optoelectronic Manufacturing (LAMOM) XXIV (G. Račiukaitis, T. Makimura, and C. Molpeceres, eds.), p. 14, SPIE, mar 2019.

[28] M. Hörstmann-Jungemann, J. Gottmann, and D. Wortmann, "Nano-and microstructuring of sio2 and sapphire with fs-laser induced selective etching," J. Laser Micro/Nanoeng, vol. 4, no. 2, pp. 135-140, 2009. 
The present chapter introduces and discusses a numerical model of lasermaterial interaction of sapphire, as well as simulation results. The chapter consists of two parts. The first part, starting on this page up to and including section 3.6, is identical to two published papers:

- L. Capuano, D. de Zeeuw and G.R.B.E. Römer "Towards a Numerical Model of Picosecond Laser-Material Interaction in Bulk Sapphire" in "Proceedings of the conference Laser Precision Microfabrication" (Edinburgh, 2018).

- L. Capuano, D. de Zeeuw and G.R.B.E. Römer "Towards a Numerical Model of Picosecond Laser-Material Interaction in Bulk Sapphire" Journal of Laser Micro/Nanoengineering, Vol. 13, No. 3, 2018.

To clarify and discuss some topics in these published papers, footnotes have been added to this chapter. After these papers were published, some additional work on the numerical simulation was performed. The latter is discussed in section 3.7 of this chapter. Combined, the two parts of this chapter address research objective 1 , as defined in section 1.3 .

A BSTRACT Crystalline sapphire $\left(\mathrm{Al}_{2} \mathrm{O}_{3}\right)$ is a hard and transparent material widely used in industry. When applying IR laser wavelengths, sapphire can be laser-processed inside the bulk (subsurface) to produce 3D structures, which can find uses, for example, in the production of microfluidic devices. Ultrashort and tightly focused laser pulses trigger several energy absorption mechanisms inside the bulk. The absorbed energy locally modifies the structure of sapphire. Existing (numerical) models of sapphire laser processing describe mainly femtosecond pulsed laser-material interaction (most of them only addressing surface processing) and, in addition, these models do not simulate the laser-induced temperatures of the lattice. Therefore, this study is aimed at a 2D-axisymmetric, time dependent, numerical model of the physics in picosecond 
laser-material interaction with sapphire. The physical phenomena in the model include, but are not limited to: multiphoton absorption, tunneling ionization, avalanche ionization, recombination of carriers, diffusion of carriers and heat diffusion. Based on these phenomena, three quantities are calculated, namely: electron density, electron temperature and lattice temperature. The model was implemented in COMSOL Multiphysics ${ }^{\circledR}$. It was found that, sapphire is modified by the laser radiation only if avalanche ionisation is triggered in the bulk.

\subsection{INTRODUCTION}

Sapphire, (or $\alpha-\mathrm{Al}_{2} \mathrm{O}_{3}$ ), is an aluminium oxide with a crystalline structure, that can be produced synthetically in a variety of shapes and sizes. Sapphire is one of the hardest materials with a hardness ranging from $1835 \mathrm{HV} 1$ to 2039 HV1 [1]. In its crystalline form it is highly chemically inert [1-3]. Because of its wide bandgap $[1 ; 4]$, sapphire is a good electric insulator and is optically transparent to a broad range of wavelengths going from deep UV to mid infrared in the electromagnetic spectrum [1]. The combination of unique physical and chemical properties and the possibility of producing the material synthetically make sapphire suitable for numerous applications. This includes bearings, smart-phone screens, optics, biomedical applications and microfluidic devices $[2 ; 3 ; 5 ; 6]$. In order to increase the understanding of the fundamental processes that contribute during subsurface processing of sapphire by means of picosecond pulsed laser sources, a numerical model, which allows simulation of the process under different conditions, is needed. The model should at least be able to describe the electron densities and lattice temperatures that are induced by the absorbed laser energy. This would allow the study of resulting structures and the physics behind the process itself, which will therefore contribute to the fundamental knowledge on subsurface micro-processing of sapphire. In literature, most models address mainly the surface damage induced by ultra-short pulsed lasers [7-12]. These studies typically cover laser pulse durations of less than one picosecond and mostly consider semiconductors, instead of large bandgap dielectric materials, such as sapphire. In addition, no models are reported, which are suitable for the application to sapphire, allowing to calculate the temperatures in the material as a result of the laser pulse. The literature on modelling of subsurface lasermaterial interaction that do take into account optical effects, such as focussing 
and spherical aberrations of a laser beam in sapphire, is quite limited. This is likely due to the complicated electromagnetic description that is required to accurately describe the envelope (caustic) of the laser beam, while taking into account absorption and the challenges that it presents for the numerical simulations. Models that describe the individual physical phenomena or a part of the laser-material interaction are more frequently reported [13-15]. Although, these models are dominantly applied to ultra-short pulse processing and in studies that show the modelling of electron densities generated, in order to describe or predict the damage threshold for ablation. Therefore, most of the studies reviewed do not take into account electron temperatures. Based on literature, the governing equations, which make up the model, were selected (see section 3.2). The equations are implemented in the numerical software tool COMSOL Multiphysics ${ }^{\circledR}$ (see section 3.3). The three main quantities which are calculated are the free electron density, the electron temperature and the lattice temperature (see section 3.4). The reader is invited to refer to the tables in the nomenclature when the variables, quantities and constants are not directly explained in the text.

\subsection{MODEL DESCRIPTION AND GOVERNING EQUATIONS}

Figure 3.1 shows a diagram of the structure of the model. The coloured arrows indicate the dependencies of the free electron density, the free electron temperature, the lattice temperature and the beam propagation on the main physical phenomena (blocks in the graph) occurring during and after the laser pulse. There are four "subsystems" that are considered. The first subsystem is the laser intensity distribution (red arrows). Depending on the level of the laser intensity, multiphoton ionization, avalanche ionization, free electron absorption and tunnelling ionization might be triggered. In turn, the laser intensity is reduced by multiphoton ionization and free electron absorption (dashed red arrows). The free electron density subsystem is indicated by the green arrows. Phenomena that generate free carriers are avalanche ionization, multiphoton ionization and tunnelling ionization. The free electron density will be reduced by recombination effects as free carrier diffusion can be neglected as discussed later in section 3.2.1. The free electron temperature depends on all phenomena that either affect the free carrier density or lead to a change of the electron kinetic energy. Energy transfer to the lattice, indicated by the black arrows, is described by the well-known two-temperature model [16]. In summary, the model consists of four partial differential equations (PDEs) describing: (i) 


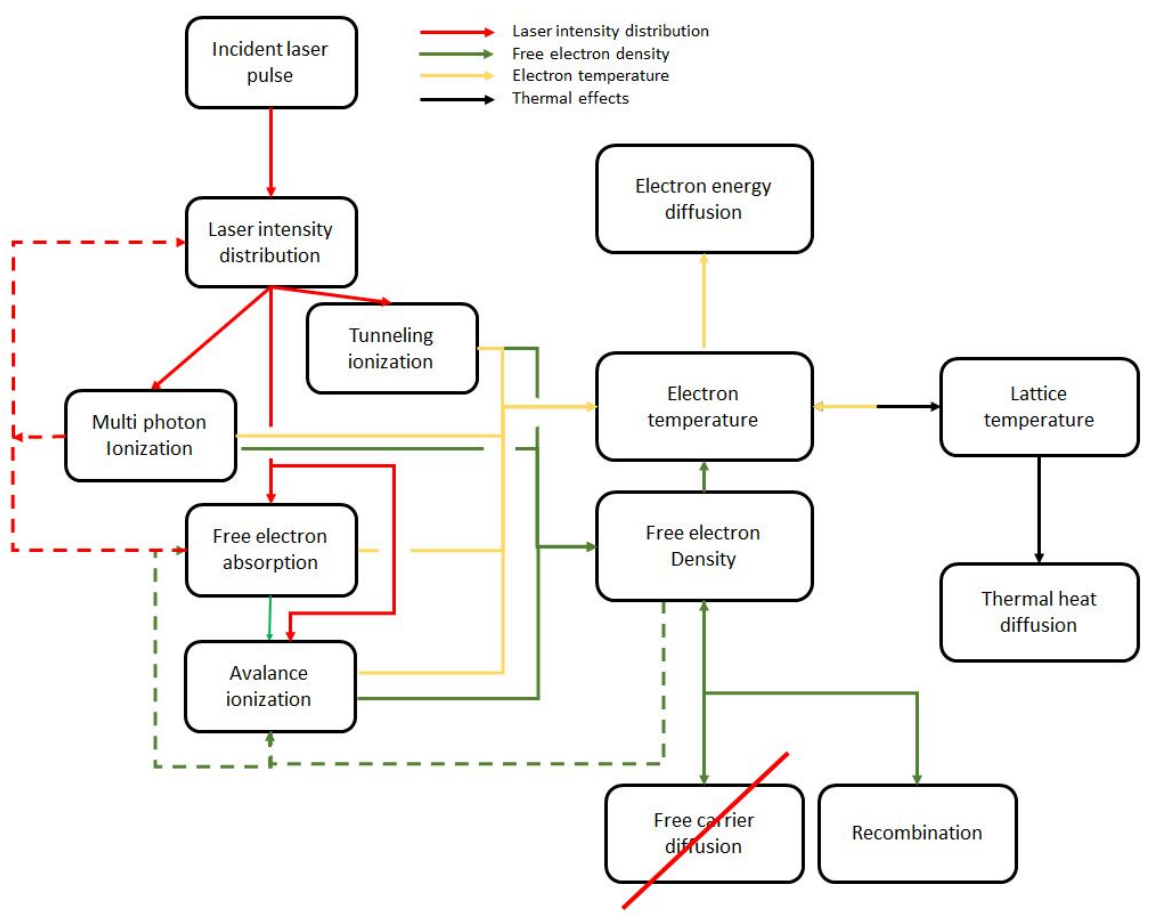

Figure 3.1: Diagram of the model, showing the four "subsystems" (arrows) and their dependencies on physical phenomena (blocks).

free electron density, (ii) free electron temperature, (iii) lattice temperature, and (iv) beam propagation. These four PDEs are described in the following subsections.

\subsubsection{Free electron density}

The free electron density $n_{e}$ can be described by a commonly used electron conservation equation [10-12; 14-17]:

$$
\frac{\partial n_{e}(t)}{\partial t}+\frac{1}{e} \frac{\partial J}{\partial x}=W_{\text {source }}+W_{\text {loss }} .
$$

where $J$ denotes the current and $x$ is the propagation coordinate. The first term on the left hand side of equation 3.1 describes the change of electron density in time. The second term describes the diffusion of electrons in the material. The terms on the right hand side are source and loss terms. The 
carrier excitation rate source term, $W_{\text {source }}$ in equation 3.1, can be described considering single or multi-photon ionization, tunnelling and avalanche ionization rates. The general expression for the single or multiphoton ionization rate equals

$$
W_{m p i}(I)=\sigma_{n} I^{n},
$$

where $n$ denotes the single or multiphoton absorption coefficient. The subscript $n$ indicates the number of photons required to excite a single electron from the valence to the conduction band. Single photon absorption - i.e. $n=1$, which is a linear process, is significant when the photon energy of a photon is equal or larger than the band gap of the material. Multiphoton absorption on the other hand, is an $n$-th order process that will only be significant for sufficiently high laser intensities [18]. Photon ionization in general is only significant at low free electron densities and when the intensity of the electric field due to the laser fluence is not sufficiently high such that tunneling ionization would dominate [19; 20]. For the wavelength of $1030 \mathrm{~nm}$, which was selected for this study, the photon energy is too low for linear, single photon absorption in sapphire. The single or multiphoton absorption coefficient $\left(\sigma_{n}\right)$ is a phenomenologically determined parameter that depends on material parameters and processing conditions [12; 21]. In large bandgap dielectrics, the density of thermally excited electrons is close to zero [22]. For short and ultra-short pulse durations, when processing large bandgap dielectrics, single and multiphoton ionization will therefore generate the required electron density to allow significant free electron absorption and subsequently impact ionization to take place [23]. A well-studied approach to model avalanche ionization is the Drude model. The parameters of the Drude model are all known and Jing et al. [23] have shown that the model performs well on fused silica for a laser with $800 \mathrm{~nm}$ wavelength and a pulse duration of $0.3 \mathrm{ps}$. That is, the avalanche ionization rate $W_{a v}$, can be calculated from

$$
W_{a v}=\frac{\sigma_{\text {Drude }}}{E_{g}} I(t),
$$

in which

$$
\sigma_{\text {Drude }}=\frac{e^{2}}{c \epsilon_{0} n m_{e}^{*}} \frac{\tau_{c}}{1+\omega^{2} \tau_{c}^{2}} .
$$

The mean electron collision time $\tau_{c}$ in equation 3.4 is crucial for estimating the avalanche ionization rate and is highly dependent on the material and process 
conditions such as the electron density, wavelength and effective electron mass. The mean electron collision time $\tau_{c}$ can be determined phenomenologically or by the expression as developed by Starke et al. [24], which reads

$$
\tau_{c}=\frac{16 \pi \epsilon_{0}^{2} \sqrt{m_{e}^{*}\left(0.1 E_{g}\right)^{3}}}{\sqrt{2} e^{4} n_{e}(t)} .
$$

This expression increases the applicability of the Drude model under various conditions and when data on the mean electron collision time for various process conditions is limited. When the absorption of photons is sufficiently high (see section 3.4), the increased absorption generates a significant amount of free carriers to trigger avalanche ionization [18]. In addition to multiphoton and avalanche ionization, tunneling ionization may occur if the laser intensities are sufficiently high. Multiphoton and tunneling ionization can be described by the same theoretical framework via the so-called Keldysh ionization rate $W_{p i}$, which is calculated as [20]

$$
W_{p i}=\frac{2 \omega}{9 \pi}\left(\frac{\omega m_{e}^{*}}{\sqrt{\gamma 1} \hbar^{2}}\right)^{3 / 2} Q(\gamma, x) \exp \left\{-\pi\langle x+1\rangle \times \frac{K\left(\gamma_{1}\right)-E\left(\gamma_{1}\right)}{E\left(\gamma_{2}\right)}\right\} .
$$

and

$$
Q(\gamma, x)=\sqrt{\frac{\pi}{2 \boldsymbol{K}\left(\gamma_{2}\right)}} \times \sum_{i=0}^{\infty} \exp \left\{-i \pi \frac{\boldsymbol{K}\left(\gamma_{1}\right)+\boldsymbol{E}\left(\gamma_{1}\right)}{\boldsymbol{K}\left(\gamma_{2}\right)}\right\} \boldsymbol{\Phi}\left(\frac{\pi}{2} \sqrt{\frac{(2\langle\boldsymbol{x}+1\rangle-2 \boldsymbol{x}+i)}{\boldsymbol{K}\left(\gamma_{2}\right) \boldsymbol{E}\left(\gamma_{2}\right)}}\right)
$$

and

$$
\boldsymbol{\Phi}(z)=\int_{0}^{z} \exp \left(y^{2}-z^{2}\right) d y,
$$

and

$$
\boldsymbol{x}=\frac{\pi}{2} \frac{E_{g}}{\hbar \omega} \frac{\sqrt{1+\gamma^{2}}}{\gamma} \boldsymbol{E}\left(\gamma_{2}\right),
$$

and

$$
\gamma=\frac{\omega}{e} \sqrt{\frac{m_{e}^{*} c n \epsilon_{0} E_{g}}{2 I}}
$$

Here, the functions $K(\gamma)$ and $E(\gamma)$ represent the complete elliptic integral of the first and second kind respectively. The "crossover" from multiphoton 
dominated ionization to tunnelling dominated ionization is characterized by the Keldysh parameter, $\gamma$. That is, for $\gamma<<1$, tunnelling ionization dominates and for $\gamma>>1$ multiphoton ionization dominates. The multiphoton ionization rate coincides with the Keldysh photo-ionization rate only for low laser intensity levels. It should be noted that, the validity of the multiphoton ionization rate, when considering a large range of laser intensities, when avalanche ionization is triggered, is questionable. When electron-hole pairs recombine the electron density is reduced. In sapphire radiative recombination is not significant due to a large radiative recombination lifetime of about $100 \mathrm{ps}$, when compared to the pulse duration [25]. Therefore, radiative recombination is neglected in the model. In the case that the pulse duration is shorter than the recombination time $\tau_{e}$, the recombination of electron-hole pairs is often neglected $[7 ; 8 ; 26]$. However, Auger recombination is included in the model. Typically, the Auger recombination rate $W_{\text {rec }}$ is calculated as $[13 ; 14 ; 16 ; 23 ; 27]$

$$
W_{\text {rec }}=-\frac{n_{e}(t)}{\tau_{e}}
$$

in which $\tau_{e}$ denotes the mean recombination time. In the case of pulse durations equal or longer than the recombination time, or when the decay and behaviour of the electron density, as well as the electron temperature is an important subject of study, recombination needs to be taken into account. For sapphire, the electron-hole recombination time of $\tau_{e}=1$ ps was applied by Bulgakova et al. $[14 ; 28]$. As this recombination time $\tau_{e}$ is smaller than the pulse duration considered in this study, Auger recombination will be significant. Besides recombination effects, diffusion of electrons into the substrate also reduce the local electron density. However, for large bandgap dielectrics, the diffusion of free electrons is small due to a high electron-hole mass. Hence, in the case of sapphire, electron diffusion can be neglected [4; 21] (see also Fig. 3.1). For the set of (simulation) parameters considered, the Keyldish parameter is never exclusively $\gamma>>1$ or $\gamma<<1$. Hence, the model will only be realistic when both multiphoton and tunnelling ionization are considered. Hence, the full Keldysh ionization rate $S_{m p i}$ is included in the model. Substituting the relevant expressions into equation 3.1, and neglecting carrier diffusion, will 
result in the PDE describing the conservation of electron-hole pairs, which will be used to describe the carrier density in the numerical model as ${ }^{1}$

$$
\frac{\partial n_{e}(t)}{\partial t}=W_{p i}+W_{a v, \text { Drude }} n_{e}(t)-W_{r e c}
$$

\subsubsection{Free electron temperature}

The absorbed laser energy will first be "stored in" the free electrons, before it is transferred to the lattice via electron-phonon scattering [16]. The energy (density) in the free electron subsystem is the sum of the kinetic energy and band-gap energy per unit of volume [20]. The kinetic energy distribution can take several "shapes". That is, when high carrier densities are encountered $\left(n_{e} \approx 10^{17}-10^{18} \mathrm{~W} / \mathrm{cm}^{3}\right)$, the carrier-carrier interactions will force the shape of the distribution into a Maxwell-Boltzmann (also referred to as Maxwellian) distribution [30; 31]. For a Maxwellian distribution the energy density of the electron-hole pairs can be computed from [30]

$$
U=n_{e}\left(E_{g}+\frac{3}{2} k_{b} T_{e}\right)
$$

The electron heat capacity $C_{e}$ is equal to the change of energy $U$ with respect to the electron temperature $T_{e}$. That is,

$$
C_{e}=\frac{\partial U}{\partial T_{e}}=\frac{3}{2} k_{b} T_{e}
$$

The overall expression to compute the change of energy in the electron subsystem reads

$$
\frac{\partial U}{\partial t}+\nabla \cdot \vec{W}=S+L
$$

in which $S$ and $L$ denote the source and loss terms respectively, and the term $\vec{W}$ on the left hand side of the equation describes the diffusion of electronic energy. This diffusion is the result of carrier-carrier scattering, which is described by [16]

$$
\vec{W}=-k_{e} \nabla T_{e},
$$

1 To take into account that the number of available ionization centers (neutral atoms/molecules) is decreasing at high laser excitations (when the ionization degree approaches $100 \%$ ), the righthand side term in equation 3.12 was multiplied by the saturation term applied by Burakov et al. [29] $\frac{n_{0}-n_{e}}{n_{0}}$ where $n_{0}$ is the number of ionization centers available in the volume. 
and

$$
k_{e}=\frac{2 k_{b}^{2} T_{e} n_{e}\left(\mu_{e}+\mu_{h}\right)}{e}
$$

in which $k_{e}$ is the electron thermal conductivity, $\mu_{e}$ is the electron mobility and $\mu_{h}$ is the hole mobility. Sapphire has a low hole mobility so that $\mu_{h}$ may be neglected [4; 21]. Substituting expression 3.13 into 3.15 will result in a differential equation

$$
C_{e} \frac{\partial T_{e}}{\partial t}+\nabla \cdot \vec{W}=S+L-\frac{\partial n_{e}}{\partial t}\left(E_{g}+\frac{3}{2} k_{b} T_{e}\right)
$$

On the right hand side of equation 3.18 are source terms $S$, which describe an increase of energy due to multiphoton-ionization and free electron absorption, and loss terms $L$ that describe transfer of energy from the electron subsystem to the lattice (via the two temperature model, see below). Multiphoton ionization will excite electrons with an excess kinetic energy and will therefore add energy to the free electron subsystem. The energy rate per volume unit can be determined by multiplying the ionization rate $W_{m p i}$ by the energy of the absorbed photons [16; 32]

$$
S_{m p i}=W_{m p i} \hbar \omega n_{p h}
$$

in which $n_{p h}$ is the number of photons and $\hbar$ is the reduced Planck constant. Free electrons will gain extra kinetic energy when they absorb photons. This process will result in an increase of energy in the free electron subsystem. Free electron absorption can be described by a source term including a free electron cross-section

$$
S_{a b}=\sigma_{a b} n_{e} I
$$

in which $\sigma_{a b}$ is the free electron cross-section. This type of source term is referred to as Coulomb heating. Karras et al. [33] determined the free electron cross-section for a $800 \mathrm{~nm}$ laser source to equal $(12.5 \pm 0.2) \cdot 10^{-18} \mathrm{~cm}$. The main loss to the electron energy is due to the interaction of the electron subsystem with the lattice caused by electron-phonon scattering, described by the wellknown Two Temperature Model (TTM) [16]. The TTM is derived under the assumption that electron and phonon energy transport is described by the classical Fourier law. This approach is valid as long as the time scale of changes of the temperature (field) is much larger than relaxation time of the free 
electrons [34]. The TTM describes a balance between the electron temperature $T_{e}$ and the lattice temperature $T_{l}$ and reads

$$
W_{T T M}=\Gamma\left(T_{e}-T_{l}\right)=\frac{C_{e}}{\tau_{r}}\left(T_{e}-T_{l}\right),
$$

in which the electron-phonon coupling coefficient $\Gamma$ may be expressed as $C_{e} / \tau_{r}$. Here $\tau_{r}$ is the characteristic electron-lattice relaxation time. The latter is chosen here to equal $\tau_{r}=1 \mathrm{ps}$ [21]. Substituting source terms (equations 3.19 and 3.20) and loss terms (equation 3.21) in equation 3.18, results in the PDE describing the free electron temperature

$$
C_{e} \frac{\partial T_{e}}{\partial t}+\nabla \cdot \vec{W}=S_{m p i}+S_{a b}-W_{T T M}-\frac{\partial n_{e}}{\partial t}\left(E_{g}+\frac{3}{2} k_{b} T_{e}\right) .
$$

\subsubsection{Lattice temperature}

The classical Fourier law describes the spatial and temporal lattice temperature $T_{l}$, which is the result of a source term $Q$ and heat conduction, and reads [35]:

$$
\rho C_{l} \frac{\partial T_{l}}{\partial t}+\nabla \cdot \overrightarrow{q_{l}}=Q
$$

in which heat conduction is described by $\overrightarrow{q_{l}}=-k_{l} \cdot \nabla T_{l}$ where $k_{l}$ denotes the thermal conductivity of the lattice. The source term $Q$ is the result of electron-phonon coupling (two temperature model, see previous subsection):

$$
\rho C_{l} \frac{\partial T_{l}}{\partial t}+\nabla \cdot \overrightarrow{q_{l}}=S_{T T M}
$$

\subsubsection{Beam propagation}

The mathematical complexity of describing both beam propagation and focussing proved to be difficult in the implementation of the model in COMSOL (see section 3.3). Therefore, the beam envelope is simplified to a collimated-i.e. a non-converging and non-diverging beam passing through the complete sapphire substrate. The laser intensity absorption can then be described by a beam optics approach. Assuming laser beam propagation in the positive z-direction, a non-diverging beam and a volume absorbing material, the propagation losses can be described as [16]

$$
\frac{\partial I}{\partial z}=-S_{m p i}-S_{a b}
$$


in which $S_{m p i}$ denotes the intensity loss of the laser beam due to multiphoton ionization. Note that the term $S_{m p i}$ is the same as the source term for the electron subsystem in equation 3.19. Intensity losses due to multiphoton ionization will be significant when multiphoton ionization rate is relevant. That is when the electron densities are low and when the Keldysh parameter $\gamma>>1$ [23]. The term $S_{a b}$ describes the intensity loss due to absorption of photons by conduction band electrons.

\subsection{MODEL IMPLEMENTATION}

The PDEs were solved using the numerical software tool COMSOL Multiphysics ${ }^{\circledR}$ (COMSOL Inc.). An axis-symmetric simplified configuration on a time-dependent study was implemented.

It proved that the evaluating the Keldysh ionization rate, containing the complete elliptic integrals of the first and second kind (see section 3.2.1), was computationally too demanding. That is because the ionization rates $W_{p i}$, (equation 3.6) and $W_{m p i}$, (equation 3.2), need to be evaluated at every node on the calculation grid at every time-step. Therefore, the Keldysh ionization rates were implemented as a lookup table, which, via an interpolation, allows COMSOL Multiphysics ${ }^{\circledR}$ to compute an approximation of the full Keldysh ionization rate, as well as allow to approximate multiphoton absorption as function of the intensity. To that end, the lookup table was generated in MATLAB $®$ (Mathworks Inc.) for a laser intensity range of $I=0$ to $10^{20}\left[\mathrm{~W} / \mathrm{m}^{2}\right]$ on a total of $10^{6}$ data points. Figure 3.2 shows this lookup table graphically.

\subsubsection{Initial and boundary conditions}

The beam diameter in the simulations was set to $w_{0}=51.5 \mathrm{~nm}$ in order to reduce the computer memory requirements and computation time. This simplification can be considered reasonable for the model because only the absorption phenomena are simulated, without taking into account optical effects (i.e. diffraction).

Also, the pulse duration was set to $t_{p}=3 \mathrm{ps}$, for the same reason. The model would still be valid for a larger pulse duration (in the picosecond regime), but the effects of the resultant increase of electron density would need further investigation. The anisotropy of sapphire is neglected. At the first time instance, the electron and lattice temperatures are at equilibrium and were set to $300 \mathrm{~K}$. For both the lattice and electron temperature, all the 


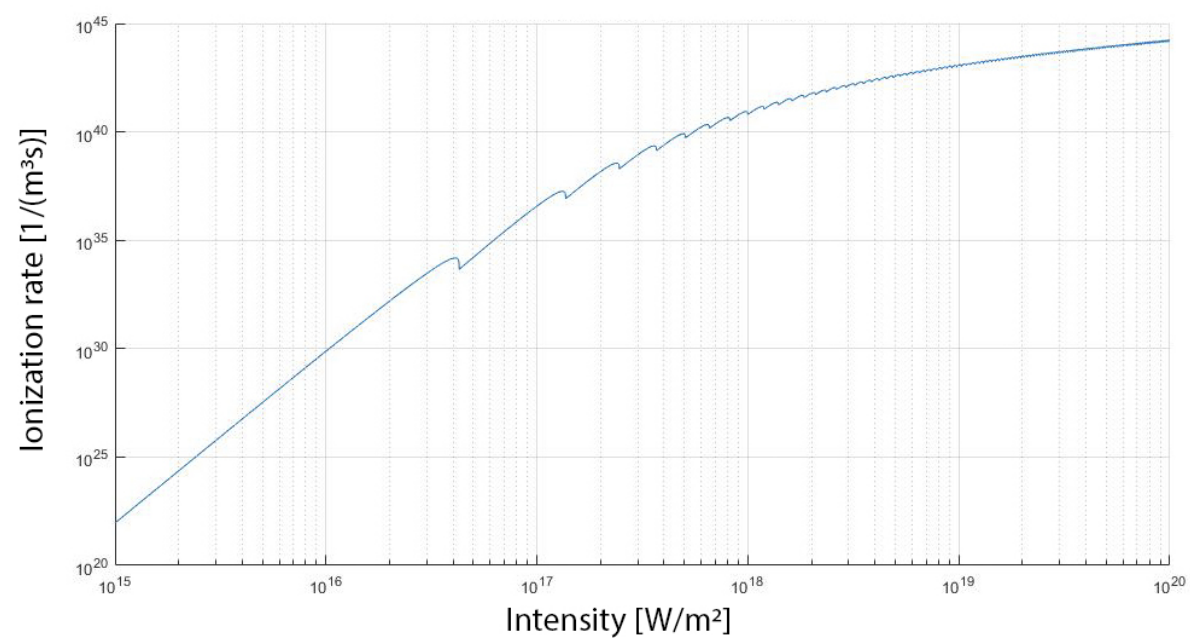

Figure 3.2: Graphical representation of the lookup table of the Keyldysh ionization rate as function of the laser intensity.

boundary conditions, except for the symmetry axis, are set to a zero flux boundary conditions, as the thermal flux passing through the boundaries, at the time ranges considered, will be negligible. In the lattice the specific heat is assumed to be constant. At the first time instance, the electron density is set to equal to the density corresponding to thermally excited electrons at 300 $\mathrm{K}$. Applying these initial conditions to calculate the initial electron density results in a density of $3.18 \cdot 10^{-48} \mathrm{~m}^{-3}$. This low value is typical for large bandgap semiconductors at low temperatures. However, due to numerical restrictions, an initial electron density of eps $\approx 2.22 \cdot 10^{-16} \mathrm{~m}^{-3}$ was applied, which corresponds to the smallest number allowable due to machine precision. This value is much smaller than the multiphoton ionization rate occurring (just) before avalanche and tunnelling ionization will dominate. Hence, this value will not "trigger" avalanche ionization or significant free electron absorption. Therefore, the simulation results are not affected by setting the initial electron density to eps $\approx 2.22 \cdot 10^{-16} \mathrm{~m}^{-3}$ instead of $3.18 \cdot 10^{-48} \mathrm{~m}^{-3}$.

\subsection{RESULTS}

This section presents the simulation results for various pulse energies listed in table 3.1. The rounded values that will be used to refer to the simulations in this section are listed in the first column of the table. 
Table 3.1: Pulse energies considered for the simulations and maximum intensity reached.

\begin{tabular}{ccc}
\hline Pulse energy simulation & Maximum intensity & Critical electron density reached? \\
\hline $0.06 \mu \mathrm{J}$ & $1.982 \cdot 10^{16} \mathrm{~W} / \mathrm{m}^{2}$ & No \\
$0.08 \mu \mathrm{J}$ & $2.972 \cdot 10^{16} \mathrm{~W} / \mathrm{m}^{2}$ & No \\
$0.11 \mu \mathrm{J}$ & $3.963 \cdot 10^{16} \mathrm{~W} / \mathrm{m}^{2}$ & No \\
$0.28 \mu \mathrm{J}$ & $9.908 \cdot 10^{16} \mathrm{~W} / \mathrm{m}^{2}$ & Yes \\
$0.45 \mu \mathrm{J}$ & $1.406 \cdot 10^{17} \mathrm{~W} / \mathrm{m}^{2}$ & Yes \\
$0.55 \mu \mathrm{J}$ & $1.515 \cdot 10^{17} \mathrm{~W} / \mathrm{m}^{2}$ & Yes \\
\hline
\end{tabular}

The simulations only converged for pulse energies which induce electron densities lower than the critical electron density, that is $n_{e}<n_{c r}$. That is, simulations where avalanche ionization was triggered resulted in an over critical electron density (plasma), see last column of table 3.1. The high absorption of the critical electron density resulted in extreme absorption rates in a very small (skin) layer of the material. The latter imposed numerical problems (failure to converge). Nevertheless, up to this instance the simulations provide interpretable results. Therefore, these results are included and discussed in the following subsections.

\subsubsection{Electron Density}

Figure 3.3 shows the maximum electron densities in the sample, as function of time for several pulse energies at three different locations: at the surface of the sample, at $5 \mathrm{~nm}$ and $10 \mathrm{~nm}$ below the surface of the sample. For low pulse energies, the maximum electron densities at different depths are close. That is, the data points in the graph coincide. This indicates that the absorption of photons in the material is small and the laser intensity, and electron densities do not vary with depth. From the graph it is clear that pulse energies over about $2.75 \mu \mathrm{J}$ induce a maximum electron density, which is over the critical electron density. It was found that, these simulations failed to converge as soon as the electron density reaches a value $n_{e}>1.5 \cdot 10^{28} \mathrm{~m}^{-3}$. In addition, in the graph, the values of the maximum electron density for the corresponding pulse energies do not coincide. This indicates that the electron density at the locations near the surface prevents/reduces the ionization (rate) at locations further below the surface. 


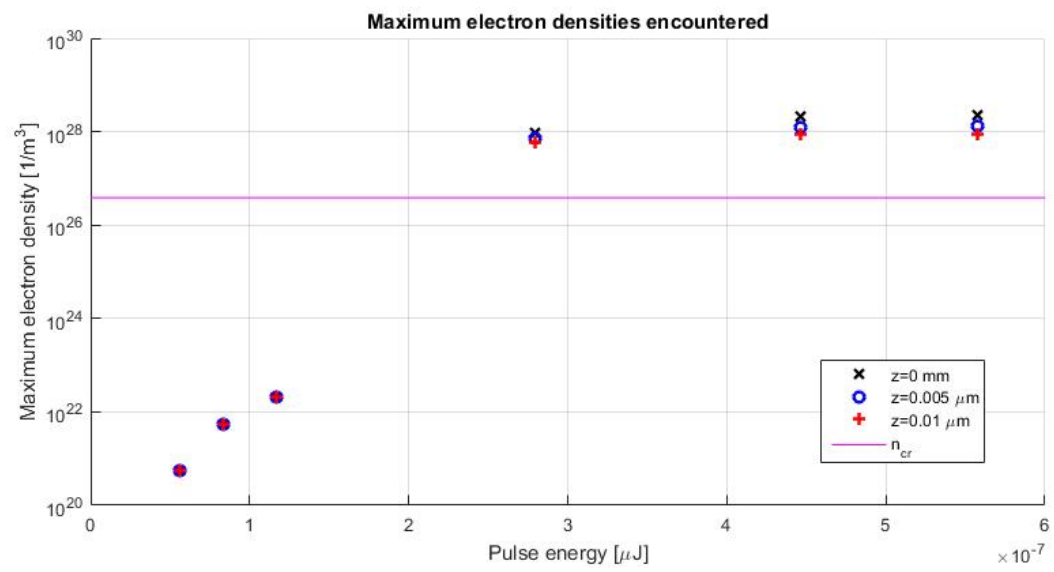

Figure 3.3: Maximum electron densities $n_{e}$ as function of the pulse energy at three different depths in the sapphire sample. The horizontal line indicates the critical electron density $n_{c r}=3.83 \cdot 10^{26}\left[\mathrm{~m}^{-3}\right]$.
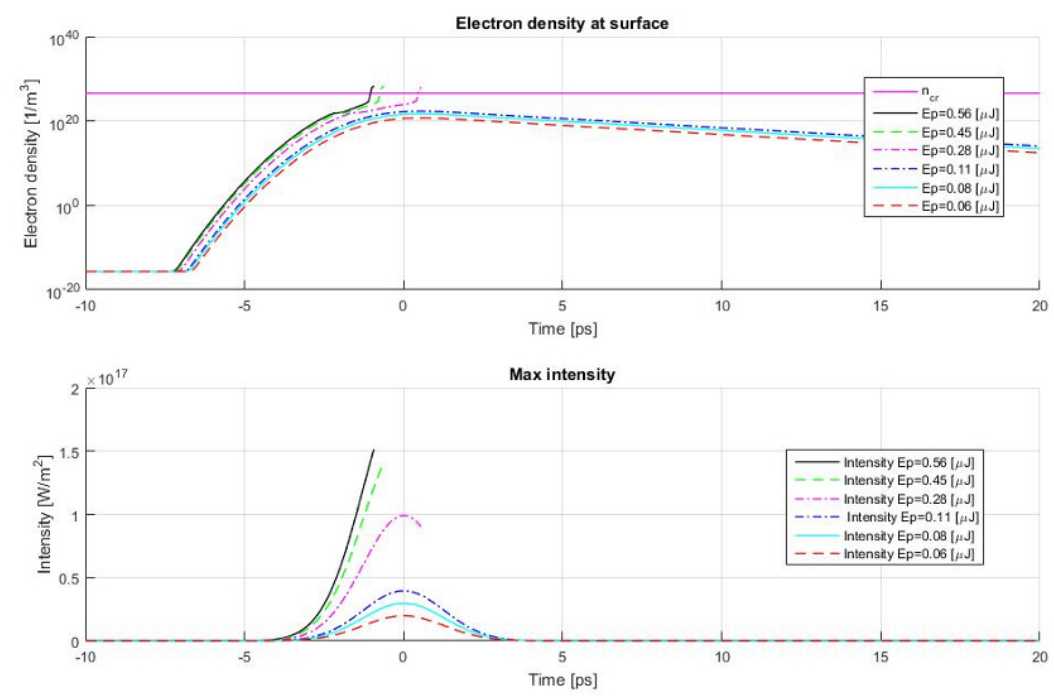

Figure 3.4: Top: Maximum electron density as function of time at three different locations in the sample, for several pulse energies. The horizontal curve indicates the critical electron density $n_{c r}$. Bottom: Maximum laser intensity at the surface of the sample as a function of time, for several pulse energies. The time instance 0 ps represents the maximum intensity of the pulse (Gaussian in time). Negative and positive time steps in the graphs are relative to this time instance. 

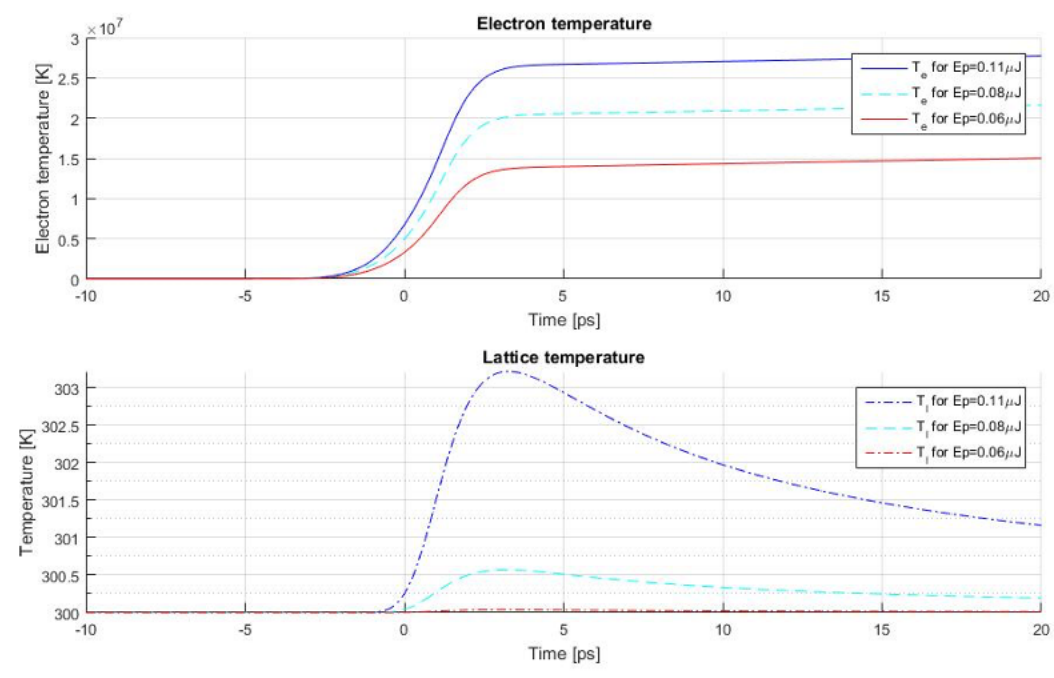

Figure 3.5: Electron temperature $T_{e}$ (top) and lattice temperature $\mathrm{Tl}$ (bottom), as function of time, corresponding pulse energy levels leading to sub-critical electron densities $\left(n_{e}<n_{c r}\right)$. The time instance 0 ps represents the maximum intensity of the pulse (Gaussian in time). Negative and positive time steps in the graphs are relative to this time instance.

Figure 3.4 (top) shows the electron density as a function of time. Here it is shown that for low pulse energies, both the generation of free electrons and the decrease of electrons (due to recombination of electron-hole pairs) is non-linear but "smooth" in time. For high electron densities, that is $n_{e} \approx 5 \cdot 10^{23} \mathrm{~m}^{-3}$, the absorption and generation of free carriers by means of avalanche ionization results in a sudden increase in the electron density at the sample surface. In the graphs, this occurs at $t \approx-2 p s$ (where the time instance $0 p s$ represents the maximum intensity of a Gaussian shaped laser pulse in time).

\subsubsection{Electron and lattice temperatures}

Figure 3.5 shows the electron and lattice temperatures in the material as function of time at several pulse energies. Here it is shown that the electron temperature increases until the pulse power has dropped significantly after 3 ps, see figure 3.5 (top). From this time instance on, the steep increase of the electron temperature does level off but still increases over time. This is due to the recombination of electron-hole pairs. Also, the lattice temperature 

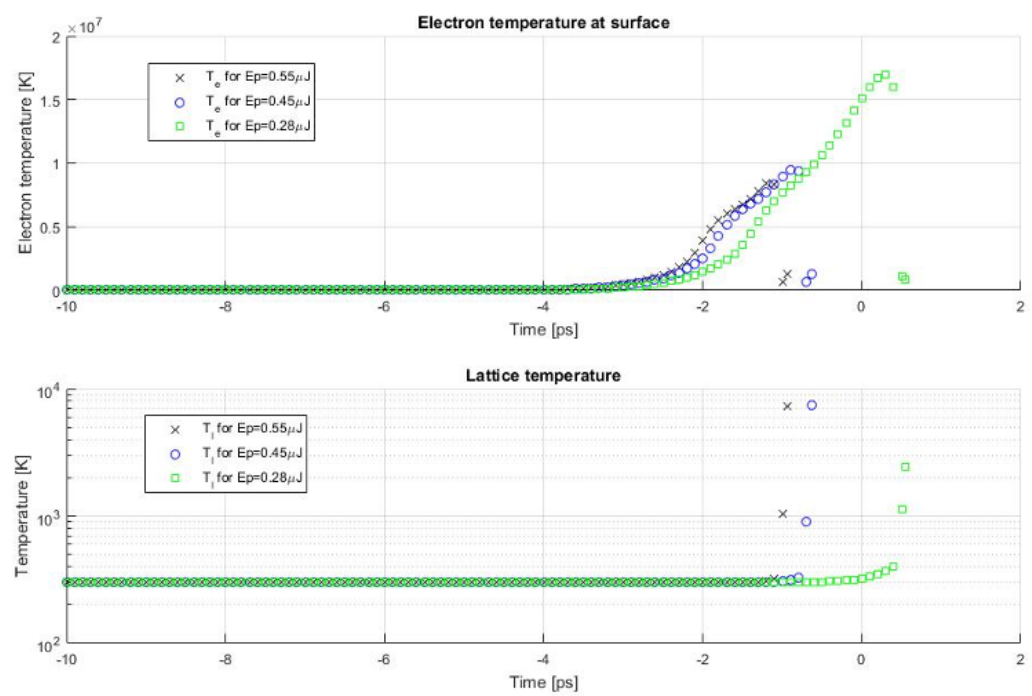

Figure 3.6: Temperature plots critical $\left(n_{e}>n_{c r}\right)$ studies for corresponding pulse energies. (Top): electron temperature $T_{e}$ and (bottom): the lattice temperature $T_{l}$. The time instance 0 ps represents the maximum intensity of the pulse (Gaussian in time). Negative and positive time steps in the graphs are relative to this time instance.

induced by a pulse energy of $E p=0.11 \mu \mathrm{J}$ is much higher than the lattice temperature due to the pulse energy below $0.11 \mu \mathrm{J}$, see Figure 3.5 (bottom). This illustrates the non-linear increase in absorption rate due to multiphoton absorption. However, the difference in electron temperatures for the same pulse energy is much smaller (see figure 3.5 (top)), due to the fact that the energy in the electron subsystem depends on the electron temperature and specific heat (which depends on the electron density), where in the lattice the specific heat is assumed constant.

Figure 3.6 shows the electron and lattice temperatures as a function of time for pulse energies $E p=0.28 \mu \mathrm{J}, 0.45 \mu \mathrm{J}$ and $0.55 \mu \mathrm{J}$. At these pulse energies, electron densities over the critical electron densities were found. In these cases, the electron temperature shows a sudden decline at $t \approx-0.8 \mathrm{ps}$ (where the time instance $0 p s$ represents the maximum intensity of a Gaussian laser pulse in time). At this instance, avalanche ionization becomes significant, resulting in a temporary decrease in the electron temperature. This behaviour was also observed by van Driel [20]. 

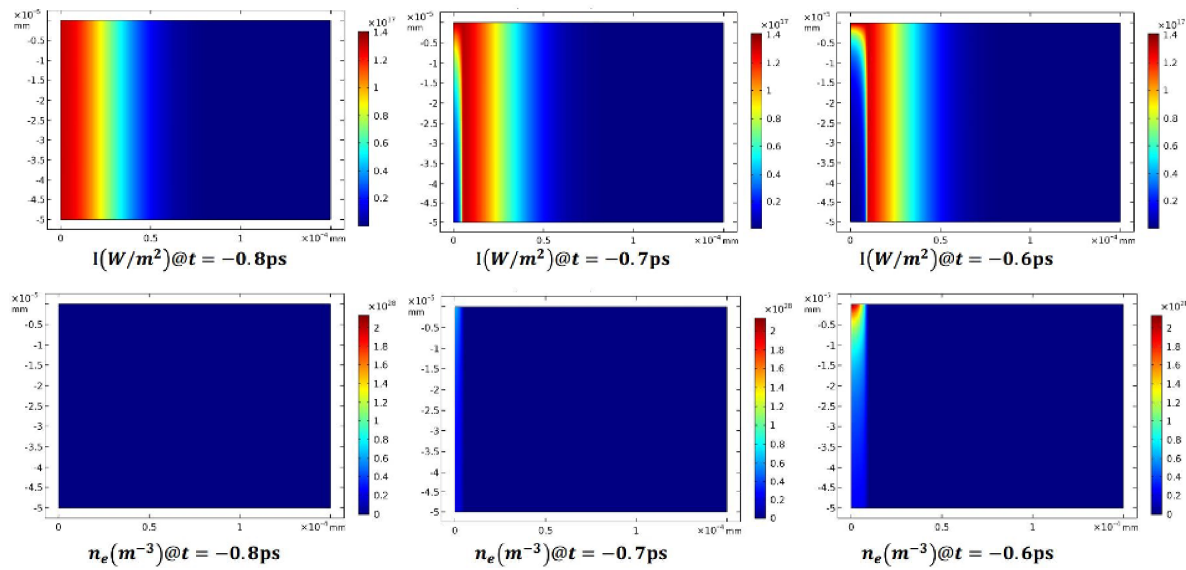

Figure 3.7: Top: Laser beam intensity distribution $I$ at several time instances induced by a pulse energy of $E p=0.45 \mu \mathrm{J}$. Bottom: Electron density distributions $n_{e}$ for a pulse energy of $E p=0.45 \mu \mathrm{J}$. The distributions are axisymmetric and the graphs only show a $2 \mathrm{D}$ projection. The full cylindrical profiles shape can be imagined as a complete rotation $\left(360^{\circ}\right)$ of the shown distributions around the vertical axis. The vertical axis represents the optical axis where the laser beam is considered to propagate from top to bottom. The horizontal axis represents the lateral distance from the optical axis.

\subsubsection{Laser intensity spatial distribution}

At a pulse energy of $E p=0.11 \mu J$ the absorption of photons in the material is negligible as the electron density is not sufficient to cause significant free electron absorption. As a result, the laser intensity distribution is not "distorted", but maintains its collimated "shape". Figure 3.7 (top) shows the laser intensity distribution for $E p=0.45 \mu \mathrm{J}$. From this graph, the effect of electron shielding can be observed, especially in the middle and right graph.

\subsubsection{Electron density distribution}

The electron density induced by a pulse energy of $E p=0.11 \mu \mathrm{J}$ was found to be nearly constant along the z-axis. This is another indication that the electron density is too low to cause any significant free electron absorption. At a higher pulse energy of $E p=0.45 \mu \mathrm{J}$, the electron densities are plotted in figure 3.7 (bottom) at three different time instances. Here the rapid increase in electron density due to the avalanche ionization can be observed, especially at 
$t=-0.6 \mathrm{ps}$. This graph also shows that the electron density is high near the surface of the sample. Here, the locally high concentration of electrons implies an increased absorption rate and avalanche ionization rate, which will result in an even higher electron density near the surface. The strong absorption lead to high spatial gradients in the laser intensity and electron density, which are hard to represent on a discrete mesh. This mechanism causes the convergence error that was encountered during the simulations with a critical electron density (see section 3.4.1).

\subsubsection{Temperature and energy distribution in the electron subsystem}

Figure 3.8 shows the lattice temperature $T_{l}$ (left graphs) and the electron energy density $E_{e}$ (right graphs) for a pulse energy of $E p=0.11 \mu \mathrm{J}$. At $t=-3 \mathrm{ps}$, the graphs do not show any significant increase in $T_{l}$ nor $E_{e}$. The highest electron energy density is reached at $t=1.2 \mathrm{ps}$. In contrast, the maximum lattice temperature is reached at $t=2.5 \mathrm{ps}$. The time difference between these maxima confirms the need for applying the two-temperature model. At $t=6 \mathrm{ps}$, the electron energy density has reduced significantly and some thermal conduction is present in the lattice. At the end of the simulation time $(t=20 \mathrm{ps})$ the electronic energy (density) is negligible. Also, the effects of heat conduction in the lattice become significant, as the spatial gradients are reduced and the energy has been spread over a larger volume in the sample.

\subsection{Limitations OF THE MOdEL}

\subsubsection{Phase transformation and material properties}

In the model, the material properties were assumed to be constant. In reality the conductivity and heat capacity of the material depend on the phase of the material, as well as on temperature [1]. Also, the anisotropy of sapphire was neglected, as the differences are small and it allows the application of an axis-symmetric simplification. The properties would in particular change when the material undergoes a phase transformation. This will affect the temperature distributions and should therefore be included when studying the lattice temperature distribution. The anisotropy may lead to a loss of axial symmetry of distributions, but the impact on the resulting is unknown and requires therefore more research. A small change in the value for effective electron mass will significantly change the ionization rates, as stated by Jing 

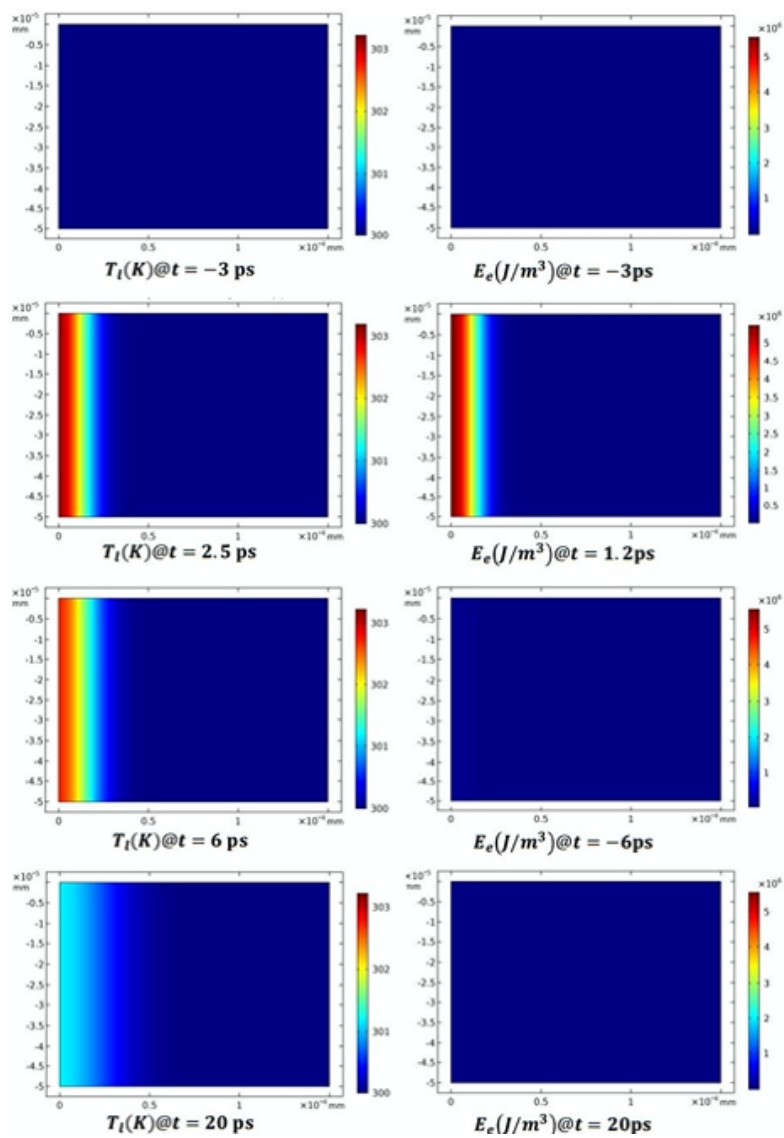

Figure 3.8: (Left): lattice temperature distribution and (right) the electronic energy density at various time instances for a pulse energy of $E p=0.11 \mu \mathrm{J}$. The distributions are axisymmetric and the graphs only show a 2D projection. The full cylindrical profiles shape can be imagined as a complete rotation $\left(360^{\circ}\right)$ of the shown distributions around the vertical axis. The vertical axis represents the optical axis where the laser beam is considered to propagate from top to bottom. The horizontal axis represents the lateral distance from the optical axis.

[23]. The values reported have a range $\left(m_{e}^{\star}=0.35-0.38\right)$ which may cause a deviation from the actual ionization rates. 


\subsubsection{Beam propagation and focusing optics}

The laser beam propagation in the governing equations was simplified to a collimated beam resulting in a system that is representative for surface processing. This rigorous simplification allows to demonstrate the phenomena during laser-material interaction of sapphire, but more work is required to include the beam propagation into the model in order to study subsurface lasermaterial interaction. Also, the beam propagation was taken one directional where in reality reflection at sample boundaries and at high electron densities may occur [7].

\subsubsection{Free electron temperature}

In section 3.2, it was shown that the electron temperature remains constant, after excitation, due to the recombination of electron-hole pairs and only converged to the lattice temperature when recombination ends. The same behavior was encountered in the simulations in the previous section, where the electron temperature keeps raising after the pulse maximum is reached, due to the recombination. However, this behavior seems to be plausible, confirmed by [36] in which is shown that this occurs due to the recombination of electron-hole pairs that alone result in a temperature difference [37].

\subsubsection{Self-Focusing and Kerr effect}

The simulation does not take into account self-focusing caused by the Kerr effect because this effect is not trigged under the laser conditions considered. That is, the critical power to trigger the Kerr effect depends on the nonlinear refractive index of sapphire $\left(n_{2}\right)$ and is given by [36]

$$
P_{\text {crit }}=\frac{\lambda_{0}^{2}}{2 \pi n_{0} n_{2}}
$$

For the parameters studied in this chapter, the critical power equals about 3.2 MW. This is one order of magnitude larger than the maximum peak power used in our study. Therefore, self-focusing is not modelled. 


\subsection{CONCLUSIONS}

The objective of the study was to set the base for a numerical model that allows the simulation of the laser-material interaction in sapphire. Based on literature, a set of governing equations was established, describing the free electron density, the free electron temperature, the lattice temperature and beam propagation. The resulting model includes beam propagation of a collimated laser beam. The model was implemented and simulated in COMSOL Multiphysics ${ }^{\circledR}$. It was shown that the resulting model is capable of simulating the laser-material interaction during short $p s$ pulse durations for sub-critical electron densities. The simulation results, when the critical electron density ${ }^{2}$ of

$n_{c r}=3.83 \cdot 10^{26} \mathrm{~m}^{-3}$ was exceeded, failed to converge due to numerical issues. Nevertheless, the behavior of the model up to this density was as expected when compared to literature. Considering the lack in the literature of models describing jointly all the mentioned physical phenomena, this study can be seen as a significant contribution to a numerical model that is able to estimate both the absorption and the resulting thermal effects of the laser-material interaction in sapphire.

\subsection{ADDITIONAL RESULTS}

As was mentioned in the preamble of this chapter, some additional work on the numerical model was performed after the publication of the results at a scientific conference and in a journal. In particular, further results were obtained, even when the condition of critical electron density is exceeded. The latter could be achieved by resolving the numerical issues that affected the model (see section 3.4). Moreover, the energy balance of the model was analysed for the validation of the model and the estimation of its accuracy.

\subsubsection{Electron density, electron temperature and lattice temperature in overcritical conditions}

It was mentioned in section 3.4 that, when the electron density reached values higher than the critical electron density $n_{c r}$, the simulation failed to converge. The main numerical issue for the failing convergence was identified to be the

2 The critical electron density, as defined by [23] is here calculated as $n_{c r}=\frac{\epsilon_{0} m_{e}^{*} \omega^{2}}{e^{2}}$, where $\epsilon_{0}$ is the vacuum permittivity, $m_{e}^{*}$ the effective electron mass, $\omega$ the frequency of the laser light and $e$ the electron charge. 
(too) steep temporal and spatial gradients, generating in the areas with high(er) intensities. To solve the problem, several measures were taken, including a finer calculation grid, as well as downscaling the simulation to facilitate the calculation. The former was addressed by performing the calculations on a mesh which was twice as fine. The second measure consisted of reducing the size of the geometrical domain, increasing the beam diameter from $51.5 \mathrm{~nm}$ to $103 \mathrm{~nm}$ and decreasing the pulse duration from $t_{p}=3 \mathrm{ps}$ to $t_{p}=1 \mathrm{ps}$.

To visualize the effects of the thermalization, the calculation window was extended to $140 \mathrm{ps}$ after the peak of the pulse.

Figure 3.9 shows 2D distribution profiles of intensity $I$ ((a) in Figure 3.9), electron density $n_{e}\left((\mathrm{~b})\right.$ in Figure 3.9), electron temperature $T_{e}((\mathrm{c})$ in Figure 3.9) and lattice temperature $T((\mathrm{~d})$ in Figure 3.9), calculated using the new conditions at a pulse energy of $E p=0.45 \mu \mathrm{J}$. At $t=-1.56 \mathrm{ps}$, all the graphs show a distribution profile which resembles the collimated shape of the beam. Around $t=-1.28 \mathrm{ps}$ the "shielding" effect caused by the concentration of the electron density near the propagation axis of the laser beam, starts to be significant. Like previously observed in Figure 3.7, the intensity in the centre increases, but becomes thinner. That is, the propagation of the intensity profile inside the material, at this stage, occurs more in the "external" part of the profile. At the same time step, the electron density starts to accumulate in the centre-top of the material, close to the surface.

The electron temperature, at $t=-1.28 p s$ has similar profile as the intensity profile and shows higher values near the surface (at the centre) and in the external part of the profile. The kinetic energy of the electrons, around this time step, starts to be transferred to the lattice, at the surface. This causes a slight raise in the lattice temperature (only by a few Kelvin). At $t=-1.24 p s$, all the profiles start to "gather" towards the optical axis, near surface. That is particularly evident with the intensity profile, in which the "tails" of the shielding effect can still be observed at the external part of the profile, but the most intensity is concentrated in the centre-top. At $t=0 \mathrm{ps}$, i.e. at the peak energy of the pulse, the intensity is confined in a skin layer at the surface, the electron temperature and the lattice temperature increase and diffuse to side material $(r>>0)$. At $t=3.8 \mathrm{ps}$, the intensity decreases towards the zero, the electron density also decreases, while the electron and lattice temperature increase and diffuse further into the material.

Finally, figure 3.10, shows the electron temperature and lattice temperature calculated at the optical axis, just below the surface (i.e. at a depth $\left.z=10^{-5} \mu m\right)$. By resolving the numerical issues, it was possible to validate the 


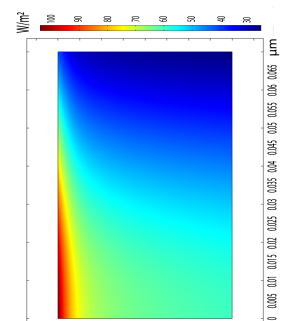

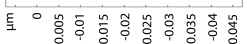
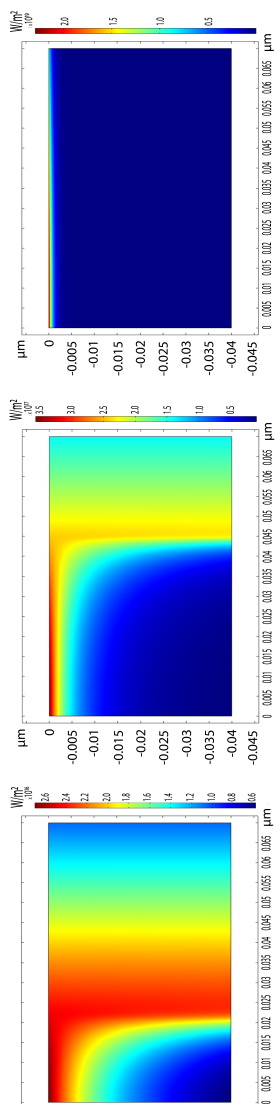

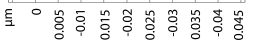

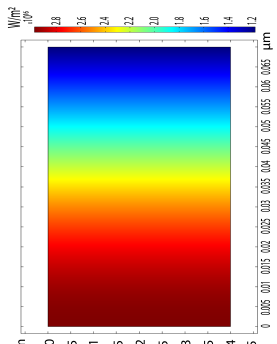

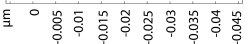

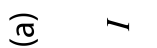

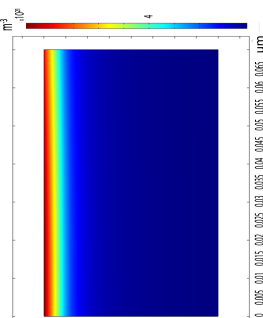

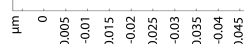

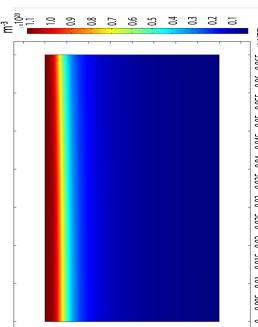

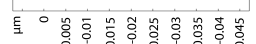

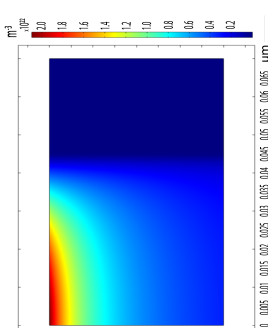

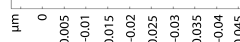

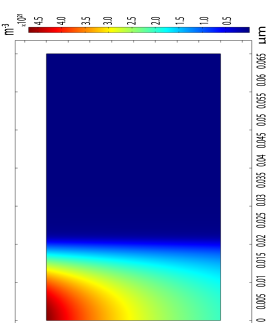

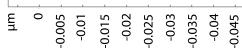

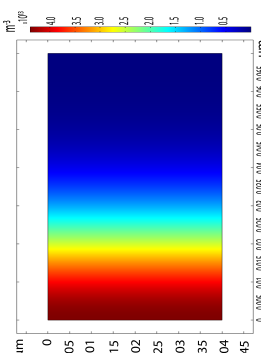

으 :

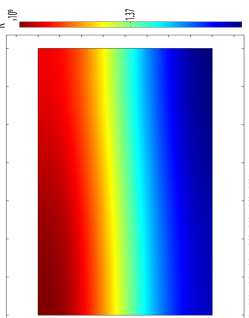

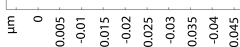

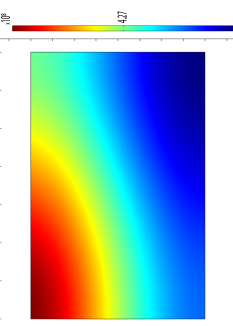

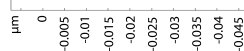
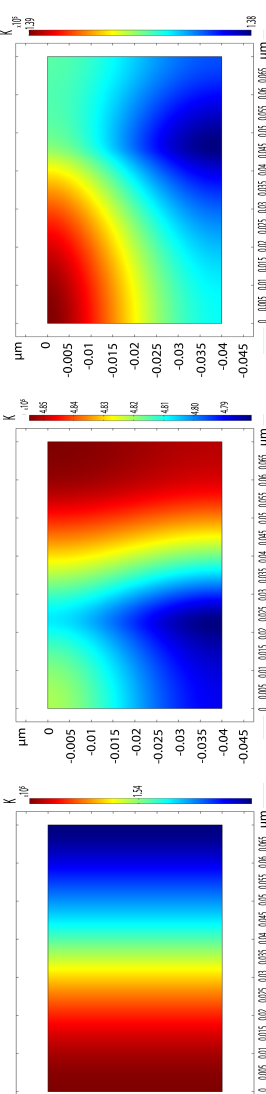

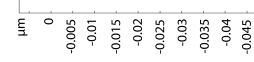

()
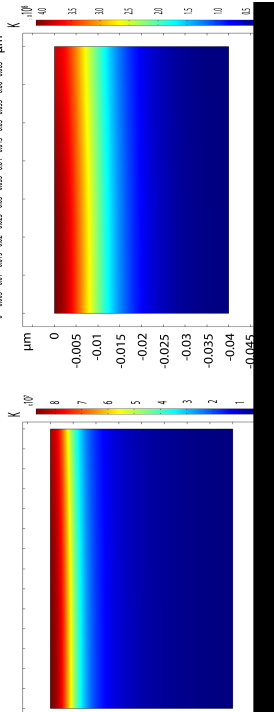

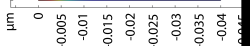
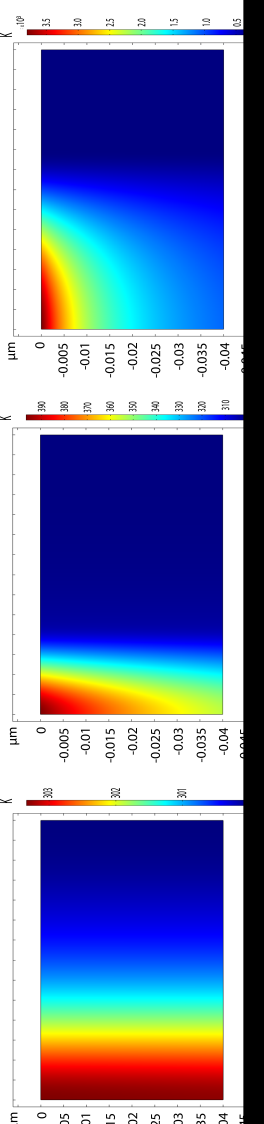

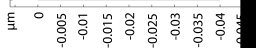

하

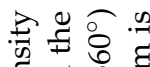

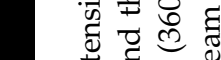

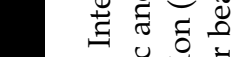

తิ

इ है

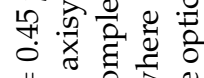

11 ¿ 3

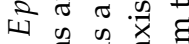

के

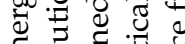

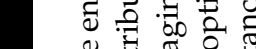

II $\quad$ 至

उ

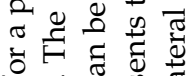

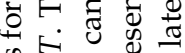

\&

펄

苛

$\exists$ 을

छ छ छ

ล 0 荡

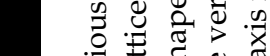

i त क के

휴휴 푱

त कृ

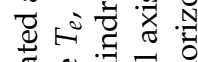

흑 정

ปु

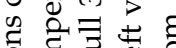

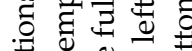

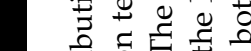

की

iั

令

की

至会吾䒕

की त्ञत

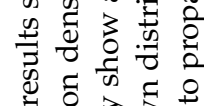

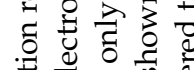

a क क क

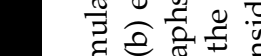

i क्ने कू पे

ตั

$\dot{m}$

苟

王 


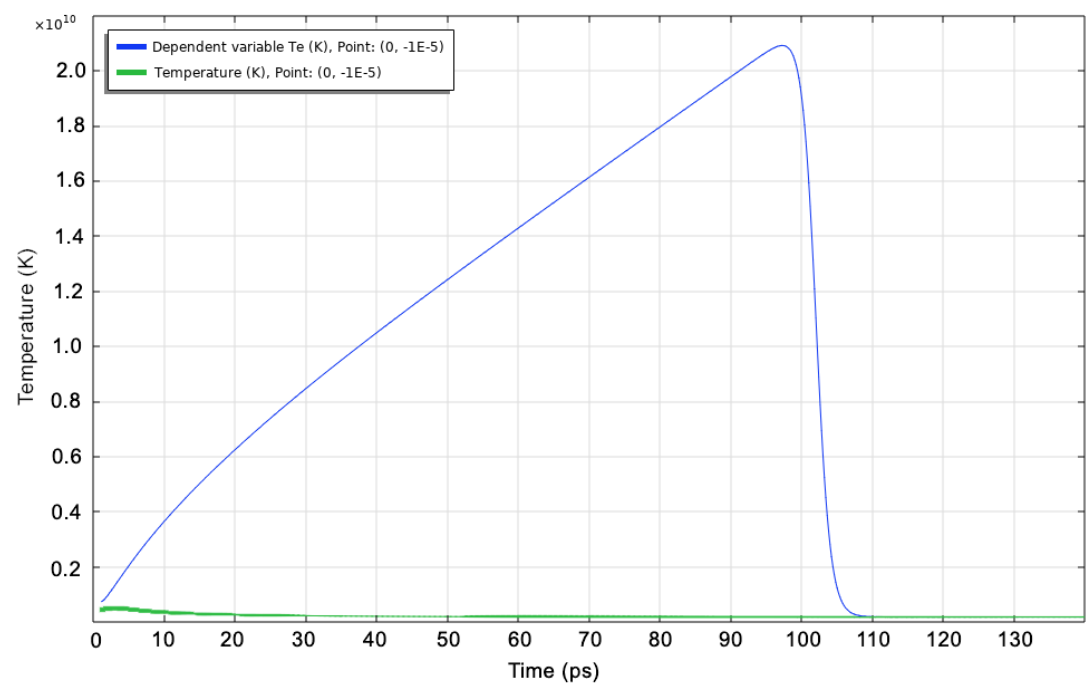

Figure 3.10: Simulated electron temperature $\left(T_{e}\right.$, in blue) and lattice temperature $(T$, in green) for a pulse energy $E_{p}=0.45 \mu \mathrm{J}$ as function of time. The time instance 0 ps represents the step in which the maximum intensity of the pulse (Gaussian in time) is reached.

implemented two temperature model. Figure 3.10 demonstrates the correct transfer of the kinetic energy from the electron subsystem to the lattice. The two systems reach the same temperature $\left(1.8 \cdot 10^{8} \mathrm{~K}\right)$ after $\approx 110 \mathrm{ps}$.

\subsubsection{Energy balance}

An important step in determining the validity of the model and estimating the accuracy is to verify its energy balance. The energy balance was calculated by taking the difference of the surface integrals of the laser intensity between top and bottom surface, which should be equal to the change in internal energy at the end of the simulation. This balance is mathematically expressed as:

$$
\begin{array}{r}
E_{\text {in,tot }}-E_{\text {out }, \text { tot }}=\Delta E \\
\int_{0}^{t_{\text {end }}} \int_{0}^{2 \pi} \int_{0}^{r_{\max }} I\left(r, z_{\text {top }}\right) r d r d \phi d t-\int_{0}^{t_{\text {end }}} \int_{0}^{2 \pi} \int_{0}^{r_{\max }} I\left(r, z_{\text {bottom }}\right) r d r d \phi d t= \\
\left.\int_{z_{\min }}^{z_{\max }} \int_{0}^{2 \pi} \int_{0}^{r_{\max }}\left(C_{e} \Delta T_{e}+\rho C_{l} \delta T_{l}\right) r d r d \phi d z\right|_{@ t=t_{\text {end }}}
\end{array}
$$


It was verified that, during the simulations in COMSOL, there is a difference of only $\sim 2 \%$ between the absorbed laser intensity and the increase of internal energy.

\section{BIBLIOGRAPHY}

[1] E. R. Dobrovinskaya, L. A. Lytvynov, and V. Pishchik, Sapphire: material, manufacturing, applications. New York: Springer Science \& Business Media, 2009.

[2] D. Wortmann, J. Gottmann, N. Brandt, and H. Horn-Solle, "Micro- and nanostructures inside sapphire by fs-laser irradiation and selective etching," in 2008 Conference on Quantum Electronics and Laser Science Conference on Lasers and Electro-Optics, CLEO/QELS, 2008.

[3] M. Hörstmann-Jungemann, J. Gottmann, and M. Keggenhoff, "3D-microstructuring of sapphire using fs-laser irradiation and selective etching," Journal of Laser Micro Nanoengineering, vol. 5, no. 2, pp. 145-149, 2010.

[4] J. Olivier and R. Poirier, "Electronic structure of Al2O3 from electron energy loss spectroscopy," Surface Science, vol. 105, pp. 347-356, apr 1981.

[5] S. Juodkazis and H. Misawa, "Forming tiny 3D structures for micro- and nanofluidics," SPIE Newsroom, pp. 4-6, 2007.

[6] S. Juodkazis, K. Nishimura, H. Misawa, T. Ebisui, R. Waki, S. Matsuo, and T. Okada, "Control over the crystalline state of sapphire," Advanced Materials, vol. 18, no. 11, pp. 1361$1364,2006$.

[7] B. C. Stuart, M. D. Feit, S. Herman, A. M. Rubenchik, B. W. Shore, and M. D. Perry, "Nanosecond-to-femtosecond laser-induced breakdown in dielectrics," Physical Review B, vol. 53, pp. 1749-1761, jan 1996.

[8] A. C. Tien, S. Backus, H. Kapteyn, M. Murnane, and G. Mourou, "Short-pulse laser damage in transparent materials as a function of pulse duration," Physical Review Letters, vol. 82, no. 19, pp. 3883-3886, 1999.

[9] K. Sokolowski-Tinten and D. von der Linde, "Generation of dense electron-hole plasmas in silicon," Physical Review B - Condensed Matter and Materials Physics, vol. 61, pp. 2643-2650, 2000.

[10] B. Rethfeld, A. Kaiser, M. Vicanek, and G. Simon, "Ultrafast dynamics of nonequilibrium electrons in metals under femtosecond laser irradiation," Physical Review B, vol. 65, p. 214303, may 2002.

[11] J. R. Peñano, P. Sprangle, B. Hafizi, W. Manheimer, and A. Zigler, "Transmission of intense femtosecond laser pulses into dielectrics.," Physical review. E, Statistical, nonlinear, and soft matter physics, vol. 72, p. 036412, sep 2005.

[12] E. Arola, "Theoretical Studies on Multiphoton Absorption of Ultrashort Laser Pulses in Sapphire," IEEE Journal of Quantum Electronics, vol. 50, pp. 1-12, aug 2014.

[13] N. M. Bulgakova, "Theoretical Models and Qualitative Interpretations of Fs Laser Material Processing," Journal of Laser Micro/Nanoengineering, vol. 2, no. 1, pp. 76-86, 2007.

[14] N. M. Bulgakova, V. P. Zhukov, Y. P. Meshcheryakov, L. Gemini, J. Brajer, D. Rostohar, and T. Mocek, "Pulsed laser modification of transparent dielectrics: what can be foreseen and predicted by numerical simulations?," Journal of the Optical Society of America B, vol. 31, no. 11, pp. C8-C14, 2014. 
[15] K. I. Popov, C. McElcheran, K. Briggs, S. Mack, and L. Ramunno, “Morphology of femtosecond laser modification of bulk dielectrics," Optics Express, vol. 19, no. 1, pp. 271-282, 2011.

[16] P. C. Verburg, G. R. Römer, and A. J. Huis In 'T Veld, “Two-temperature model for pulsedlaser-induced subsurface modifications in Si," Applied Physics A: Materials Science and Processing, 2014.

[17] T.-L. Chang, Z.-C. Chen, and Y.-C. Lee, "Micro/nano structures induced by femtosecond laser to enhance light extraction of GaN-based LEDs," Optics Express, vol. 20, no. 14, p. 15997, 2012.

[18] S. K. Sundaram and E. Mazur, "Inducing and probing non-thermal transitions in semiconductors using femtosecond laser pulses," vol. 1, no. 4, pp. 217-224, 2002.

[19] L. V. Keldysh, "Ionization in the field of a strong electromagnetic wave," Soviet Physics JETP, vol. 20, no. 5, pp. 1307-1314, 1965.

[20] H. M. Van Driel, "Kinetics of high-density plasmas generated in Si by 1.06- and 0.53- $\mathrm{m}$ picosecond laser pulses," Physical Review B, vol. 35, no. 15, pp. 8166-8176, 1987.

[21] N. M. Bulgakova, R. Stoian, A. Rosenfeld, I. V. Hertel, and E. E. Campbell, “Electronic transport and consequences for material removal in ultrafast pulsed laser ablation of materials," Physical Review B - Condensed Matter and Materials Physics, vol. 69, no. 5, pp. 112, 2004.

[22] B. Van Zeghbroeck, "Principles of semiconductor devices," Colarado University, vol. 34, 2004.

[23] X. Jing, Y. Tian, J. Zhang, S. Chen, Y. Jin, J. Shao, and Z. Fan, "Modeling validity of femtosecond laser breakdown in wide bandgap dielectrics," Applied Surface Science, vol. 258, no. 10, pp. 4741-4749, 2012.

[24] K. Starke, D. Ristau, H. Welling, T. V. Amotchkina, M. Trubetskov, A. A. Tikhonravov, and A. S. Chirkin, "Investigations in the nonlinear behavior of dielectrics by using ultrashort pulses (Best Oral Presentation)," vol. 5273, no. 0, p. 501, 2004.

[25] F. Wang, J. Shan, E. Knoesel, M. Bonn, and T. F. Heinz, "Electronic charge transport in sapphire studied by optical-pump/THz-probe spectroscopy," in Ultrafast Phenomena in Semiconductors and Nanostructure Materials VIII (K.-T. Tsen, J.-J. Song, and H. Jiang, eds.), vol. 5352, p. 216, jun 2004.

[26] T. Q. Jia, H. X. Chen, M. Huang, F. L. Zhao, X. X. Li, S. Z. Xu, H. Y. Sun, D. H. Feng, C. B. Li, X. F. Wang, R. X. Li, Z. Z. Xu, X. K. He, and H. Kuroda, “Ultraviolet-infrared femtosecond laser-induced damage in fused silica and CaF2 crystals," Physical Review B - Condensed Matter and Materials Physics, vol. 73, no. 5, pp. 1-9, 2006.

[27] R. Stoian, A. Rosenfeld, D. Ashkenasi, I. V. Hertel, N. M. Bulgakova, and E. E. B. Campbell, "Surface charging and impulsive ion ejection during ultrashort pulsed laser ablation," Physical review letters, vol. 88, no. 9, p. 097603, 2002.

[28] N. M. Bulgakova, V. P. Zhukov, and Y. P. Meshcheryakov, "Theoretical treatments of ultrashort pulse laser processing of transparent materials: Toward understanding the volume nanograting formation and "quill" writing effect," Applied Physics B: Lasers and Optics, vol. 113, no. 3, pp. 437-449, 2013.

[29] I. M. Burakov, N. M. Bulgakova, R. Stoian, A. Rosenfeld, and I. V. Hertel, "Theoretical investigations of material modification using temporally shaped femtosecond laser pulses," Applied Physics A, vol. 81, no. 8, pp. 1639-1645, 2005.

[30] M. Lundstrom, "Fundamentals of Carrier Transport, 2nd edn," Measurement Science and Technology, vol. 13, no. 2, pp. 230-230, 2002. 
[31] J. Shan, F. Wang, E. Knoesel, M. Bonn, and T. F. Heinz, "Measurement of the FrequencyDependent Conductivity in Sapphire," Physical Review Letters, vol. 90, no. 24, p. 4, 2003.

[32] E. Gamaly, B. Luther-Davies, A. Rode, S. Joudkazis, H. Misawa, L. Hallo, P. Nicolai, and V. Tikhonchuk, "Laser-matter interaction in the bulk of transparent dielectrics: Confined micro-explosion," vol. 59, p. 002, 2007.

[33] C. Karras, Z. Sun, D. N. Nguyen, L. A. Emmert, and W. Rudolph, "The impact ionization coefficient in dielectric materials revisited," vol. 8190, p. 819028, 2011.

[34] B. Rethfeld, D. S. Ivanov, M. E. Garcia, and S. I. Anisimov, “Modelling ultrafast laser ablation," Journal of Physics D: Applied Physics, vol. 50, no. 19, p. 193001, 2017.

[35] Y. A. Çengel and A. J. Ghajar, Heat and Mass Transfer A Practical Approach. 2014.

[36] E. G. Gamaly, S. Juodkazis, K. Nishimura, H. Misawa, and B. Luther Davies, "Lasermatter interaction in the bulk of a transparent solid: Confined microexplosion and void formation," Physical review. B, vol. 73, no. 21, p. 214101, 2006.

[37] T. L. Leung and H. M. Van Driel, "Time-resolved thermionic and photoemission from nanosecond, pulsed laser excited germanium and silicon," Applied Physics Letters, vol. 45, no. 6, pp. 683-685, 1984. 



\section{4}

MORPHOLOGY OF SINGLE PICOSECOND PULSE SUBSURFACE LASER-INDUCED MODIFICATIONS OF SAPPHIRE AND SUBSEQUENT SELECTIVE ETCHING

ABSTRACT The effect of $1030 \mathrm{~nm}$ single picosecond pulsed laserinduced modification of the bulk of crystalline sapphire using a combined process of laser amorphization and selective wet chemical etching is studied. Pulse durations of more than 1 picosecond are not commonly used for this subsurface process. We examine the effect of 7 picosecond pulses on the morphology of the unetched, as well as etched, single pulse modifications, showing the variation of shape and size when varying the pulse energy and the depth of processing. In addition, a qualitative analysis of the material transformation after irradiation is provided as well as an analysis of cracking phenomena. Finally, a calculated laser intensity profile inside sapphire, using the Point Spread Function (PSF), is compared to the shape of the modifications. This comparison is employed to calculate the intensity threshold leading to amorphization, which equals $2.5 \cdot 10^{14} \pm 0.4 \cdot 10^{14} \mathrm{~W} / \mathrm{cm}^{2}$.

The present chapter is identical to the journal paper "Morphology of single picosecond pulse subsurface laser-induced modifications of sapphire and subsequent selective etching" by L. Capuano, R. Pohl, R.M. Tiggelaar, J.W. Berenschot, J.G.E. Gardeniers and G.R.B.E. Römer published in "Optics express" 26, no 22 (2018): 29283-29295. To clarify and discuss some topics in this published paper, footnotes have been added to this chapter. This chapter addresses research objectives 2 and 3 , as defined in section 1.3 .

\subsection{INTRODUCTION}

Single crystal sapphire $\left(\alpha-\mathrm{Al}_{2} \mathrm{O}_{3}\right)$ is remarkably hard (9 on the Mohs scale [1]), chemically inert and shows a wide band gap [2]. Sapphire can be used as a substrate material in applications like Gallium Nitride based light emitting diodes (LEDs, [3-8]) and silicon-on-sapphire devices [9], but it is also used for waveguides [10], and in the field of microfluidics [11-13]. 
Processing of sapphire has been investigated widely by means of dry etching-i.e. plasma etching [6;14-16], wet etching [5; 8; 17] and mechanical processing like diamond blade sawing [18]. Although the capabilities of such methods have been demonstrated, these techniques are applicable to surface processing only.

As sapphire shows a large band gap, it is transparent ${ }^{1}$ to laser light with wavelengths ranging from about $0.3 \mu \mathrm{m}$ to about $5 \mu \mathrm{m}$ [19], which, in turn, allows the laser beam to be focused below the surface.

When exposed to ultra-short pulsed laser radiation, with pulse durations in the picosecond and femtosecond regime, crystalline sapphire is amorphized due to the absorbed laser energy [20]. Hence, an amorphized volume enclosed in the crystalline bulk is formed. When exposed to an aqueous solution of hydrofluoric acid (HF), amorphous sapphire can be etched significantly faster than crystalline sapphire (selectivity $10^{5}$ [20]). Hence, a two-step process, in which sapphire is first exposed to intense laser radiation and subsequently (selectively) etched in HF, allows the fabrication of subsurface structures-i.e. embedded in the bulk of sapphire substrates [11-13; 20-24].

This two-step fabrication method has been extensively studied using femtosecond pulsed laser sources, studying the effects of single pulse exposure [20; 25; 26] or showing the possibilities of this method in the field of microfluidics or 3D subtractive manufacturing in general [11; 13; 21].

Unfortunately, only few authors have investigated the characteristics of the method and the resulting armorphous modifications when applying picosecond laser pulses [12]. Although more affected by complications due to the heat accumulation, picosecond laser sources are typically more competitive in terms of price and generally more industrially available than femtosecond laser sources. Juodkazis et al. [20; 27] state that laser pulse durations above 1 ps induce extensive crack formation, which is attributed to heat accumulation due to high pulse rates. Unfortunately, the authors do not show the extent of these cracks experimentally in sapphire. When carefully tuning the laser parameters heat accumulation and crack formation might be minimized. Moreover, most authors study the laser-induced modifications realized by geometrically overlapping laser pulses, resulting in amorphous "channels" in sapphire [11-13; 20; 21]. In order to exploit the two-step process with pulse durations in the picosecond regime, first the morphology and features of the single pulse laser-induced modifications need to be studied. 
The phenomena responsible for the final morphology of the single picosecond laser modified sapphire can be roughly divided into three main phases: absorption of laser energy, amorphization of the crystalline sapphire, wet etching of the amorphized material.

The physical phenomena leading to the absorption of laser light and the ionization of the atoms in sapphire are complex and highly nonlinear [28]. To trigger the ionization in the material, the electrons on the outer shells have to gain enough energy to pass from the valence band to the conduction band, thus surpassing the ionization energy. At intensities in the order of $10^{14} \mathrm{~W} / \mathrm{cm}^{2}$ [29] the material can be ionized [20; 22]. The wavelength used for this work is $1030 \mathrm{~nm}$; such focused laser pulses have insufficient photon energy to be linearly absorbed. Considering the band gap of $8.8 \mathrm{eV}$ of sapphire, in fact, the wavelength for the linear photon absorption via the band gap, in bulk sapphire can be calculated using the Planck-Einstein relation in vacuum $\lambda_{0}=h c_{0} / E_{g}=0.141 \mu \mathrm{m}$, where $h$ is the Planck constant, $c_{0}$ is the speed of light in vacuum and $E_{\mathrm{g}}$ is the bandgap energy of the sapphire used for the experiments. Hence, the linear absorption is not possible with IR radiation. At sufficiently high intensities, though, multiphoton absorption, free carrier absorption, tunneling ionization and avalanche ionization become dominant phenomena enhancing absorption [23; 29-31]. These phenomena eventually cause an avalanche effect leading to the optical breakdown of the material.

The formation of amorphous sapphire is the result of the optical breakdown of the material near or close to the focus of the laser beam in the bulk of sapphire. The optical breakdown, in fact, causes a violent "microexplosion" generating lattice temperatures in the order of $10^{5} \mathrm{~K}$ and pressures in the order of $10^{12} \mathrm{~Pa}$ [22; 32]. The combined effect of ultra-fast cooling and high pressures triggers formation of amorphous sapphire.

At this stage, when the intensity is high enough, a void may appear enclosed by the amorphous region. In this phase also cracks are generated around the modified area. Figure 4.1(b) shows a schematic of a typical cross-section produced using the described processes, before the etching.

The phenomena associated with selective etching of amorphous sapphire were proposed by Misawa and Juodkazis [23]: due to a change of the angle in the bonds of the molecule of $\mathrm{Al}_{2} \mathrm{O}_{3}$, the amorphous material becomes more reactive to etchants such as hydrofluoric acid.

When processing using high numerical aperture (NA) lenses, optical aberrations "deform" the intensity profile of the laser beam in the bulk [33], which are expected to affect the morphology of the modification, see Fig. Fig. 4.1(a). 

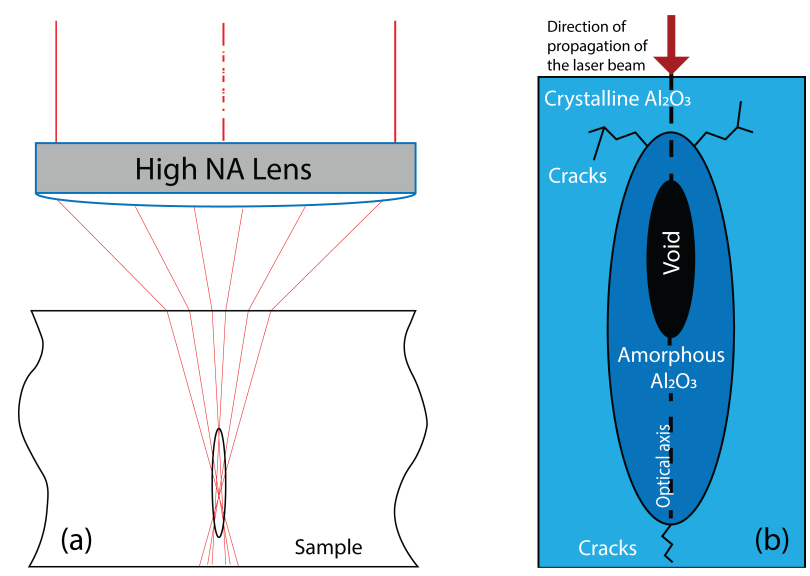

Figure 4.1: (a) The sapphire specimen behaves like a non-corrected lens in the path of the focusing beam and the morphology of the modifications will change depending on the depth of focusing below the surface. (b) After the irradiation, a modified volume is created, enclosed inside the crystalline phase (light blue), which consists of amorphous material (dark blue). Depending on the experimental parameters, a void (black) may or may not occur in the amorphous region. Cracks typically originate from and surround the modified region.

In this work a detailed parameter study is presented in order to establish a relation between the laser parameters (pulse energy, focus depth) and the morphology (shape, length, width) and material transformations of the singlepulse modifications in the picosecond regime. This involves a detailed analysis of the cross-sections of modifications induced by single picosecond laser pulses (at a wavelength of $1030 \mathrm{~nm}$ ) at various pulse energies and various locations of the focus below the surface.

A laser source with a fixed pulse duration of 7 s was chosen for this study. This pulse duration allows to study the effects of pulses longer than $1 p s$, but is still short enough to qualify as a duration in the ultrashort pulse regime.

Besides the laser-induced material changes (amorphization and crack formation), the effect of etching is studied.

A simulation tool was used to calculate the optical laser intensity profile inside the bulk of sapphire. These profiles are compared to shape and size of experimentally obtained shape and dimension of unetched modifications, from which the laser intensity threshold leading to amorphization can be derived. 


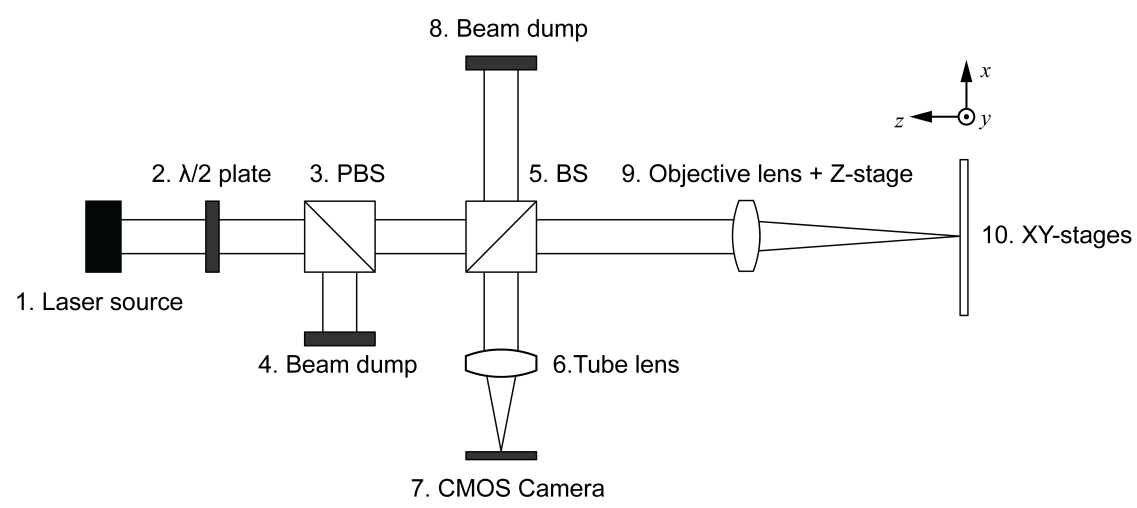

Figure 4.2: Schematic of the experimental set-up used for the experiments

\subsection{MATERIALS AND METHODS}

\subsubsection{Materials}

Crystalline (0001-orientation along C-plane) sapphire wafers of 2" in diameter and a thickness of $430 \mu \mathrm{m}$, supplied by Crystec, Germany are used. Both the top and bottom surface of these substrates are polished to optical quality by the manufacturer.

\subsubsection{Laser set-up}

A Yb:YAG laser source (TruMicro5050 of Trumpf, Germany) emitting pulses of $7 \mathrm{ps}$ of linearly polarized light at a central wavelength of $1030 \mathrm{~nm}$ is used, see 1 in Fig. 4.2. The power density profile of the laser beam is nearly Gaussian $\left(M^{2}\right.$ <1.3). A $\lambda / 2$ wave plate (2 in Fig. 4.2), a polarizing beam splitter (3 in Fig. 4.2), and a beam dump (4 in Fig. 4.2) are used as an attenuator, allowing to vary the pulse energy. A microscope objective (type 11101666 of Leica Microsystems, Germany), corrected for a $100 \mu \mathrm{m}$ thick coverslip of silicon (refractive index $n=3.55$ ) and with a numerical aperture of 0.7 is used to focus the laser beam to a diameter of $0.9 \mu \mathrm{m}$ (calculated), see 9 in Fig. 4.2. The medium between the objective and the sample is air. A beam splitter ( $50 \%-50 \%, 5$ in Fig. 4.2) and a tube lens (focal length 75 mm, 6 in Fig. 4.2) are used to image light, originating from the substrate, on a CMOS camera (DCC1545M of Thorlabs, Germany, 7 in Fig. 4.2). 

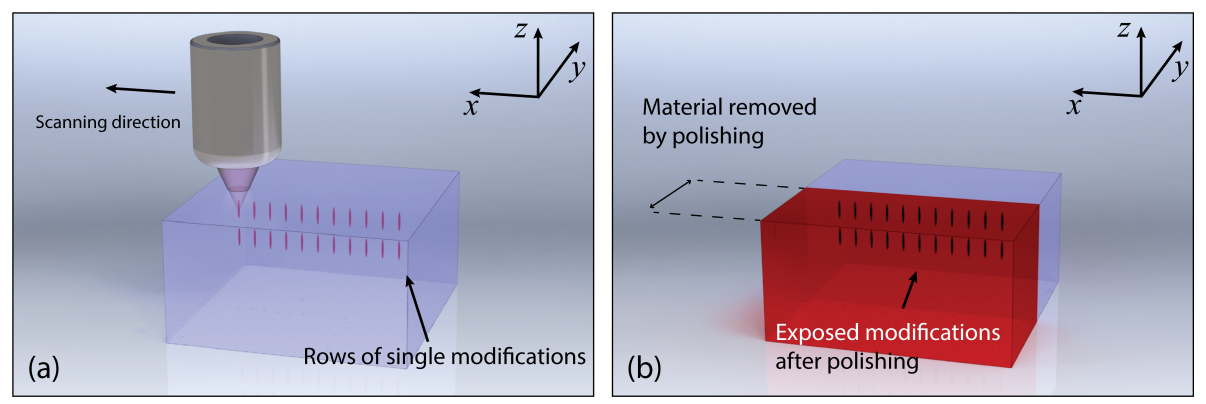

Figure 4.3: Schematic process sequence: (a) first, the sample is irradiated to form a pattern (array) of single modifications in rows, repeated at different depths beneath the surface of the sapphire specimen. Here, two rows are shown. The deepest row is formed first, (b) after laser processing the substrate is polished to remove bulk material (red in the graph) in order to "expose" cross-sections of the modifications.

These components allow to position the focus of the laser beam relative to the surface of the substrate. The sample is mounted on a vacuum chuck, which is positioned in the $x y$-plane by servo-controlled stages (UPS-150 of Physik Instrumente, Germany) with a resolution (minimum incremental motion) of $15 \mathrm{~nm}$ and bidirectional repeatability of $\pm 35 \mathrm{~nm}$. The objective (9 in Fig. 4.2) is also positioned by a servo-controlled stage (M-511 of Physik Instrumente, Germany) with a resolution of $50 \mathrm{~nm}$ and bidirectional repeatability of \pm 200 $\mathrm{nm}$. The laser experiments are carried out in a cleanroom environment (class ISO 8 , air exchange rate of 6 times per hour, temperature of $21^{\circ} \mathrm{C}$, relative humidity of $40 \%$ ).

\subsubsection{Analysis tools}

Cross-sections of laser-induced modifications in sapphire are imaged by Scanning Electron Microscopy (SEM) using a JSM-7200F SEM of JEOL (Japan).

\subsubsection{Methods}

Numerous "rows" of single pulse modifications were produced at different depths below the surface ( $z$-direction in Fig. 4.3 (a)) of the substrate, at different pulse energies. The horizontal distance (in $y$-direction) between each modification in a row was set to about $10 \mu \mathrm{m}$. Four pulse energy levels were 
analyzed: $4.0 \mu \mathrm{J}, 7.5 \mu \mathrm{J}, 10.0 \mu \mathrm{J}$ and $18.0 \mu \mathrm{J}$ respectively. To prevent optical effects induced by laser processing (too) close to the edge(s) of the sapphire substrate, the laser beam was focused at least at a distance $5 \mathrm{~mm}$ from the edges of the sample. Moreover, in order to avoid optical "disturbances" originating from modifications produced above, the first row of pulses was produced by positioning the focus of the laser beam at a distance of $400 \mu \mathrm{m}$ below the surface. Subsequent rows of modifications were produced at increments of $30 \mu \mathrm{m}$ (along $\mathrm{z}$ direction in Fig. 4.3) above the first row. By doing so, modifications were produced from $400 \mu \mathrm{m}$ to as close as $0 \mu \mathrm{m}$ below the surface.

The polarization of the laser was set perpendicular to the scanning direction.

After irradiation, the sample was cut with a diamond scribe to allow crosssectional analysis. After cutting, the edge of the substrate was polished, using a Struers Tegramin polishing device, to approximately the center of the single modifications in the $z x$-plane, see Fig. 4.3 (b). Best polishing results were obtained by the use of silicon carbide sandpapers for the grinding and subsequent steps of finer diamond pastes (down to $1 \mu \mathrm{m}$ ).

This methodology proved to be a quite elaborated exercise, that inevitably limited the amount of data available for the analysis.

Next, the samples were cleaned in ultrasonic bath with isopropanol and the modifications were analyzed by SEM. The amorphous material in the SEM micrograph appears darker with a different texture than the surrounding crystalline material.

After that, the substrate was immersed in a $50 \%$ hydrofluoric acid aqueous solution (BASF, Germany) for about 20 minutes. Subsequently, studying the SEM micrographs allowed a comparison of the unetched and etched modifications. In this way the dimensions of the former amorphous regions were confirmed.

Presented SEM images are characteristic, since obtained data is reproducible.

\subsubsection{Simulations}

The software tool PSF Lab [34] was used to calculate the electromagnetic field induced by a laser beam focused inside sapphire, which is based on the illumination point spread function. Input parameters to the simulation tool were the refractive index of sapphire $(n=1.75$ at a wavelength of $1030 \mathrm{~nm}$ [35]), properties of the focusing objective (numerical aperture, the fact that it is corrected for a coverslip of $100 \mu \mathrm{m}$ thick silicon, but which is not used in the experiments), the intensity profile of the incoming collimated beam 
(and the fill factor of the lens), and the distance of the objective relative to the top surface of the sapphire. The software was used to simulate the effect of the location of the focus (inside the bulk) on the intensity profile in the bulk. It should be emphasized that the simulation does not include any physical model of phenomena associated with the absorption of laser radiation. The tool calculates normalized two dimensional cross-sections of the intensity distributions of the electromagnetic field inside sapphire. These fields are rotationally symmetric around the propagation axis of the laser beam and were converted into a three-dimensional profile, using MATLAB. Next, the intensity profile was calculated by squaring the absolute electric field in every node in the simulation grid, so $|E|^{2}$. Finally, the intensity profile was scaled in order to match with the laser pulse energy used in the experiments. Comparing the simulation results to the experimental morphology of the modifications, allows to conclude whether the shape and size of the modifications are mainly the result of the beam profile inside the sapphire, or by phenomena associated with the absorption of laser radiation.

\subsection{RESULTS AND DISCUSSION}

\subsubsection{The effect of pulse energy on morphology of modifications}

Figure 4.4 shows SEM images of typical modifications, consisting of amorphized sapphire, induced by single laser pulses at four pulse energy levels: $4.0 \mu \mathrm{J}, 7.5 \mu \mathrm{J}, 10.0 \mu \mathrm{J}$ and $18.0 \mu \mathrm{J}$ respectively. These modifications are all located at the same depth below the surface of the sample-i.e. at $30 \mu \mathrm{m}$ below the surface. Note that, to highlight the details of each modification, the SEM pictures were taken using different magnifications. From these and other, not shown SEM images, it was found, that modifications only occur if the pulse energy is above a threshold of $4 \mu \mathrm{J}$, see Fig. 4.4(a). As can be observed from Fig. 4.4, all modifications are elliptically shaped, with the major axis coaxially aligned to the propagation axis of the laser beam. Bulk processing of sapphire is affected by spherical aberrations. The specimen, in this case, acts as a "non-corrected lens" in the path of the laser beam. Increasing the depth of processing causes the stretching of the focal spot (mainly in the $z$ direction), thus, reducing the applied intensity. It can be concluded from Fig. 4.4 that, the length and width, and therefore the volume of the modifications, increase with the increasing pulse energy. At pulse energies of about $7.5 \mu \mathrm{J}$ 


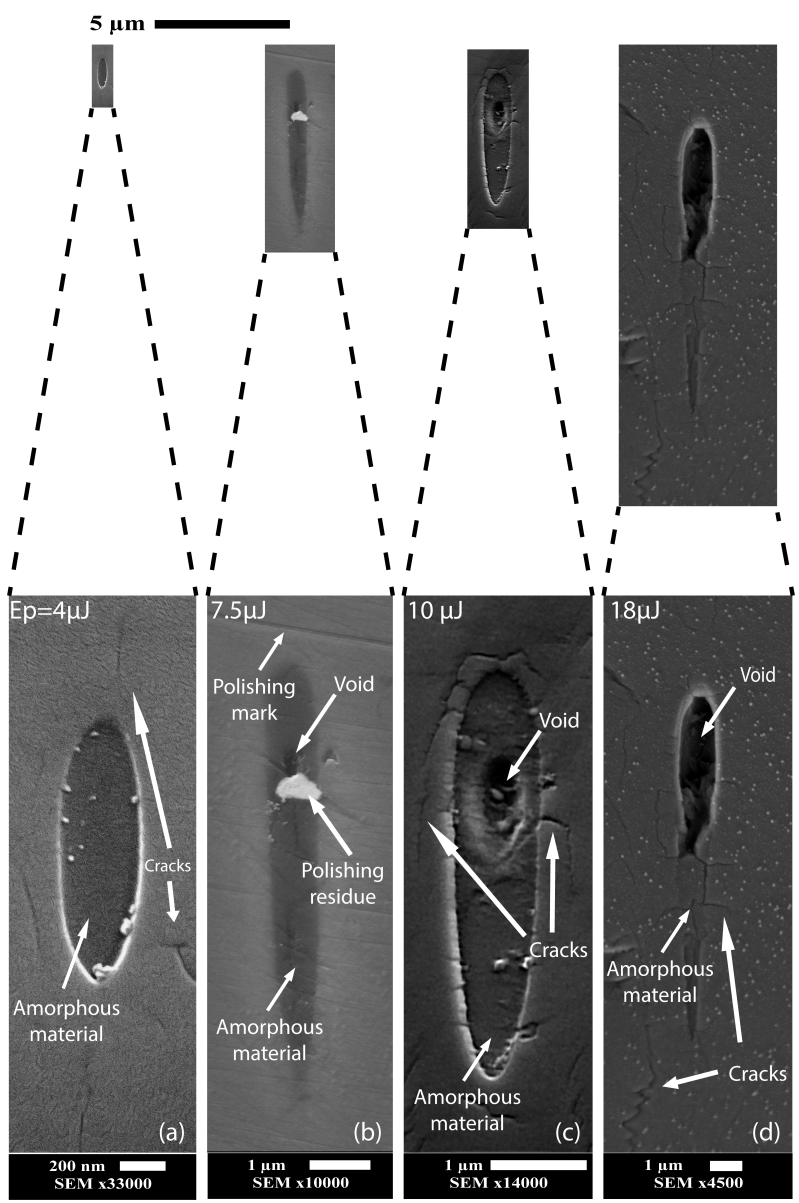

Figure 4.4: SEM micrographs of typical modifications (not etched) induced by single $7 \mathrm{ps}$ laser pulses at $30 \mu \mathrm{m}$ below the sapphire surface, applying various pulse energies $\left(E_{p}\right)$. On top, for an easy comparison, the micrographs are presented using the same scale. On bottom, to highlight the details of each modification, the pictures have different magnifications (see scale bars). The debris shown in (b) is a polishing particle. The laser beam propagated from top to bottom.

and higher, a void is observed in the upper center of the amorphized region, see Fig. 4.4(b)-(d).

The position of the void is mainly influenced by absorption phenomena and will be discussed in section 4.3.4. It was found that the length-i.e. longest dimension (from top to bottom of the pictures in Fig. 4.4 of single modifications vary from $1.10 \mu m$ (for $\mathrm{E}_{\mathrm{p}}=4 \mu \mathrm{J}$ ) to $11.30 \mu m$ (for $\mathrm{E}_{\mathrm{p}}=18 \mu \mathrm{J}$ ). The short 


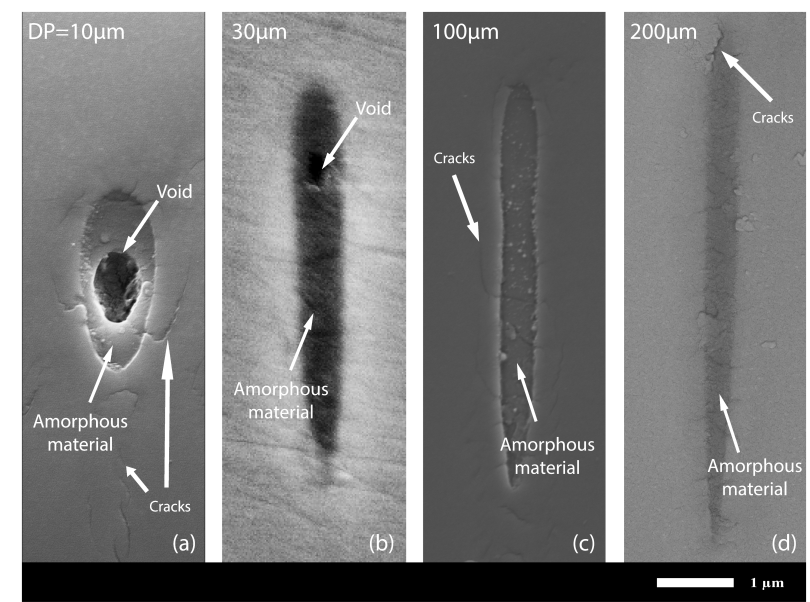

Figure 4.5: SEM micrographs of typical modifications (not etched) induced by single by 7 ps laser pulses at various depths (depth of processing, DP) below the surface of sapphire, at a fixed pulse energy of $10 \mu \mathrm{J}$. The laser beam propagated from top to bottom.

dimension, horizontal in the pictures, varied from 0.62 (for $\mathrm{E}_{\mathrm{p}}=4 \mu J$ ) $\mu m$ to $1.60 \mu m\left(\right.$ for $\left.\mathrm{E}_{\mathrm{p}}=18 \mu \mathrm{J}\right)$.

\subsubsection{The effect of focus depth on morphology of modifications}

Figure 4.5 shows SEM images of typical modifications, consisting of amorphized sapphire, induced below the surface, by single laser pulses at a fixed pulse energy of $10 \mu \mathrm{J}$, but at four different focus depths: $10 \mu \mathrm{m}, 30 \mu \mathrm{m}, 100$ $\mu \mathrm{m}$ and $200 \mu \mathrm{m}$ respectively. This pulse energy proved to be sufficiently high to modify the bulk at relatively large depths, allowing to study the effect of spherical aberrations in detail.

It was found that, at processing depths of about $100 \mu \mathrm{m}$ or more, a void no longer occurs within the amorphized region, see Figs. 4.5 (c) and (d). It was found that the length-i.e. longest dimension of the modifications varied from $2.3 \mu \mathrm{m}$ (for a depth of $10 \mu \mathrm{m}$ ) to $5.9 \mu \mathrm{m}$ (for a depth of $200 \mu \mathrm{m}$ ). The short dimension (width) varied from 1.01 (for a depth of $10 \mu \mathrm{m}$ ) to $0.42 \mu \mathrm{m}$ (for a depth of $200 \mu m)$. 


\subsubsection{Cracks}

The presence of cracks was observed even at the lowest pulse energy of $4 \mu \mathrm{J}$. Varying the depth of processing or the applied pulse energy we found to have a similar effect on the presence (and extension) of the cracks. This suggests that the phenomenon is mainly influenced by the applied intensity. At high intensity, cracks are large and propagating through the material. The most frequent type of crack is displayed in Fig. 4.6 (a), propagating from the bottom of the modification and extending in the direction of the longest dimension of the modification (vertical in the picture). This type of cracks was found for all the energies per pulse analyzed, growing in size typically from $800 \mathrm{~nm}(4 \mu \mathrm{J}$ at $30 \mu \mathrm{m}$ depth) to tens of microns for higher intensities.

In the case of a pulse energy of $18 \mu \mathrm{J}$ (Fig. 4.6 (b)), cracks extended to neighboring modifications. It is assumed that, given the distribution of the modifications inside the bulk of the material, this effect is similar to what was shown by Izawa et al. in [36], where cracks propagate via other close cracks. When a low intensity is applied, and the focus is close to the surface of the substrate, the crack length is similar to the width (shortest dimension of the modification) see Fig. 4.6 (c).

As mentioned, cracks are considered to be caused by thermal effects in particular for pulse durations longer than one $p s$. However, the cracks shown in Fig. 4.6 (c), are similar to the cracks observed by Juodkazis et al. [22] for femtosecond pulsed processing, where single pulse modifications are surrounded by cracks of the size of the modifications themselves (about $0.1 \mu \mathrm{m}$ ).

\subsubsection{Simulation and experimental validation}

Figure 4.7 shows three examples of a comparison of the cross sectional morphology of laser-induced modifications (SEM microgaphs) with "cross-sections" of calculated 2D laser intensity profiles (contour plots), using PSF Lab, for three processing depths and two pulse energies. As can be observed from Fig. 4.7 , the "shape" of the modifications matches well with the shapes of the calculated intensity profiles. From these comparisons, it can be found that, when averaged over 10 measurements at different depths and energies (from these and other not shown SEM micrographs), the modification intensity threshold value for sapphire equals $2.5 \cdot 10^{14} \pm 0.4 \cdot 10^{14} \mathrm{~W} / \mathrm{cm}^{2}$. This value matches well with the threshold of $10^{13}-10^{14} \mathrm{~W} / \mathrm{cm}^{2}$ found in literature for femtosecond processing of sapphire [20; 29]. The high standard deviation of the 

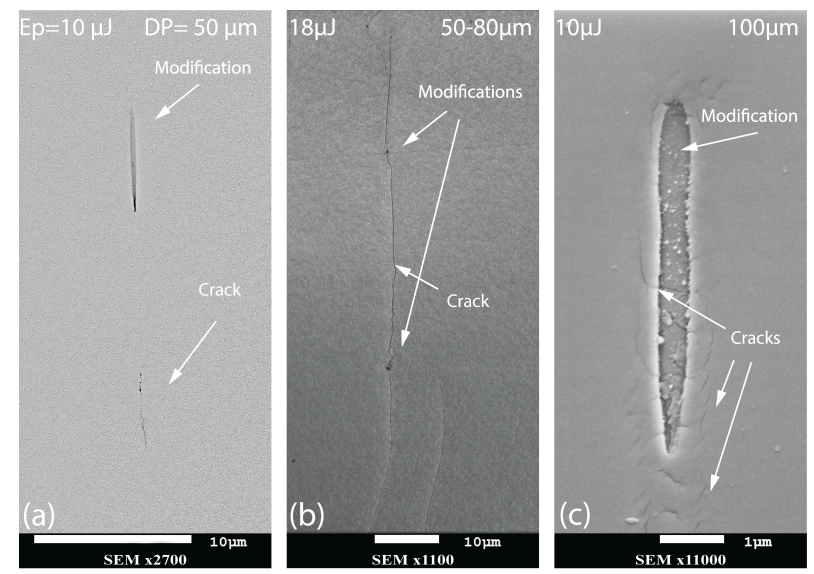

Figure 4.6: Cracks induced by single by 7 ps laser pulses at various depths (depth of processing, DP) below the surface of sapphire and various pulse energies (Ep). The laser beam propagated from top to bottom. To show the details of the modifications, they were imaged at different magnifications, see scale bars.

intensity threshold value $\left( \pm 0.4 \cdot 10^{14} \mathrm{~W} / \mathrm{cm}^{2}\right)$ is attributed to the fact that the determination of the dimensions of the single modifications is limited by the accuracy of the polishing process. In addition, the amount and magnitude of cracks, induced by energy laser pulses, bias the measurements. Nevertheless, the comparison (shown in Fig. 4.7 ) shows a strong correlation between the shape of the modification and the laser beam intensity profile in the sapphire, caused by spherical aberration.

The void is always found above the center of the modification (towards the impinging laser beam) and not in the center of the calculated maximum intensity. This phenomenon is attributed to the front of excited electrons, which travel in the opposite direction of the beam, spreading the excited electron density and the absorbed laser energy towards that direction [37].

Using PSF lab and MATLAB, the modification intensity threshold was used to calculate the length of the laser-induced modifications as function of the pulse energy and the locations of the focus below surface, see Figure 4.8.

In this figure, the central curve of each region represents the value calculated using the modification threshold of $2.5 \cdot 10^{14} \mathrm{~W} / \mathrm{cm}^{2}$. The top and bottom curve of each colored area represent the standard deviation $\left( \pm 0.4 \cdot 10^{14} \mathrm{~W} / \mathrm{cm}^{2}\right)$ relative to the average threshold value of $2.5 \cdot 10^{14} \mathrm{~W} / \mathrm{cm}^{2}$. The diamond shaped markers are data points as derived from SEM micrographs. 

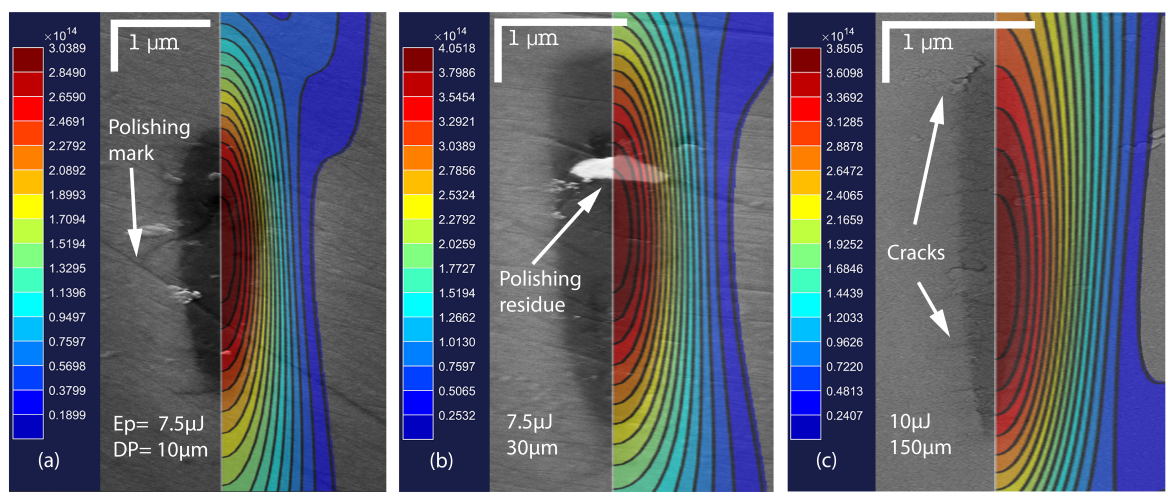

Figure 4.7: Three SEM micrographs of modifications obtained at different processing conditions and overlaid calculated 2D laser intensity profiles (contour plots). To highlight the details of the comparison of the experimental data and the calculated data, the images were cropped and show different magnification in vertical and horizontal directions (see scale bars). The laser beam propagated from top to bottom.

It can be concluded from this graph that, for low pulse energies (pink curve), the intensity is not enough to induce modifications. That is, the curve associated with the $4 \mu \mathrm{J}$ (in pink) is only appearing for the lowest modification threshold and only up to about $100 \mu \mathrm{m}$ focus depth. The curves for $7.5 \mu \mathrm{J}$ (in blue) are also "interrupted" for the same reason. For pulse energies of $10 \mu \mathrm{J}$ and $18 \mu \mathrm{J}$, the curves are only shown up to a focus depth of about $220 \mu \mathrm{m}-\mathrm{i}$.e. deeper focus locations result in modifications which are often "disrupted" and difficult to measure.

The measured modification lengths follow the trends of the simulation curves. That is, both the measured and simulated length show a minimum length at a focus depth of about $50 \mu \mathrm{m}$. At this focus depth, the objective lens is designed to compensate for the aberrations (about half of the theoretical value specified for silicon). For larger focus depths, the stretching of the intensity profile (caused by the aberrations) and the related loss of intensity play opposite roles in the final dimension of the modifications. That is, stretching of the profile results in an increase of the length of the modification, but the loss of intensity decreases the length.

As can be observed from Fig. 4.8 , the simulation values underestimate the measured length of the modifications. This can be attributed to the fact that the simulations do not take absorption phenomena and the effects of the material heating into account. In fact, nonlinear absorption phenomena could cause an 


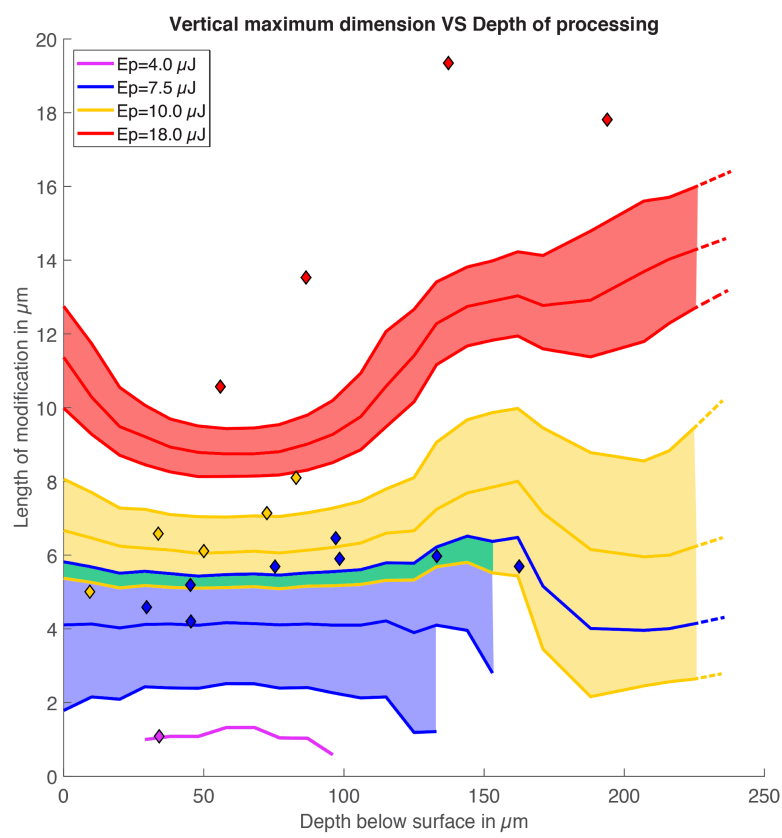

Figure 4.8: The four areas (pink, blue, yellow, red, green for the overlapping area between blue and yellow) represent the length of the amorphized regions (including the confidence intervals) calculated using PSF tool varying the depth below the surface of the specimen. The plot lines are for easy visualization of the trends; the actual graphs were made by single points for each depth. The diamond shaped markers represent the measured values.

increment in the size of the modification. The same phenomena can cause the void to "move" up towards the incident laser beam. Self-focusing caused by Kerr effect, however, can be excluded because the critical power threshold to trigger this effect is calculated as [25]

$$
P_{\text {crit }}=\frac{\lambda_{0}^{2}}{2 \pi n_{0} n_{2}}
$$

where $\lambda_{0}$ is the wavelength, $n_{0}$ the linear refractive index [1] and $n_{2}$ the nonlinear refractive index [38]. $P_{\text {crit }}$ is at least one order of magnitude bigger than the peak power calculated for the experimental conditions. 
The presence of large cracks (in particular in the case of a pulse energy of $18 \mu \mathrm{J}$ ) also biases the measurements of the modifications, thereby causing the measured length to be larger than the length derived from simulated profiles.

Similar results can be found-and conclusions can be drawn- when comparing the measured width of modifications, to the width derived from the intensity simulations.

\subsubsection{Morphology of etched amorphous sapphire}

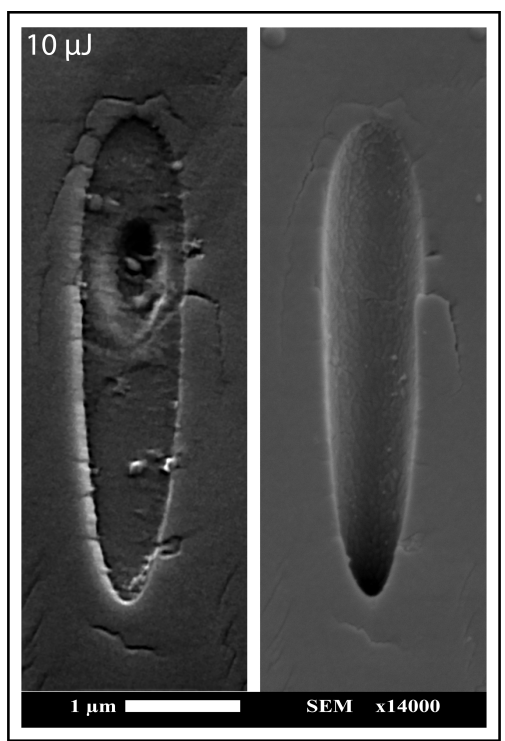

Figure 4.9: SEM micrographs of a modification produced by a $7 p s$ pulse at a pulse energy of $10 \mu \mathrm{J}$, and a focus location at $30 \mu \mathrm{m}$ below the sapphire surface, (a) before and (b) after etching for $20 \mathrm{~min}$ in stagnant $50 \%$ aqueous solution of hydrofluoric acid at room temperature.

Using the procedure discussed in section 4.2.4, the cross-sectioned samples were etched in order to remove amorphous sapphire. As an example, Fig. 4.9 shows SEM micrographs of the same modification before and after etching. It was found that the dimensions of the modifications, delimited by the border between crystalline and amorphous, before and after etching were unchanged. That is, the etching process completely removes the amorphous material. This explains why the void, surrounded by the formerly amorphous material (see Fig 4.1(b)), is not observed anymore. This leaves an "empty structure". Note 
that the boundary between crystalline and formerly amorphous is remarkably smooth. These results are very similar to what has been reported by Juodkazis et al. [20; 22] for femtosecond laser processing. In addition, also in the case of picosecond processing, the etching does not have any observable effect on the cracks surrounding the modification.

\subsection{CONCLUSIONS}

In contrast to femtosecond laser sources, picosecond pulsed laser sources are generally regarded as unsuitable in a two-step method involving laserinduced amorphization of bulk sapphire and subsequent chemical wet etching. To study the effect of picosecond irradiation on single pulse modifications, a study has been performed using a $7 \mathrm{ps}$ infrared $(1030 \mathrm{~nm})$ laser, varying the energy per pulse ( $4 \mu \mathrm{J}$ to $18 \mu \mathrm{J}$ ) and the depth of processing (from $0 \mu \mathrm{m}$ to 400 $\mu \mathrm{m})$. Both the shape and properties of the modifications were observed.

The shapes and dimensions of the modifications obtained are in line with results found when using femtosecond laser pulses. Like in femtosecond laser processing, we found a relation between the appearance of a void inside the amorphized region and the applied intensity.

A qualitative study on the cracking phenomena was performed, showing that, for low levels of intensity, cracks do originate from the laser-induced modification, but these cracks are limited in extension and resembled the cracks found in literature for femtosecond single pulse modifications.

The shapes of the modification were related to optical laser intensity profiles calculated using the illumination Point Spread Function (PSF). The relation allows to predict the shape of the single modifications in sapphire as function of the pulse energy and as function of the focus location (depth) below the surface of the sample. It was found that the laser intensity modification threshold above which sapphire amorphizes equals $2.5 \cdot 10^{14} \pm 0.4 \cdot 10^{14} \mathrm{~W} / \mathrm{cm}^{2}$.

Finally, it was found that hydrofluoric etching is affecting only the amorphous material, without causing observable changes on the crystalline sapphire.

Based on this study, we conclude that when carefully tuning processing parameters, picosecond pulsed laser sources can be applied for amorphization and selective wet chemical etching of sapphire. 


\section{BIBLIOGRAPHY}

[1] E. R. Dobrovinskaya, L. A. Lytvynov, and V. Pishchik, Sapphire: material, manufacturing, applications. Springer Science \& Business Media, 2009.

[2] I. P. Batra, "Electronic structure of $\alpha-\mathrm{Al}_{2} \mathrm{O}_{3}$," Journal of Physics C: Solid State Physics, vol. 15, no. 26, pp. 5399-5410, 1982.

[3] J.-T. Chen, W.-C. Lai, Y.-J. Kao, Y.-Y. Yang, and J.-K. Sheu, "Laser-induced periodic structures for light extraction efficiency enhancement of GaN-based light emitting diodes.," 2012.

[4] T.-L. Chang, Z.-C. Chen, and Y.-C. Lee, "Micro/nano structures induced by femtosecond laser to enhance light extraction of GaN-based LEDs," Optics Express, vol. 20, no. 14, p. 15997, 2012.

[5] Y. J. Lee, J. M. Hwang, T. C. Hsu, M. H. Hsieh, M. J. Jou, B. J. Lee, T. C. Lu, H. C. Kuo, and S. C. Wang, "Enhancing the output power of GaN-based LEDs grown on wet-etched patterned sapphire substrates," IEEE Photonics Technology Letters, vol. 18, no. 10, pp. 1152 $1154,2006$.

[6] B. J. Kim, M. A. Mastro, H. Jung, H. Y. Kim, S. H. Kim, R. T. Holm, J. Hite, C. R. Eddy, J. Bang, and J. Kim, "Inductively coupled plasma etching of nano-patterned sapphire for flip-chip GaN light emitting diode applications," 2008.

[7] Y. Sohn and C. Kim, "Nucleation characteristics of GaN nanorods grown on etched sapphire substrates by hydride vapor phase epitaxy," Journal of Crystal Growth, vol. 311, no. 10, pp. 2953-2955, 2009.

[8] D. S. Wuu, W. K. Wang, K. S. Wen, S. C. Huang, S. H. Lin, R. H. Horng, Y. S. Yu, and M. H. Pan, "Fabrication of pyramidal patterned sapphire substrates for high-efficiency InGaN-based light emitting diodes," Journal of The Electrochemical Society, vol. 153, no. 8, pp. G765-G770, 2006.

[9] F. Li, S. D. Jackson, C. Grillet, E. Magi, D. Hudson, S. J. Madden, Y. Moghe, C. O’Brien, A. Read, S. G. Duvall, P. Atanackovic, B. J. Eggleton, and D. J. Moss, “Low propagation loss silicon-on-sapphire waveguides for the mid-infrared," Optics Express, vol. 19, no. 16, p. 15212, 2011.

[10] S. J. Saggese, J. A. Harrington, and G. H. Sigel, "Attenuation of incoherent infrared radiation in hollow sapphire and silica waveguides," Opt. Lett., vol. 16, no. 1, pp. 27-29, 1991.

[11] D. Wortmann, J. Gottmann, N. Brandt, and H. Horn-Solle, "Micro- and nanostructures inside sapphire by fs-laser irradiation and selective etching," in 2008 Conference on Quantum Electronics and Laser Science Conference on Lasers and Electro-Optics, CLEO/QELS, 2008.

[12] R. Moser, N. Ojha, M. Kunzer, and U. T. Schwarz, "Sub-surface channels in sapphire made by ultraviolet picosecond laser irradiation and selective etching," Optics Express, vol. 19, no. 24, p. 24738, 2011.

[13] S. Juodkazis and H. Misawa, "Forming tiny 3D structures for micro- and nanofluidics," SPIE Newsroom, pp. 4-6, 2007.

[14] Y. P. Hsu, S. J. Chang, Y. K. Su, J. K. Sheu, C. H. Kuo, C. S. Chang, and S. C. Shei, "ICP etching of sapphire substrates," Optical Materials, vol. 27, no. 6, pp. 1171-1174, 2005.

[15] C. H. Jeong, D. W. Kim, H. Y. Lee, H. S. Kim, Y. J. Sung, and G. Y. Yeom, "Sapphire etching with BCl3/HBr/Ar plasma," Surface and Coatings Technology, vol. 171, no. 1-3, pp. 280-284, 2003. 
[16] H. Furuya, N. Okada, and K. Tadatomo, “Growth of $\{11-22\}$ GaN on shallowly etched r -plane patterned sapphire substrates," Physica Status Solidi (C) Current Topics in Solid State Physics, vol. 9, no. 3-4, pp. 568-571, 2012.

[17] T. V. Cuong, H. S. Cheong, H. G. Kim, H. Y. Kim, C. H. Hong, E. K. Sun, H. K. Cho, and B. H. Kong, "Enhanced light output from aligned micropit InGaN-based light emitting diodes using wet-etch sapphire patterning," Applied Physics Letters, vol. 90, no. 13, 2007.

[18] K. Matsumaru, A. Takata, and K. Ishizaki, "Advanced thin dicing blade for sapphire substrate," Science and Technology of Advanced Materials, vol. 6, no. 2, pp. 120-122, 2005.

[19] Kyocera, "Sapphire - fine ceramics (advanced ceramics)." Acessed on: 18 September 2017.

[20] S. Juodkazis, K. Nishimura, H. Misawa, T. Ebisui, R. Waki, S. Matsuo, and T. Okada, "Control over the crystalline state of sapphire," Advanced Materials, vol. 18, no. 11, pp. 13611364, 2006.

[21] M. Hörstmann-Jungemann, J. Gottmann, and M. Keggenhoff, "3D-microstructuring of sapphire using fs-laser irradiation and selective etching," Journal of Laser Micro Nanoengineering, vol. 5, no. 2, pp. 145-149, 2010.

[22] S. Juodkazis, K. Nishimura, S. Tanaka, H. Misawa, E. G. Gamaly, B. Luther-Davies, L. Hallo, P. Nicolai, and V. T. Tikhonchuk, "Laser-induced microexplosion confined in the bulk of a sapphire cystal: Evidence of multimegabar pressures," Physical Review Letters, vol. 96, no. 16, p. 166101, 2006.

[23] H. Misawa and S. Juodkazis, "3D Laser Microfabrication," Wiley-Vch Verlag GmbH $\mathcal{E}$ Co.KGaA, pp. 387-388, 2006.

[24] E. Gamaly, B. Luther-Davies, A. Rode, S. Joudkazis, H. Misawa, L. Hallo, P. Nicolai, and V. Tikhonchuk, "Laser-matter interaction in the bulk of transparent dielectrics: Confined micro-explosion," Journal of Physics: Conference Series, 2007.

[25] E. G. Gamaly, S. Juodkazis, K. Nishimura, H. Misawa, and B. Luther Davies, "Lasermatter interaction in the bulk of a transparent solid: Confined microexplosion and void formation," Physical review. B, vol. 73, no. 21, p. 214101, 2006.

[26] S. Juodkazis, S. Kohara, Y. Ohishi, N. Hirao, A. Vailionis, V. Mizeikis, A. Saito, and A. Rode, "Structural Characterization of Femtosecond Laser Modified Regions Inside Sapphire," Journal of Nanoscience and Nanotechnology, vol. 11, pp. 2931-2936, apr 2011.

[27] S. Juodkazis, H. Misawa, and I. Maksimov, "Thermal accumulation effect in threedimensional recording by picosecond pulses," Applied Physics Letters, vol. 85, no. 22, pp. 5239-5241, 2004.

[28] N. M. Bulgakova, “Theoretical Models and Qualitative Interpretations of Fs Laser Material Processing," Journal of Laser Micro/Nanoengineering, vol. 2, no. 1, pp. 76-86, 2007.

[29] D. von der Linde and H. Schüler, "Breakdown threshold and plasma formation in femtosecond laser-solid interaction," Journal of the Optical Society of America B, vol. 13, no. 1, p. 216, 1996.

[30] S. W. Winkler, I. M. Burakov, R. Stoian, N. M. Bulgakova, A. Husakou, A. MermillodBlondin, A. Rosenfeld, D. Ashkenasi, and I. V. Hertel, “Transient response of dielectric materials exposed to ultrafast laser radiation," Applied Physics A-Materials Science $\backslash \mathcal{E}$ Processing, vol. 84, no. 4, pp. 413-422, 2006.

[31] S. S. Mao, F. Quéré, S. Guizard, X. Mao, R. E. Russo, G. Petite, and P. Martin, “Dynamics of femtosecond laser interactions with dielectrics," Applied Physics A: Materials Science and Processing, vol. 79, no. 7, pp. 1695-1709, 2004.

[32] A. Vailionis, E. G. Gamaly, V. Mizeikis, W. Yang, A. V. Rode, and S. Juodkazis, “Evidence of superdense aluminium synthesized by ultrafast microexplosion," Nature Communications, 
vol. 2, no. 1, pp. 1-6, 2011.

[33] C. Hnatovsky, R. S. Taylor, E. Simova, V. R. Bhardwaj, D. M. Rayner, and P. B. Corkum, "High-resolution study of photoinduced modification in fused silica produced by a tightly focused femtosecond laser beam in the presence of aberrations," Journal of Applied Physics, vol. 98, no. 1, p. 013517, 2005.

[34] M. J. Nasse and J. C. Woehl, "Realistic modeling of the illumination point spread function in confocal scanning optical microscopy.," Journal of the Optical Society of America. A, Optics, image science, and vision, vol. 27, no. 2, pp. 295-302, 2010.

[35] I. H. Malitson, "Refraction and Dispersion of Synthetic Sapphire," Journal of the Optical Society of America, vol. 52, no. 12, p. 1377, 1962.

[36] Y. Izawa, S. Tanaka, H. Kikuchi, Y. Tsurumi, N. Miyanaga, M. Esashi, and M. Fujita, "Debris-free in-air laser dicing for multi-layer MEMS by perforated internal transformation and thermally-induced crack propagation," in Proceedings of the IEEE International Conference on Micro Electro Mechanical Systems (MEMS), pp. 822-827, 2008.

[37] E. G. Gamaly, L. Rapp, V. Roppo, S. Juodkazis, and A. V. Rode, “Generation of high energy density by fs-laser-induced confined microexplosion," New Journal of Physics, vol. 15, 2013.

[38] A. Major, F. Yoshino, I. Nikolakakos, J. S. Aitchison, and P. W. E. Smith, "Dispersion of the nonlinear refractive index in sapphire," Optics Letters, vol. 29, p. 602, mar 2004. 

FABRICATION OF MILLIMETER-LONG STRUCTURES IN SAPPHIRE USING FEMTOSECOND INFRARED LASER PULSES AND SELECTIVE ETCHING

A BSTRACT This paper analyses laser and etching parameters to fabricate open and continuous microchannels and stacks of such microchannels in the bulk of crystalline sapphire $\left(\alpha-\mathrm{Al}_{2} \mathrm{O}_{3}\right)$. The structures are produced using a two-step method consisting of laser irradiation and selective etching. Infrared femtosecond laser pulses are focused in the bulk to locally render the crystalline material into amorphous. The amorphous material is, then, selectively etched in hydrofluoric acid. Amorphous sapphire shows a high etching selectivity in comparison to its crystalline state, which makes this material very attractive for a use with this technique. However, some of its properties make the processing challenging, especially during the laser-induced amorphization phase. This paper studies the effect of laser parameters by a step- by-step approach to fabricate long structures (longest dimensions up to millimeters) of different shapes inside the bulk of sapphire. The minimum cross-sectional dimensions of the resulting structures (microchannels) vary from few hundreds of nanometers for the smallest channels to tens of micrometers for the largest stacks of microchannels. The effect of the variation of repetition rate, pulse energy and channel-to-channel distance on the microchannels and stacks of microchannels is studied. SEM micrographs of polished cross-sections are used for performing a quantitative and qualitative analysis of the morphology of the structures after laser irradiation and, subsequently, after selective wet chemical etching.

The present chapter is identical to the journal paper "Fabrication of millimeter-long structures in sapphire using femtosecond infrared laser pulses and selective etching." by L. Capuano, R.M. Tiggelaar, J.W. Berenschot, J.G.E. Gardeniers and G.R.B.E. Römer published in Optics and Lasers in Engineering 133 (2020): 106114. This chapter addresses research objectives 2 and 3 as defined in section 1.3. 


\subsection{INTRODUCTION}

Crystalline sapphire $\left(\alpha-\mathrm{Al}_{2} \mathrm{O}_{3}\right)$ is nowadays used as construction component or base material in many sectors of science and technology. The hardness of sapphire (9 on the Mohs scale [1]) and its transparency in the visible spectrum (from $450 \mathrm{~nm}$ to $2000 \mathrm{~nm}$ [2]), together with other physical and chemical properties make the material suitable in many applications in the fields of semiconductors (particularly with high efficiency Gallium Nitride LEDs [3-10], and in photonics in general [11-14].

Processing of sapphire has been demonstrated using different methods: direct laser writing [15; 16], mechanical sawing [17], dry (plasma etching [18-20]) and wet etching ([21-24]). In this manuscript we study a two-step method consisting of laser irradiation of crystalline sapphire with consequent modification of the exposed material into amorphized material and successive selective removal of the latter by wet etching.

Due to the transparency of sapphire, the laser beam can be focused inside the bulk. If femtosecond or picosecond laser pulses are used with intensities in the order of $10^{13}-10^{14} \mathrm{~W} / \mathrm{cm}^{2}$ [25; 26], absorbed laser energy [27] leads to the amorphization of the crystalline sapphire. Amorphous sapphire is selectively etchable by hydrofluoric acid (HF) at a $10^{5}$ faster rate than crystalline $[25 ; 26$; 28-31]. If the material is exposed to several, overlapping laser pulses, it is possible to create regions and volumes of amorphized material.

Figure 5.1 (a) shows a cross-sectional model of a single microchannel in the bulk of sapphire, which forms the targeted basic shape for this study. Such structures can be exploited for, e.g. microfluidic devices in the form of millimeter long hollow microchannels. More complex shapes can be created by superposition of microchannels.

However, when laser pulses are geometrically overlapping with the aim to form large amorphized structures - such as one-dimensional modified lines (made by amorphous material, before etching)- a series of phenomena may affect the formation and morphology of the amorphous sapphire. The latter, in turn, affects the solubility of the formed material.

In fact, publications on etched channels in sapphire, often report crosssections in which, after the wet chemical etching, the obtained structure is not completely hollow $[11 ; 21 ; 32 ; 33]$. That is, in these structures hollow/open regions, where amorphized sapphire is dissolved, can be found, as well as crystalline/unetched regions. These latter regions can be characterized by series of parallel nanochannels, see Fig. 5.1 (b), or by discontinued and irregular 

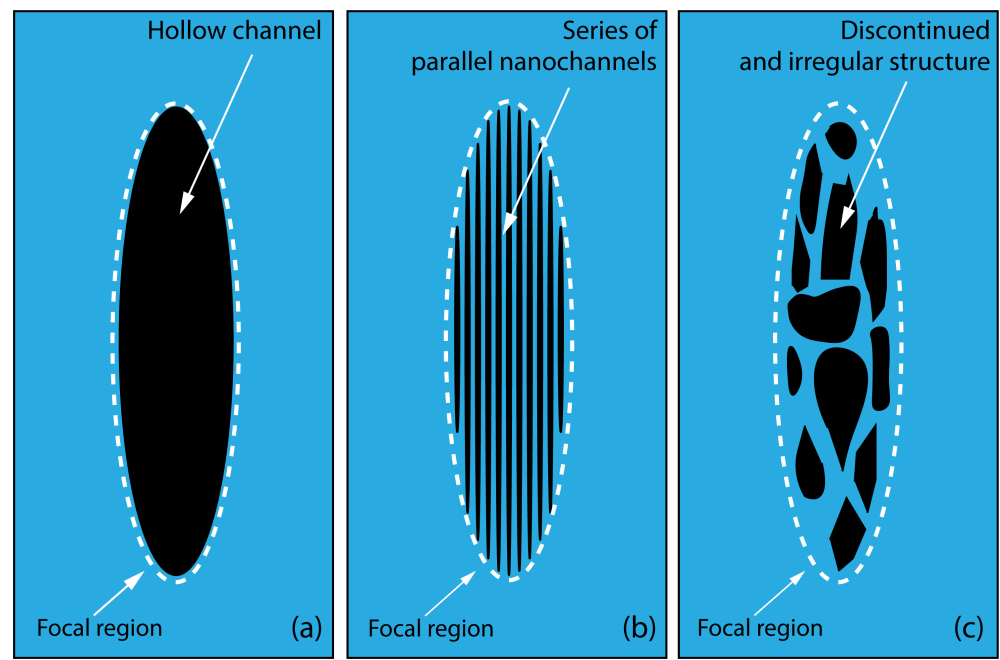

Figure 5.1: Cross-sectional model of the types of structures which can be obtained using the two step technique, after etching: (a) hollow/empty microchannel, (b) series of parallel nanochannels, (c) discontinued and irregular structures.

structures Fig. 5.1 (c). In 2008, Juodkazis et al. [32] studied this phenomenon and showed that overlapping single pulse modifications causes recrystallization of the amorphized material, which makes it non-etchable by an acid like HF. On the other hand, Gottmann et al. [21] showed the change in morphology of cross-sections of channels obtained with this method, and found that the results of laser irradiation and wet etching depend mainly on laser parameters and focusing conditions. More specifically, the authors showed that, within a range of parameters (mainly numerical aperture and energy per pulse) the cross-section of channels either show a series of amorphized parallel nanochannels (Fig. 5.1(b)), or hollow channels (Fig. 5.1(a)).

Both Juodkazis et al. [32] and Gottmann et al. [21] studied the effect of only a limited number of processing parameters. Despite these results, until now, a well-ordered study regarding the main factors playing a role on the final morphology of the irradiated lines and other structures (formed by overlapping lines) in the bulk of sapphire is lacking in the literature. A wider investigation is needed, in fact, to understand the problem and have a general view of which specific conditions determine the final shape and appearance and how to tune the settings to obtain exact and distinct types of channels. 


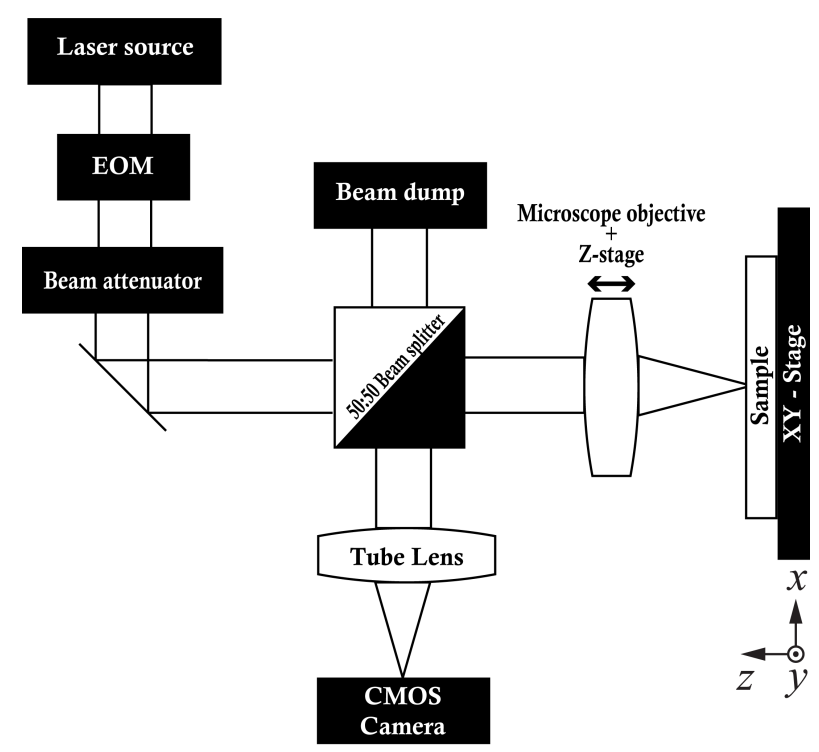

Figure 5.2: Schematic of the set-up used during the laser irradiation phase of the experiments.

\subsection{EXPERIMENTAL SET-UP AND ANALYSIS TOOLS}

Figure 5.2 shows a schematic of the set-up used for the laser irradiation experiments presented in this work.

A KMLabs Y-Fi femtosecond laser source was used, which emits a linearly polarized laser beam at a central wavelength of $\lambda=1035 \mathrm{~nm}$. The pulse duration of this source is $230 \mathrm{fs}$, measured with an autocorrelator (APE Berlin Pulse Check, Germany). Heat transmission phenomena inside the lattice of sapphire occur on a time scale in the order of tens of picoseconds [34]. Hence, the selected ultrashort pulse duration limits the heat transmission inside the sample during the laser pulse. The spatial distribution of the laser beam is nearly Gaussian $\left(\mathrm{M}^{2}<1.2\right)$.

Since the laser source does not offer the option of changing the repetition rate to less than $1 \mathrm{MHz}$, an electro-optic modulator (EOM, Model 360-80 by Conoptics, USA) is mounted after the laser source for pulse picking. A beam attenuator (Ultrafast Version, Altechna, Lithuania) is used to set the pulse energy of the laser pulses. A microscope objective (11101666, Leica Microsystems, Germany, NA $=0.7$ ) is used to focus the beam to a spot of about $0.9 \mu \mathrm{m}$ diameter (calculated). The microscope objective is mounted on a 
linear stage (ATS100, Aerotech USA), which moves the lens in the z-direction, allowing the focal spot of the laser beam to be positioned relative to the surface of the sample. The sample is fixed with a vacuum chuck on xy-stages (ALS130150, Aerotech USA). The microscope objective is also used as magnifying element for imaging, that is, the light reflected by the sample passes again through the objective and a tube lens to arrive finally on a CMOS camera (DCC1545, Thorlabs, USA). This alignment facilitates the positioning of the focal spot in the bulk (z-direction) of the sample as well as in the xy-plane. It also allows to observe the progress and quality of the irradiation during machining.

After irradiation, the samples are inspected using an optical microscope (Keyence VHX 5000, Japan), as well as using a Scanning Electron Microscope (SEM, JEOL JSM 7200F, Japan). After HF-etching, samples are analyzed at the same positions as after irradiation.

\subsection{MATERIALS AND METHODS}

\subsubsection{Materials}

Circular sapphire wafers ( 2 inches in diameter) with a thickness of $430 \mu \mathrm{m}$ and crystal orientation (0001), purchased from Crystech $\mathrm{GmbH}$ (Germany), were used. The circular samples were cut into rectangularly shaped (of various sizes) strips for easier handling.

The wet chemical etchant, hydrofluoric acid aqueous solution $50 \%$ (BASF, Germany) was used at room temperature.

\subsubsection{Methods}

To investigate one directional structures, the sample is moved in one direction ( $x$ or $y$ in Figure 5.3), while exposing the sample to single femtosecond laser. This results in a modified line/track, see Figure 5.3 (a).

The laser beam is focused inside the bulk of sapphire at about $50 \mu \mathrm{m}$ below the top surface of a specimen. The velocity $v$ of the stage is kept constant at $1 \mathrm{~mm} / \mathrm{s}$. By varying the pulse repetition rate of the laser source, the geometrical overlap between the laser pulses can be varied.

In order to produce stacks of lines, as is shown in Figure 5.3 (b), the approach for single lines is applied repeatedly. That is, stacks of lines are produced by overlapping single modified parallel tracks. The geometrical overlap of 


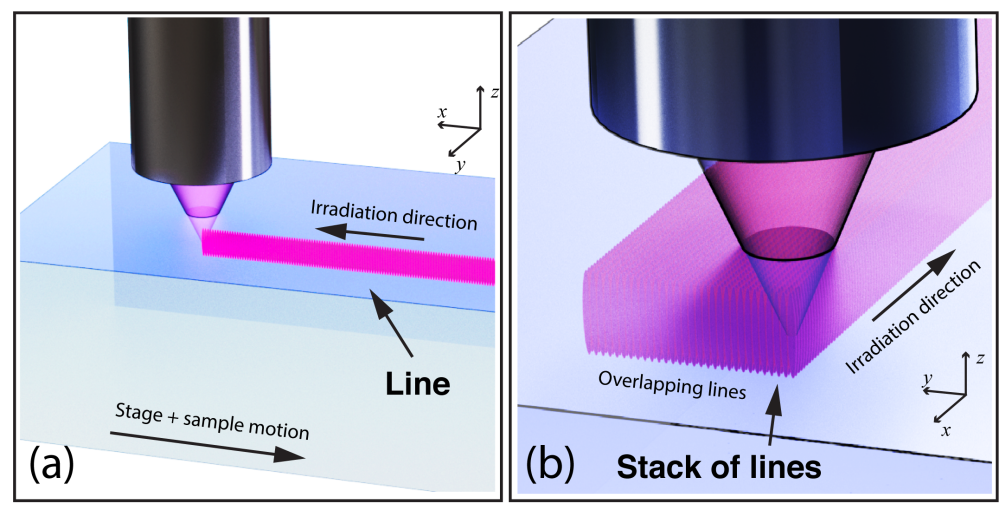

Figure 5.3: (a) Single lines are produced by exposing the sample to laser pulses, while translating the sample at a constant velocity of $v=1 \mathrm{~mm} / \mathrm{s}$. (b) A stack of microlines is created by laterally overlapping single lines.

adjacent tracks is limited by the minimal incremental step of the xy stage, which equals about $50 \mathrm{~nm}$. Since the smallest cross-sectional dimension is about $600 \mathrm{~nm}$, it is possible to vary the lateral geometrical overlap between adjacent lines from $90 \%$ down to separated lines (no overlap).

Geometrical overlap is defined as the percentage of the overlap of diameters of adjacent pulses and is calculated as:

$$
O L=\left(1-\frac{v}{f \cdot D}\right) \times 100
$$

Where $v$ is the scanning speed of the $X Y$ stage, $f$ the pulse repetition rate of the laser source and $D$ is the (calculated) diameter of the focal spot.

All the line-based structures are irradiated close to an edge of the specimen for easy inspection. Table 5.1 provides an overview of the range of the other laser parameters.

Cross-sections of the structures were obtained by grinding the sample along the direction shown in Figure 5.4, and removing enough sapphire to expose the amorphous material. Subsequently, for ease of inspection of the crosssections, the sample was polished to optical quality (average roughness $R_{a}<5$ $n m$ ). Grinding and polishing were carried out using a Tegramin (Struers, Netherlands) polishing apparatus using silicon carbide papers for the grinding and diamond pastes for the polishing, with progressive finer steps.

After polishing, the cross-section of each line is inspected by SEM and analyzed. Afterwards, the irradiated samples are immersed in 50\% HF for about 2 


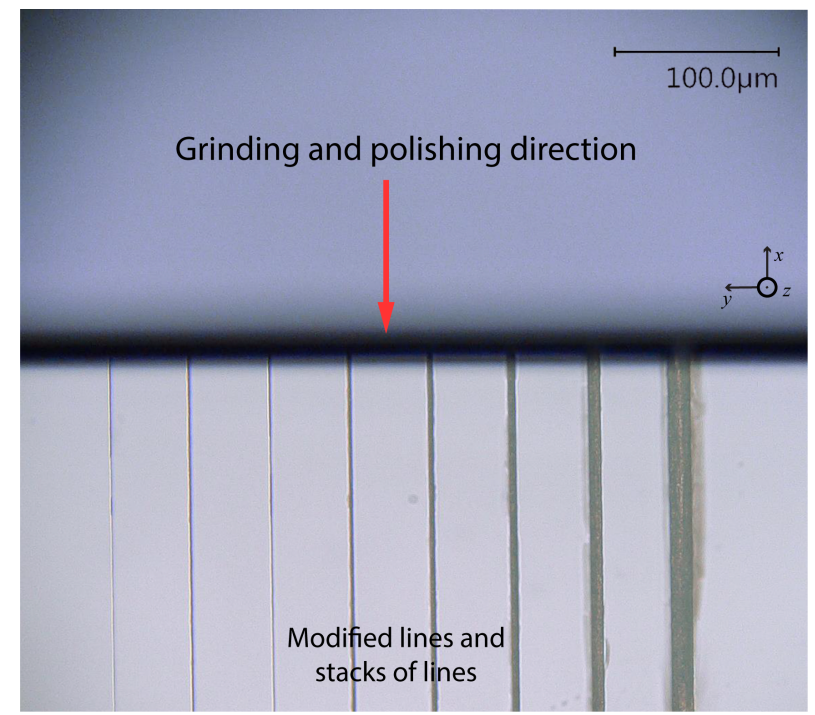

Figure 5.4: Optical microscopy image (top view) of channels and stacks of channels obtained after irradiation and etching in $\mathrm{HF}$ at room temperature for about 2 hours. To expose the (amorphized) channels and study the cross-sections, samples are grinded and polished.

Table 5.1: Set of experimental parameters.

// Parallel to the direction of irradiation

Laser Polarization

$\perp$ Perpendicular to the direction of irradiation $0.001 \mathrm{MHz}, 0.010 \mathrm{MHz}, 0.050 \mathrm{MHz}, 0.100 \mathrm{MHz}, 0.200 \mathrm{MHz}, 0.500 \mathrm{MHz}$,

Pulse repetition rate

$1 \mathrm{MHz}, 5 \mathrm{MHz}, 10 \mathrm{MHz}, 15 \mathrm{MHz}$

$94.5 \mathrm{~nJ}, 234 \mathrm{~nJ}, 457 \mathrm{~nJ}$ for repetition rates: $0.001 \mathrm{MHz} \leq \mathrm{f} \leq 1 \mathrm{MHz}$

Laser pulse energy

$18.9 n J, 46.8 \mathrm{~nJ}, 91.4 \mathrm{~nJ}$ for repetition rates: $5 \mathrm{MHz} \leq \mathrm{f} \leq 15 \mathrm{MHz}$

No. of stacked lines $\quad 2,4,8,16,32,64,128,256$

hours to dissolve the amorphous material. After rinsing in demineralized water and drying, SEM inspection of the cross-sections of formed microchannels (and stacks), at the same locations, is performed. 


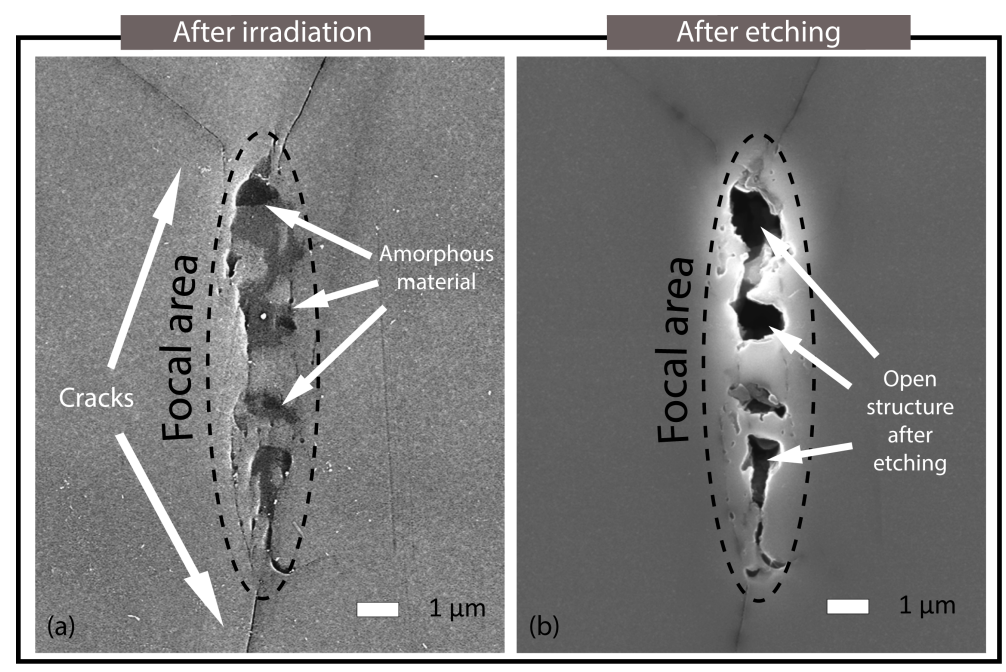

Figure 5.5: SEM micrographs of a typical cross-section of a single modified line (a) after laser irradiation at a laser pulse energy of $457 \mathrm{~nJ}$ and a repetition rate of $0.010 \mathrm{MHz}$ and (b) after 2 hours etching in hydrofluoric acid at room temperature. The irradiation was performed along the direction parallel to the polarization of the laser beam. The laser radiates from top to bottom of the picture. Linear velocity of the stage was $v=1 \mathrm{~mm} / \mathrm{s}$, geometrical pulse to pulse overlap (calculated) $\mathrm{OL}=90 \%$.

\subsection{RESULTS AND DISCUSSION}

Figure 5.5 shows the general features of a typical cross-section before (i.e. line) and after (i.e. channel) the wet etching step.

As can be observed from this figure, the shape of the cross-section of the modified line after laser irradiation generally follows the original shape of the laser focal spot. In Figure 5.5 (a) amorphized sapphire appears darker in the SEM micrographs than crystalline sapphire. As was mentioned in section 5.1 , the amorphous region is not homogeneous in many cases. That is, the laser-affected volume shows both amorphous regions and crystalline regions. For this reason, the cross-sections of channels obtained after the etching in Figure 5.5 (b) fall in the model in Figure 5.1 (c).

The "microexplosions" caused by the absorption of the laser energy [26] in a very short time are causing cracking of the crystalline sapphire. As will be shown in the next paragraphs, most of the modified lines are surrounded by cracks which may change in length from few hundreds of nanometers up to 


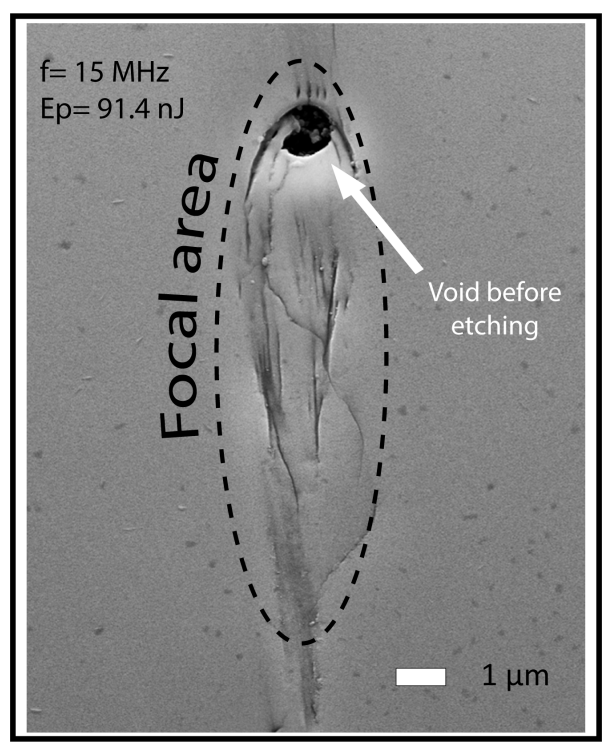

Figure 5.6: SEM micrograph of a cross-section of a single modified line obtained using a pulse energy $\mathrm{Ep}=91.4 \mathrm{~nJ}$ and a pulse repetition rate of $\mathrm{f}=15 \mathrm{MHz}$. The irradiation was performed along the direction perpendicular to the polarization of the laser beam. At a high energy per pulse and high repetition rates a void can appear near the top of the laser-affected volume. The laser radiated from top to bottom of the picture. Linear velocity of the stage was $v=1 \mathrm{~mm} / \mathrm{s}$, geometrical pulse to pulse overlap (calculated) $\mathrm{OL}=99.999$ $\%$.

millimeters, depending mainly on the pulse energy and the repetition rate. These cracks are not modified in size and morphology by the etching process.

Moreover, at high repetition rates (typically $15 \mathrm{MHz}$ ) and high pulse energies (typically $91.4 \mathrm{~nJ}$ ), the presence of small voids may be observed in the cross-sections of the lines (i.e. prior to etching) as well, see Figure 5.6.

As mentioned, the linear velocity of the XY stages moving the sample was $1 \mathrm{~mm} / \mathrm{s}$, whereas the pulse repetition rate was varied from $0.001 \mathrm{MHz}$ to $15 \mathrm{MHz}$, corresponding respectively to geometrical pulse to pulse overlaps ranging from $0 \%$ (completely separated single modifications) to $99.999 \%$.

\subsubsection{Structures parallel or perpendicular to the polarization of the laser light}

The cross-sectional shape of the irradiated and etched structures is affected by the angle between the (linear) polarization direction of the laser radiation 


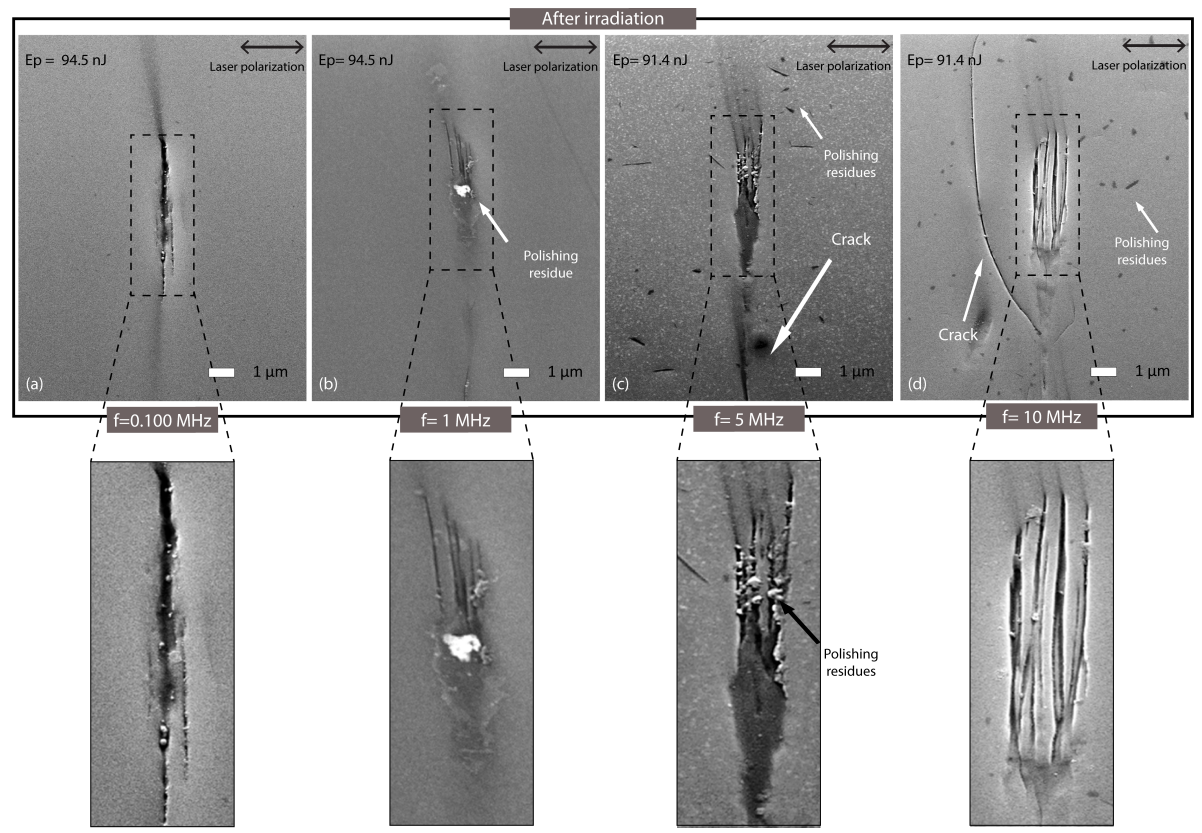

Figure 5.7: SEM micrographs (top row) and zoomed SEM micrographs (bottom row) of cross-sections of modified lines (non-etched) after irradiation obtained using: (a) $\mathrm{f}=0.1 \mathrm{MHz}$ and $\mathrm{Ep}=94.5 \mathrm{~nJ}$, (b) $1 \mathrm{MHz}$ and $\mathrm{Ep}=94.5 \mathrm{~nJ}$, (c) $5 \mathrm{MHz}$ and $\mathrm{Ep}=91.4 \mathrm{~nJ}$, (d) $10 \mathrm{MHz}$ and $\mathrm{Ep}=91.4 \mathrm{~nJ}$. The amorphized parallel nanochannels increase in size and number with increasing pulse repetition rate. In all the pictures the sample is irradiated along the direction perpendicular to the polarization of the laser. The laser radiated from top to bottom of the picture. Linear velocity of the stage was $v=1 \mathrm{~mm} / \mathrm{s}$, geometrical pulse to pulse overlap (calculated) varied from OL $=99.0 \%$ for $\mathrm{f}=0.100 \mathrm{MHz}$ to $\mathrm{OL}=99.990 \%$ for $10 \mathrm{MHz}$.

[21; 29; 35-37] and the direction of irradiation (direction along which the stage moves).

Hnatovsky et al. [36] demonstrated that modifying the bulk of fused silica using linearly polarized laser pulses results in periodic structures oriented in a direction perpendicular to the irradiation direction.

Taylor et al. [38] explained the formation, during processing, of periodic structures perpendicular to the polarization of the laser radiation, using the transient nanoplasmonics model. This model theorizes the formation of ionization hotspots during the irradiation by ultrashort laser pulses, which eventually induces plasma. These hotspots may lead to a preferential local ionization of the material. In particular, field enhancement on the boundary of the 
generated ionized spots facilitates the generation of plasma in the direction perpendicular to the polarization of the laser light.

To study the effect of the orientation of the polarization on the irradiated lines and etched channels, structures were produced both parallel and perpendicular to the polarization of the laser radiation.

If the laser polarization is perpendicular to the scan-direction of the stage, the presence of parallel nanochannels is observed in the focal region (Figure 5.1 (b)), which are not observed if the irradiation direction is parallel to the polarization direction. These regular amorphized parallel nanolines are observed for pulse repetition rates over $0.1 \mathrm{MHz}$ and are more pronounced when a repetition rate of at least $1 \mathrm{MHz}$ is applied, see Figure 5.7.

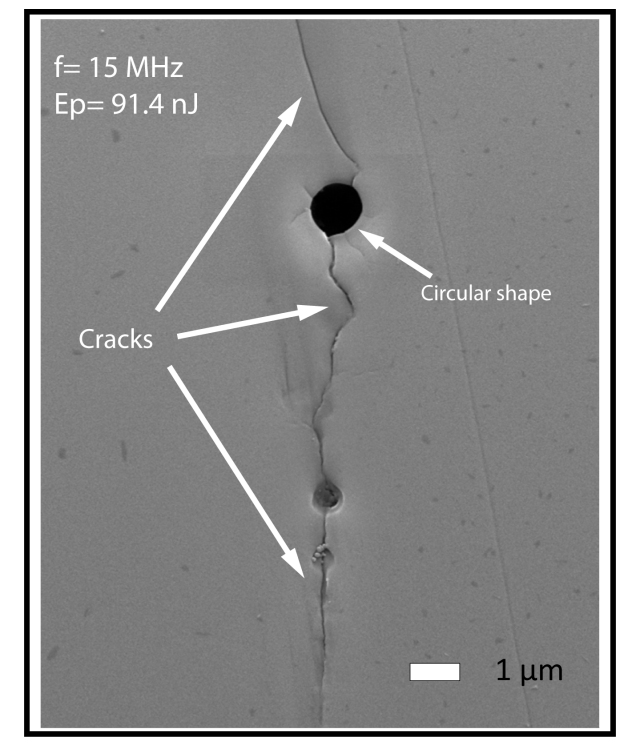

Figure 5.8: SEM micrograph of a cross-section of a single irradiated line (non-etched) obtained using $\mathrm{Ep}=91.4 \mathrm{~nJ}$ and $\mathrm{f}=15 \mathrm{MHz}$ along the direction perpendicular to the polarization of the laser beam before etching. The laser radiates from top to bottom of the picture. Linear velocity of the stage was $v=1 \mathrm{~mm} / \mathrm{s}$, geometrical pulse to pulse overlap (calculated) $\mathrm{OL}=99.999$ $\%$.

Upon increasing the repetition rate, an increase in both horizontal and vertical dimension of the cross sections and in the number of nanolines per area is observed. However, at a pulse repetition rate of $15 \mathrm{MHz}$, a circular shape is observed frequently, see Figure 5.8. 

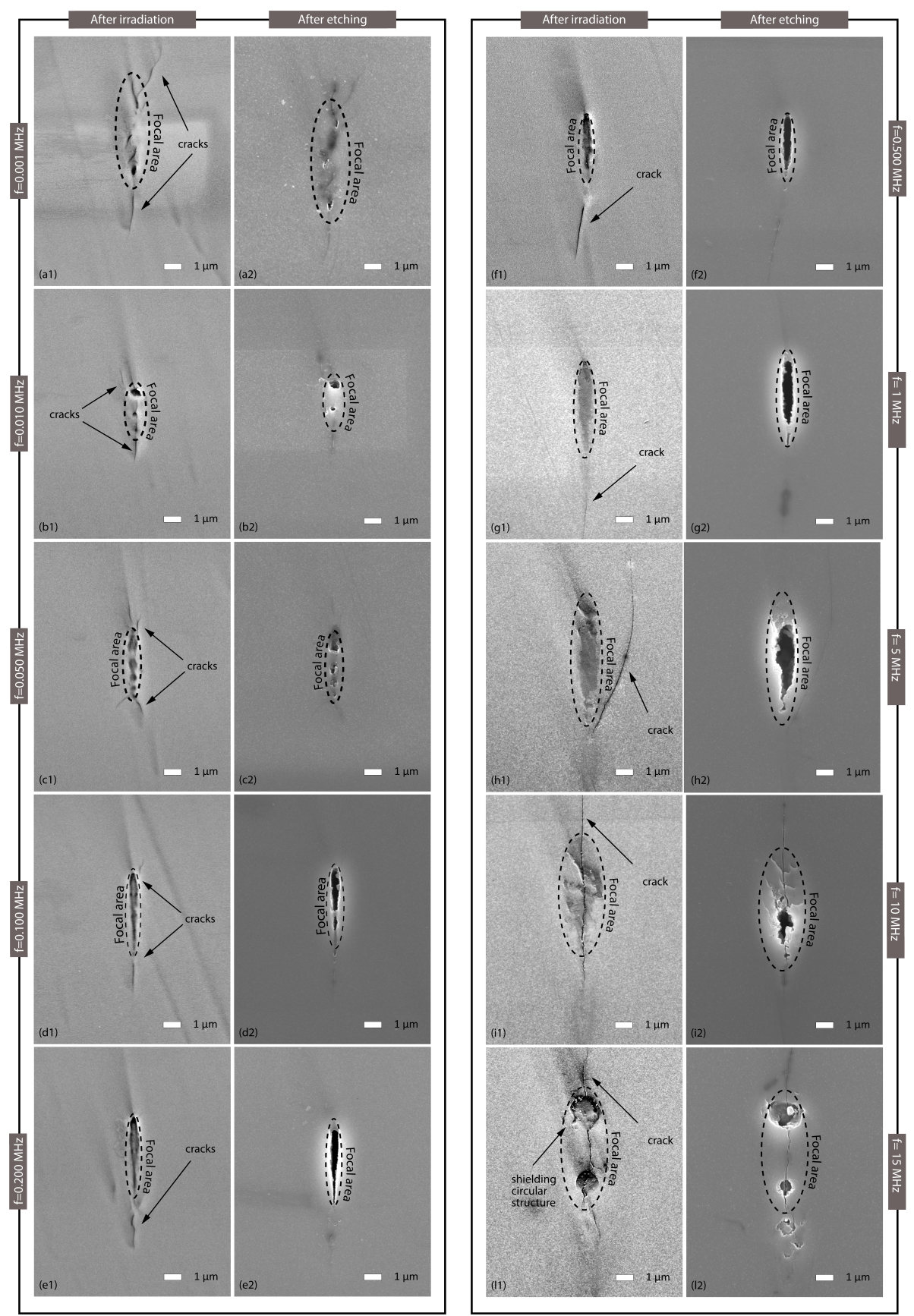

Figure 5.9: SEM micrographs of cross-sections after irradiation of lines and after etching of channels obtained at different repetition rates: (a) $\mathrm{f}=0.001 \mathrm{MHz}$, (b) $0.010 \mathrm{MHz}$, (c) $0.050 \mathrm{MHz}$, (d) $0.100 \mathrm{MHz}$, (e) $0.200 \mathrm{MHz}$, (f) 0.500 $\mathrm{MHz}$, (g) $1 \mathrm{MHz}$, (h) $5 \mathrm{MHz}$, (i) $10 \mathrm{MHz}$, (l) $15 \mathrm{MHz}$. The laser radiated the samples from top to bottom of the pictures. Linear velocity of the stage was $v=1 \mathrm{~mm} / \mathrm{s}$, geometrical pulse to pulse overlap (calculated) varied from completely detached pulses at $\mathrm{f}=0.001 \mathrm{MHz}=$ to an overlap $\mathrm{OL}=$ $99.999 \%$ at $15 \mathrm{MHz}$. 
This spherical shape impedes the propagation of the focused laser beam deeper into the sample. This phenomenon will be explained in detail in section 5.4.2.

Objective of this study is to form hollow/open microchannels and stacks of hollow/open microchannels. Hence, the origin and growth of parallel nanolines/nanochannels are out of the scope of this chapter. For this reason, in the next sections, only results obtained with the irradiation direction parallel to the polarization of the laser are discussed.

\subsubsection{Effect of pulse repetition rate on lines and stacks of lines}

Figure 5.9 shows the effects of pulse repetition rate on the cross-sections of single lines (only irradiation) and channels (after HF-etching of lines). Since the velocity of the stages is constant at $1 \mathrm{~mm} / \mathrm{s}$, the geometrical pitch between the laser pulses changes from single isolated pulses (at $f=0.001 \mathrm{MHz}$ ) to a geometrical overlap of $99.999 \%$ between laser pulses (at $f=15 \mathrm{MHz}$ ).

At $f=0.001 \mathrm{MHz}$, the laser pulses are not geometrically overlapping. This is also reflected in Figure 5.9(a), where a clear cross-section of the line in the focal region cannot be identified. At $0.010 \mathrm{MHz}$ the geometrical overlap between the laser pulses is over $80 \%$ (overlap calculated when an energy per pulse of $94,5 \mathrm{~nJ}$ was used with an effective minimal cross-sectional dimension of $0.6 \mu \mathrm{m}$ before and after etching). However, when a repetition rate below $\mathrm{f}=0.100 \mathrm{MHz}$ is used (Figure 5.9 (b) and (c)), the obtained irradiated lines show irregular cross-sections- i.e. amorphous sapphire alternates with crystalline to form an irregular pattern such as the one seen in Figure 5.1 (c).

This phenomenon may be explained by recrystallization of previously amorphized material. That is, even after the first laser pulse, each subsequent, overlapping laser pulse is irradiating a volume of both crystalline and amorphized material. As was reported by Juodkazis et al. [32], this may recrystallize parts of the amorphized material, leaving it non-soluble by the etchant.

Another hypothesis is that the overlap between pulses is not sufficient to cause hollow channels with a constant width, because the material amorphized by previous laser pulses is optically distorting the propagation and profile of the laser beam. This effect will be discussed more in detail in section 5.4.4.

For pulse repetition rates ranging from $f=0.100 \mathrm{MHz}$ to $1 \mathrm{MHz}$ the crosssections in Figure 5.9 (d), (e), (f), and (g) show open channels with a constant cross-section along their length. These are the targeted hollow microchannels 
shown in Figure 5.1 (a). In these figures, the cross-sectional width increases from $0.6 \mu \mathrm{m}$ at $f=0.100 \mathrm{MHz}$ to $1 \mu \mathrm{m}$ at $1 \mathrm{MHz}$.

Figure 5.9 (h), (i), (l) shows that, for pulse repetition rates of $5 \mathrm{MHz}$ and higher, the cross-sections of lines/channels reveal a disrupted and fragmented morphology. At these repetition rates large cracks have a strong effect, detrimental on the propagation and fluence profile of the incident laser beam, and, in turn, on the amorphization of the material.

Moreover, at $f=15 \mathrm{MHz}$, the laser-affected regions show a (nearly) circular shape near the top of the laser affected volume and smaller features below it, see Figure $5.9(l)$, as well as Figure 5.8. This phenomenon can possibly be associated with the findings of Gamaly et al. [39]. These authors reported the formation of plasma at the apex of the focal spot during the ionization of the material both at high repetition rate and at high pulse energies. This plasma is, most likely, preventing exposure of material below it to the laser radiation.

\subsubsection{Effect of energy per pulse}

For pulse repetition rates up to $1 \mathrm{MHz}$, the sample was irradiated using three pulse energies: $94.5 n J, 234 n J, 457 n J$. Below the smallest pulse energy, the material is not affected by the laser (at the mentioned repetition rates), whereas at the highest pulse energy it is not possible to irradiate sapphire without the formation of cracks so large that cause the breaking of the specimen. For pulse repetition rates of $f=5 \mathrm{MHz}, 10 \mathrm{MHz}$ and $15 \mathrm{MHz}$ lower pulse energies were applied because of the power limitations of the laser source. At these pulse repetition rates experiments were performed at $E_{\mathrm{p}}=18.9 \mathrm{~nJ}, 46.8 \mathrm{~nJ}$ and 91.4 nJ.

Figure 5.10 shows the effect of the pulse energy on the cross-sections of irradiated lines and etched channels. The shape of the amorphized region deviates from the shape of the focal spot and the cross-sections show multiple foci, with increasing pulse energy. The latter can be associated with Kerrinduced self-focusing. Self-focusing induced by the electro-optic Kerr effect is a change of the refractive index caused by an applied strong electrical field, in this case the laser radiation. This change in the refractive index causes the focal spot to elongate. If the focusing due to the Kerr effect is counterbalanced by a defocusing effect due to the presence of plasma in the focal spot [39], which lowers the refractive index, this may result in spatial focusing/defocusing (multifoci) along the propagation axis of the laser beam. 


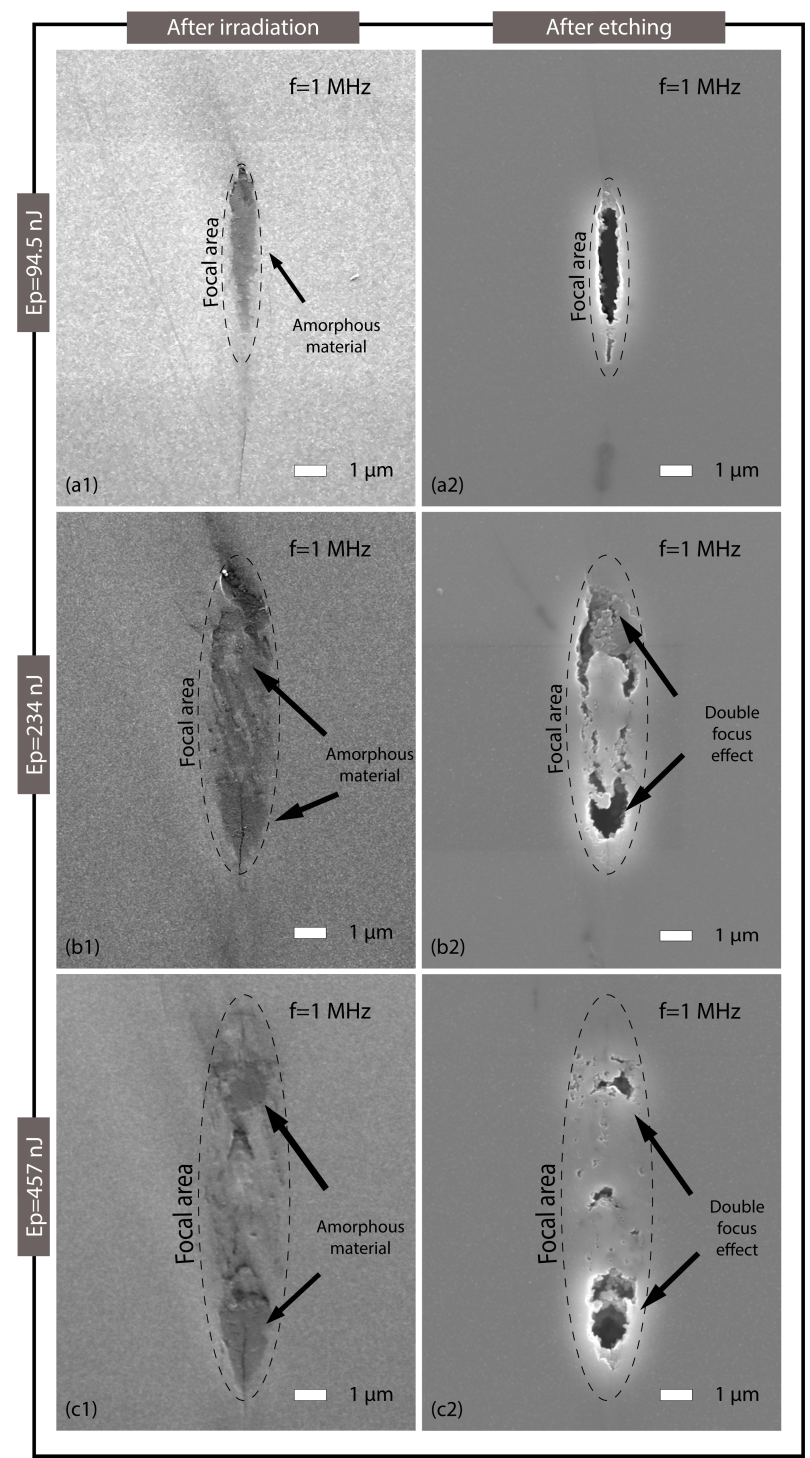

Figure 5.10: SEM micrographs of cross-sections after irradiation of lines and after etching of channels obtained using a pulse repetition rate of $\mathrm{f}=1 \mathrm{MHz}$ at different energies per pulse: (a) Ep=457 nJ, (b) $234 n \mathrm{~J}$, (c) 94,5 $n \mathrm{~J}$. The laser radiated from top to bottom of the picture. Linear velocity of the stage was $v=1 \mathrm{~mm} / \mathrm{s}$, geometrical pulse to pulse overlap (calculated) $\mathrm{OL}=99.90 \%$. 
The power threshold $P_{\text {crit }}$ above which Kerr effect is triggered can be expressed as [40]:

$$
P_{\text {crit }}=\frac{\lambda_{0}^{2}}{2 \pi n_{0} n_{2}}
$$

where $\lambda_{0}$ denotes the laser wavelength, $\mathrm{n}_{0}$ the linear refractive index $\left(\mathrm{n}_{0}=1.755\right.$ at $1030 \mathrm{~nm}$ [41]) of the material and $\mathrm{n}_{2}$ the nonlinear refractive index $n_{2}=3 \cdot 10^{-16} \mathrm{~cm}^{2} / W$ [42]). Hence, $P_{\text {crit }}=3.02 \cdot 10^{6} \mathrm{~W}$, which has the same order of magnitude of the applied peak powers in this work, especially at $E_{\mathrm{p}}=234$ $n J$ and $457 n J$. This confirms the possible occurrence of self-focusing/multifoci at these levels of pulse energy.

\subsubsection{Overlapping of the modified lines}

For each repetition rate and pulse energy, single lines were overlapped laterally for producing stacks. The number of stacked lines per structure produced is $2^{\mathrm{n}}$, with $\mathrm{n}=1$ to 8 (see Table 5.1). However, at high pulse energies, it is often not possible to go above 8-16 lines because of severe cracking that hampers proper irradiation.

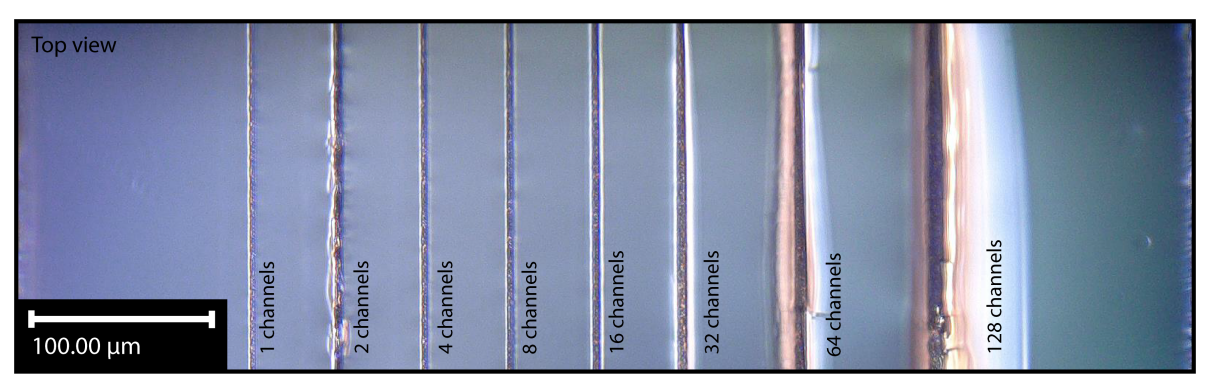

Figure 5.11: Polarized optical microscopy image (top view) of channels and stacks of channels obtained after irradiation and etching in HF at room temperature for about 2 hours. The number of stacked channels increases from 1 (extreme left) to 128 (extreme right). The structures were made using a pulse repetition rate of $0.200 \mathrm{MHz}$ and a pulse energy of $94,5 \mathrm{~nJ}$. Linear velocity of the stage was $v=1 \mathrm{~mm} / \mathrm{s}$, geometrical pulse to pulse overlap (calculated) $\mathrm{OL}=99.50 \%$.

A pitch of $50 \mathrm{~nm}$ (corresponding to an overlap of 90\% ) as the lateral shift between the adjacent lines is used. At low pulse energies, it is possible to 
create stacks of up to 256 lines, although other factors are influencing the formation of fully empty (with no residual crystalline material left) stacks of microchannels.

Accumulated stress inside transparent materials is known to cause birefringence $[43 ; 44]$. Stress induced by laser processing can facilitate the etching of the material itself [45]. In this case, though, the difference in refractive indices between unchanged crystalline, stress-affected and amorphous material will most likely cause a deflection of the incident laser beam. In Figure 5.11, it is shown the increasing stress accumulation (and consequent birefringence) in a polarized light microscopy picture of a series of stacks of lines increasing in number from 1 to 128 .

Cracks additionally interfere with the formation of amorphous material. Cracked material, in fact, is composed of normal crystalline sapphire, voids and stressed crystalline sapphire and has therefore also a mix of refractive indices which are affecting the regular focusing of the laser beam, sometimes even shielding the crystalline material, which is directly below the crack, thus preventing its amorphization.

Figure 5.12 shows an example of this: a crack occurring at about the center of the stacks of microlines was "shielding" the material underneath: the lines irradiated after/next to the line during which the crack was generated exhibit a smaller cross-section which, in turn, causes an "interruption" in the structure itself.

Figure 5.12 (c) shows an optical microscopy picture of the same channel (top view, after etching) showing that the crack, which propagated longitudinally, maintained the shielding effect for almost the entire remainder of the irradiated stack.

Given the step resolution of $50 \mathrm{~nm}$ of the setup and because the minimal cross-sectional dimension of single lines composing the stack is in the order of few hundred nanometers, it should be possible to obtain stacks of microchannels with a single and uninterrupted cross-section. However, amorphized sapphire of a previously irradiated line has a lower refractive index compared to the crystalline sapphire [46]. This index difference has a deflecting effect on the incoming beam that irradiates the following line. The result is that subsequent lines are often irradiated at a slightly tilted angle, which yields a separation between adjacent lines (Figure 5.13). 

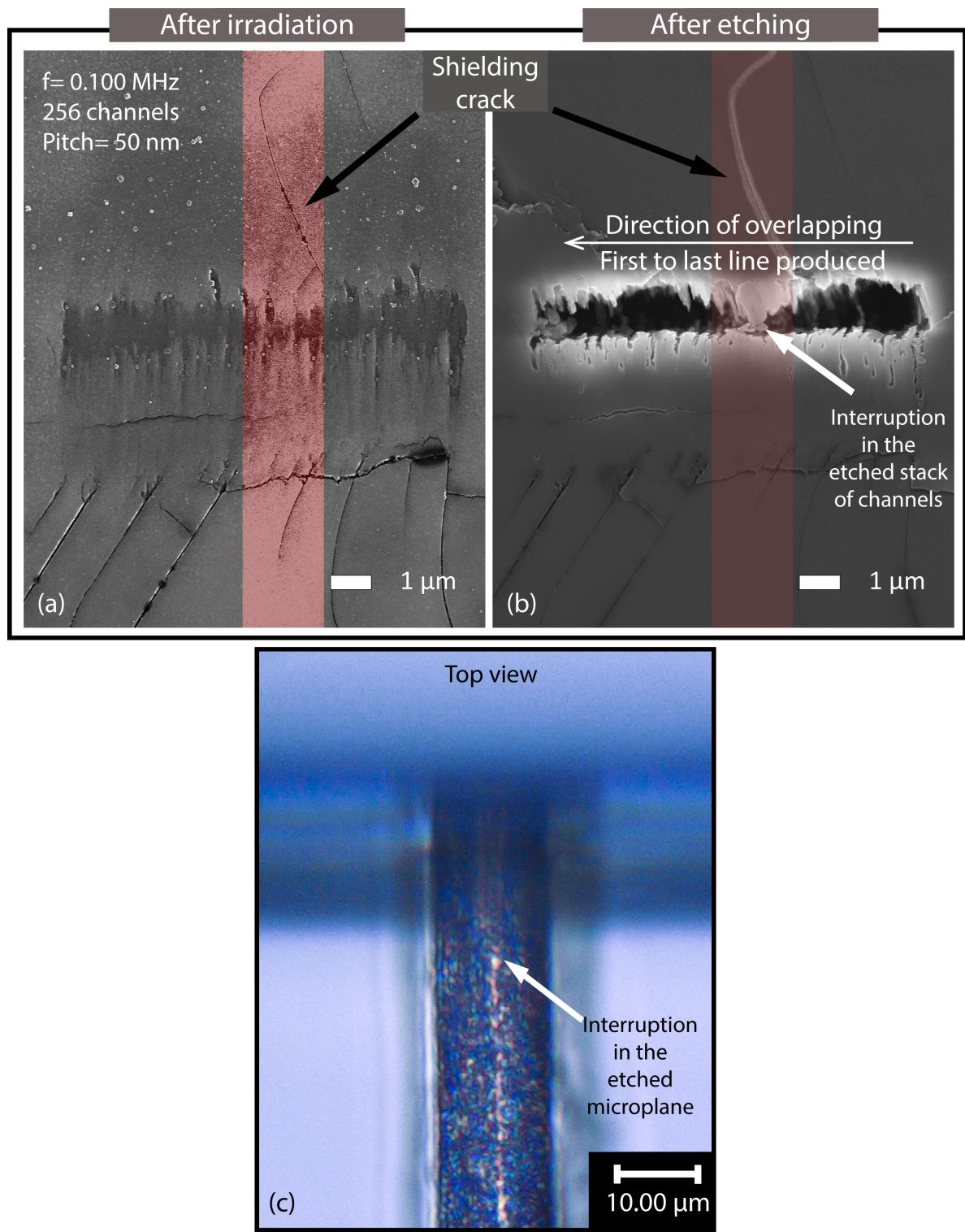

Figure 5.12: SEM micrographs of cross-sections after irradiation of a stack of 256 lines (a) and the structure left after etching (b) obtained using a repetition rate of $0.100 \mathrm{MHz}$ at 94,5 $\mathrm{nJ}$. A crack towards the center of the stack of lines is having a "shielding effect" on the material below resulting in locally no formation of amorphous sapphire. (c) is an optical microscopy picture in top view of the same etched channel. The laser radiated from top to bottom of the pictures (a) and (b). For each line/channel the linear velocity of the stage was $v=1 \mathrm{~mm} / \mathrm{s}$, geometrical pulse to pulse overlap (calculated) $\mathrm{OL}=99.0 \%$. 


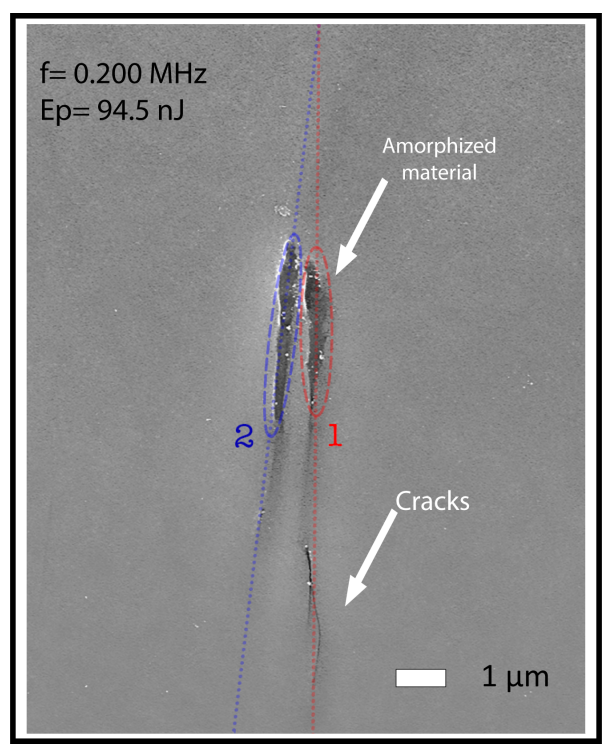

Figure 5.13: SEM micrograph of a cross-section before etching of a stack of 2 irradiated lines (non-etched) obtained using a pulse energy of 94,5 $\mathrm{nJ}$ and a repetition rate of $0.200 \mathrm{MHz}$. The mismatch in refractive indexes between crystalline and amorphous sapphire is causing a separation between line 1 (the first to be irradiated) and line 2. The laser radiates from top to bottom of the picture. Linear velocity of the stage was $v=1 \mathrm{~mm} / \mathrm{s}$, geometrical pulse to pulse overlap (calculated) $\mathrm{OL}=99.50 \%$.

Finally, in Figure 5.14 an overview is presented of a series of stacks of microchannels produced with a repetition rate of $0.500 \mathrm{MHz}$ and a pulse energy Ep=94.5 $\mathrm{nJ}$, starting from a single channel (Figure 5.14 (a)) up to 256 overlapping channels (Figure $5.14(\mathrm{~h})$ ). The shielding effect caused by the cracks is prominent in Figure 5.14 (g) and (h), while the separation of the channels caused by mismatch of the refractive indices is visible starting from (d) and in varying degrees for every other case. Overall, the results for experiments with more than 64 lines show the presence of large cracks.

\subsection{CONCLUSIONS}

A study has been performed on the fabrication of microchannels and stacks of microchannels inside the bulk of sapphire. A detailed step-by step approach regarding the formation of such channels with an analysis of the main factors 
playing a role on the final morphology was, to the best of our knowledge, missing.
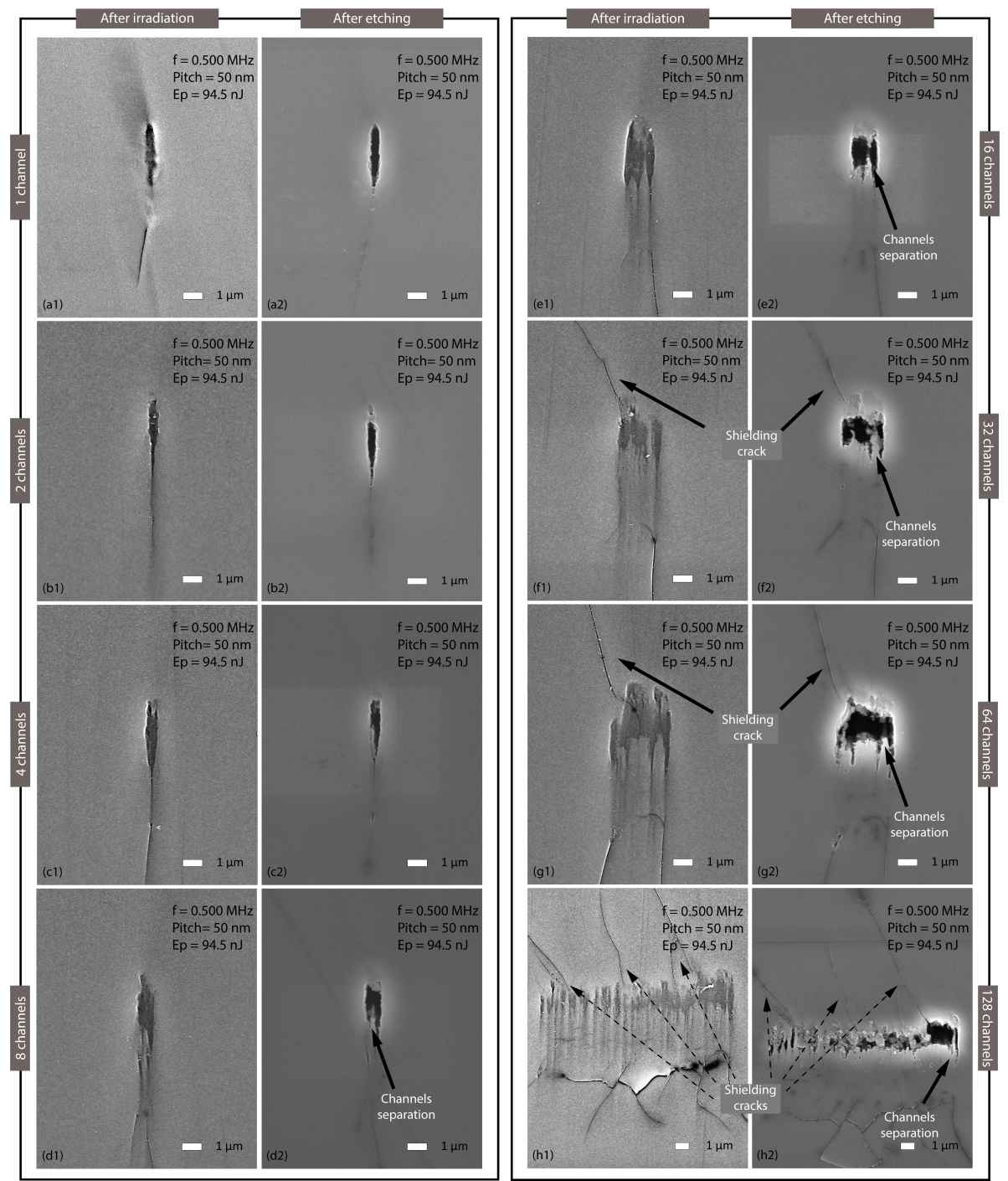

Figure 5.14: SEM micrographs of cross-sections after irradiation of stacks of lines and the structures left after etching obtained at a repetition rate of $0.500 \mathrm{MHz}$ and a pulse energy of $94,5 \mathrm{~nJ}$. The number of single structures overlapped is in order: (a) 1, (b) 2, (c) 4, (d) 8, (e) 16, (f) 32, (g) 64, (h) 128. The laser radiated from top to bottom of the pictures. Linear velocity of the stage was $v=1 \mathrm{~mm} / \mathrm{s}$, geometrical pulse to pulse overlap (calculated) $\mathrm{OL}=$ $99.80 \%$. 
The study included the effects of polarization of the light, repetition rate, pulse energy and number of stacked lines on the morphology and appearance of the structures after irradiation and wet chemical etching. The main results found are the following:

- The first part of the investigation regarded the direction of the irradiation: parallel or perpendicular to the polarization of the light. It was found that, if the sample is irradiated along the direction perpendicular to the polarization of the light, the irradiated lines do not show a smooth single amorphized cross-section, but rather a series of vertical amorphized parallel nanolines propagating along the whole length of the channel. Such structures were not in line with the objective of the study; therefore, next experiments were restricted to irradiation parallel to the light polarization.

- With this arrangement, the next phase comprised studying the effect of repetition rate on the obtained structures. It was found that the ideal window of laser irradiation is between $0.100 \mathrm{MHz}$ and $1 \mathrm{MHz}$. Below this range the structures do not show a single and constant cross-section, but fragmented. Upon using a repetition rate higher than this range, the modified lines also show irregular cross-sections. In fact, they are disrupted and often contain a circular shape on top of the focal region which is shielding the lower/deeper located material and preventing it to be modified.

- The effect of pulse energy was investigated, and it was found that, if a pulse energy of more than $234 n J$ for pulse repetition rates of $(f=0.001$ to $1 \mathrm{MHz}$ ) is used, the focus is split in multiple foci. The splitting is most probably caused by the Kerr-effect and, as a consequence, the cross-sections of the channels after etching are not as targeted.

- Finally, stacks of microlines were studied by varying the number of single lines composing them. In general, the presence of cracks prevent the formation of hollow stacks of microchannels and limits its size to 64 laterally overlapping channels. Moreover a possible non-sufficient overlapping (technically limited by the setup) often causes separation of adjacent channels.

This work demonstrates the possibility of controlling the cross-sectional shape of channels obtained in sapphire using a double-step processing technique based on femtosecond pulsed laser irradiation and selective etching 
in hydrofluoric acid. It is believed that structures with a hollow, continuous and constant (along the length of the structure) cross-section can be used for microfluidic applications.

\section{BIBLIOGRAPHY}

[1] E. R. Dobrovinskaya, L. A. Lytvynov, and V. Pishchik, Sapphire: material, manufacturing, applications. Springer Science \& Business Media, 2009.

[2] Kyocera, "Single crystal sapphire datasheet - Kyocera," 2011.

[3] M. Craven, S. Lim, F. Wu, J. Speck, and S. DenBaars, "Structural characterization of nonpolar (1120) a-plane gan thin films grown on (1102) r-plane sapphire," Applied Physics Letters, vol. 81, no. 3, pp. 469-471, 2002.

[4] A. Halstuch, O. Westreich, N. Sicron, and A. A. Ishaaya, "Femtosecond laser inscription of bragg gratings on a thin gan film grown on a sapphire substrate," Optics and Lasers in Engineering, vol. 109, pp. 68-72, 2018.

[5] D. Kelly, C. Brindle, C. Kemerling, and M. Stuber, "The state-of-the-art of silicon-onsapphire CMOS RF switches," in Technical Digest - IEEE Compound Semiconductor Integrated Circuit Symposium, CSIC, 2005.

[6] T. Lei, K. Ludwig Jr, and T. Moustakas, "Heteroepitaxy, polymorphism, and faulting in gan thin films on silicon and sapphire substrates," Journal of applied physics, vol. 74, no. 7, pp. 4430-4437, 1993.

[7] I. Reklaitis, T. Grinys, R. Tomašiūnas, T. Puodžiūnas, L. Mažulè, V. Sirutkaitis, C. Lin, and C. Yang, "A new geometrical approach for rapid led processing by using femtosecond laser," Optics and Lasers in Engineering, vol. 74, pp. 17-21, 2015.

[8] W. S. Wong, T. Sands, and N. W. Cheung, "Damage-free separation of GaN thin films from sapphire substrates," Applied Physics Letters, 1998.

[9] Z. H. Wu, A. M. Fischer, F. A. Ponce, B. Bastek, J. Christen, T. Wernicke, M. Weyers, and M. Kneissl, "Structural and optical properties of nonpolar GaN thin films," Applied Physics Letters, 2008.

[10] S. Yoshida, S. Misawa, and S. Gonda, "Improvements on the electrical and luminescent properties of reactive molecular beam epitaxially grown GaN films by using AlN-coated sapphire substrates," Applied Physics Letters, vol. 42, pp. 427-429, mar 1983.

[11] M. Kaiser, M. Kumkar, R. Leute, J. Schmauch, R. Priester, J. Kleiner, M. Jenne, D. Flamm, and F. Zimmermann, "Selective etching of ultrafast laser modified sapphire," in Laser Applications in Microelectronic and Optoelectronic Manufacturing (LAMOM) XXIV (G. Račiukaitis, T. Makimura, and C. Molpeceres, eds.), p. 14, SPIE, mar 2019.

[12] D. Lioubtchenko, S. Dudorov, J. Mallat, J. Tuovinen, and A. Raisanen, "Low-loss sapphire waveguides for 75-110 ghz frequency range," IEEE Microwave and Wireless Components Letters, vol. 11, no. 6, pp. 252-254, 2001.

[13] N. Singh, D. D. Hudson, and B. J. Eggleton, "Silicon-on-sapphire pillar waveguides for mid-ir supercontinuum generation," Optics express, vol. 23, no. 13, pp. 17345-17354, 2015.

[14] J. Wang, Y. Zhou, M. Watkinson, J. Gautrot, and S. Krause, "High-sensitivity lightaddressable potentiometric sensors using silicon on sapphire functionalized with selfassembled organic monolayers," Sensors and Actuators, B: Chemical, 2015.

[15] T. Kudrius, G. Šlekys, and S. Juodkazis, "Surface-texturing of sapphire by femtosecond laser pulses for photonic applications," Journal of Physics D: Applied Physics, 2010. 
[16] A. Shamir and A. Ishaaya, "Large volume ablation of Sapphire with ultra-short laser pulses," Applied Surface Science, vol. 270, pp. 763-766, apr 2013.

[17] K. Matsumaru, A. Takata, and K. Ishizaki, "Advanced thin dicing blade for sapphire substrate," Science and Technology of Advanced Materials, vol. 6, no. 2, pp. 120-122, 2005.

[18] A. Dutta, N. Kinsey, S. Saha, U. Guler, V. M. Shalaev, and A. Boltasseva, "Plasmonic interconnects using zirconium nitride," in 2016 Conference on Lasers and Electro-Optics, CLEO 2016, 2016.

[19] S.-H. Park, H. Jeon, Y.-J. Sung, and G.-Y. Yeom, “Refractive sapphire microlenses fabricated by chlorine-based inductively coupled plasma etching," Applied Optics, vol. 40, no. 22, pp. 3698-3702, 2001.

[20] J. Zhou, H. Luo, S. Wen, and Y. Zeng, “ABCD matrix formalism for propagation of Gaussian beam through left-handed material slab system," Optics Communications, vol. 282, no. 14, pp. 2670-2675, 2009.

[21] J. Gottmann, D. Wortmann, and M. Hörstmann-Jungemann, “Fabrication of subwavelength surface ripples and in-volume nanostructures by fs-laser induced selective etching," Applied surface science, vol. 255, no. 10, pp. 5641-5646, 2009.

[22] Y. J. Lee, J. M. Hwang, T. C. Hsu, M. H. Hsieh, M. J. Jou, B. J. Lee, T. C. Lu, H. C. Kuo, and S. C. Wang, "Enhancing the output power of GaN-based LEDs grown on wet-etched patterned sapphire substrates," IEEE Photonics Technology Letters, vol. 18, no. 10, pp. 1152 1154, 2006.

[23] J. Wang, L. W. Guo, H. Q. Jia, Y. Wang, Z. G. Xing, W. Li, H. Chen, and J. M. Zhou, "Fabrication of patterned sapphire substrate by wet chemical etching for maskless lateral overgrowth of GaN," Journal of the Electrochemical Society, 2006.

[24] D. S. Wuu, W. K. Wang, K. S. Wen, S. C. Huang, S. H. Lin, R. H. Horng, Y. S. Yu, and M. H. Pan, "Fabrication of pyramidal patterned sapphire substrates for high-efficiency InGaN-based light emitting diodes," Journal of The Electrochemical Society, vol. 153, no. 8, pp. G765-G770, 2006.

[25] L. Capuano, R. Pohl, R. M. Tiggelaar, J. W. Berenschot, J. G. E. Gardeniers, and G. R. B. E. Römer, "Morphology of single picosecond pulse subsurface laser-induced modifications of sapphire and subsequent selective etching," Optics Express, vol. 26, no. 22, pp. 29283-29295, 2018.

[26] S. Juodkazis, K. Nishimura, H. Misawa, T. Ebisui, R. Waki, S. Matsuo, and T. Okada, "Control over the crystalline state of sapphire," Advanced Materials, vol. 18, no. 11, pp. 13611364, 2006.

[27] L. Capuano, D. de Zeeuw, and G. R. B. E. Römer, "Towards a numerical model of picosecond laser-material interaction in bulk sapphire," Journal of Laser Micro Nanoengineering, vol. 13, no. 3, pp. 166-177, 2018.

[28] E. G. Gamaly, S. Juodkazis, K. Nishimura, H. Misawa, and B. Luther Davies, “Lasermatter interaction in the bulk of a transparent solid: Confined microexplosion and void formation," Physical review. B, vol. 73, no. 21, p. 214101, 2006.

[29] M. Hörstmann-Jungemann, J. Gottmann, and M. Keggenhoff, "3D-microstructuring of sapphire using fs-laser irradiation and selective etching," Journal of Laser Micro Nanoengineering, vol. 5, no. 2, pp. 145-149, 2010.

[30] R. Moser, N. Ojha, M. Kunzer, and U. T. Schwarz, "Sub-surface channels in sapphire made by ultraviolet picosecond laser irradiation and selective etching," Optics Express, vol. 19, no. 24, p. 24738, 2011. 
[31] D. Wortmann, J. Gottmann, N. Brandt, and H. Horn-Solle, "Micro- and nanostructures inside sapphire by fs-laser irradiation and selective etching," in 2008 Conference on Quantum Electronics and Laser Science Conference on Lasers and Electro-Optics, CLEO/QELS, 2008.

[32] S. Juodkazis and H. Misawa, "Laser processing of sapphire by femtosecond pulses," Appl. Phys. A, vol. 93, pp. 857-861, 2008.

[33] S. Matsuo, Y. Shichijo, T. Tomita, and S. Hashimoto, "Laser fabrication of ship-in-a-bottle microstructures in sapphire," JLMN, vol. 2, pp. 114-116, 2007.

[34] S. K. Sundaram and E. Mazur, "Inducing and probing non-thermal transitions in semiconductors using femtosecond laser pulses," vol. 1, no. 4, pp. 217-224, 2002.

[35] N. M. Bulgakova, V. P. Zhukov, and Y. P. Meshcheryakov, "Theoretical treatments of ultrashort pulse laser processing of transparent materials: Toward understanding the volume nanograting formation and "quill" writing effect," Applied Physics B: Lasers and Optics, vol. 113, no. 3, pp. 437-449, 2013.

[36] C. Hnatovsky, R. Taylor, E. Simova, V. Bhardwaj, D. Rayner, and P. Corkum, “Highresolution study of photoinduced modification in fused silica produced by a tightly focused femtosecond laser beam in the presence of aberrations," Journal of applied physics, vol. 98, no. 1, p. 013517, 2005.

[37] Y. Shimotsuma, P. G. Kazansky, J. Qiu, and K. Hirao, "Self-organized nanogratings in glass irradiated by ultrashort light pulses," Physical review letters, vol. 91, no. 24, p. 247405, 2003.

[38] R. Taylor, C. Hnatovsky, and E. Simova, "Applications of femtosecond laser induced self-organized planar nanocracks inside fused silica glass," Laser $\mathcal{E}$ Photonics Reviews, vol. 2, no. 1-2, pp. 26-46, 2008.

[39] E. G. Gamaly, L. Rapp, V. Roppo, S. Juodkazis, and A. V. Rode, "Generation of high energy density by fs-laser-induced confined microexplosion," New Journal of Physics, vol. 15, no. 2, p. 025018, 2013.

[40] S. Juodkazis, K. Nishimura, S. Tanaka, H. Misawa, E. G. Gamaly, B. Luther-Davies, L. Hallo, P. Nicolai, and V. T. Tikhonchuk, "Laser-induced microexplosion confined in the bulk of a sapphire cystal: Evidence of multimegabar pressures," Physical Review Letters, vol. 96, no. 16, 2006.

[41] I. H. Malitson, "Refraction and Dispersion of Synthetic Sapphire," Journal of the Optical Society of America, vol. 52, no. 12, p. 1377, 1962.

[42] A. Major, F. Yoshino, I. Nikolakakos, J. S. Aitchison, and P. W. E. Smith, "Dispersion of the nonlinear refractive index in sapphire," Optics Letters, vol. 29, p. 602, mar 2004.

[43] H. Fan, M. Ryu, R. Honda, J. Morikawa, Z.-Z. Li, L. Wang, J. Maksimovic, S. Juodkazis, Q.-D. Chen, and H.-B. Sun, "Laser-inscribed stress-induced birefringence of sapphire," Nanomaterials, vol. 9, no. 10, p. 1414, 2019.

[44] L. A. Fernandes, J. R. Grenier, P. R. Herman, J. S. Aitchison, and P. V. Marques, "Stress induced birefringence tuning in femtosecond laser fabricated waveguides in fused silica," Optics express, vol. 20, no. 22, pp. 24103-24114, 2012.

[45] A. Agarwal and M. Tomozawa, "Correlation of silica glass properties with the infrared spectra," Journal of Non-Crystalline Solids, vol. 209, no. 1-2, pp. 166-174, 1997.

[46] R. Boidin, T. Halenkovič, V. Nazabal, L. Beneš, and P. Němec, "Pulsed laser deposited alumina thin films," Ceramics International, vol. 42, no. 1, pp. 1177-1182, 2016. 
FABRICATION OF MICROSTRUCTURES IN AND ON SAPPHIRE BY ANISOTROPIC SELECTIVE WET ETCHING OF FEMTOSECOND INFRARED LASER AFFECTED VOLUMES

ABSTRACT In this paper a processing technique for sapphire is presented which combines laser-induced amorphization and subsequent selective wet etching of amorphized sapphire and anisotropic wet etching of crystalline sapphire $\left(\alpha-\mathrm{Al}_{2} \mathrm{O}_{3}\right)$. Using this technique, microstructures can be realized on and in sapphire substrates. By focusing ultra-short laser pulses inside the bulk of synthetic sapphire, its structure can be transformed from crystalline into amorphous. The modified material can be selectively removed using etchants solely dissolving the amorphized part, such as hydrofluoric acid (HF). In this work, however, a novel etchant consisting of a mix of sulphuric acid $\mathrm{H}_{2} \mathrm{SO}_{4}$ and phosphoric acid $\mathrm{H}_{3} \mathrm{PO}_{4}$ at $180^{\circ} \mathrm{C}$ is utilized. Using this mixture, (fast) dissolution of amorphized sapphire occurs as well as (slow) anisotropic etching of the crystalline sapphire. The latter allows the realization of structures on and in sapphire impossible to achieve upon using conventional etchants which solely dissolve the amorphized sapphire. In this study, laser irradiation is used as seed/starting point for the subsequent anisotropic etching. This processing sequence forms microstructures showing particular geometrical shapes (trapezohedral and tetrahedral) on the surface or in the bulk of sapphire. Such structures may be employed, for example, for microfluidic applications or functionalized surfaces.

The present chapter is identical to a paper titled "Fabrication of microstructures in and on sapphire by anisotropic selective wet etching of femtosecond infrared laser affected volumes" by L. Capuano, R.M. Tiggelaar, M. Feinaeugle, J.W. Berenschot, N. R. Tas, J.G.E. Gardeniers and G.R.B.E. Römer, which is being prepared for submission to a scientific journal. This chapter addresses research objective 3 , as defined in section 1.3. 


\subsection{INTRODUCTION}

Crystalline sapphire is a material used in many branches of science and technology. It is transparent for wavelengths in a range spanning from UV to near-infrared (visible spectrum), it has a hardness of 9 on the Mohs scale, it is a good electrical and thermal insulator, it has a high melting temperature of $2030{ }^{\circ} \mathrm{C}$ and is highly chemically inert [1]. These properties make the material a prime choice for many applications. For example, its chemical and physical properties are exploited in the field of silicon-on-sapphire devices and gallium nitride LEDs [2-5]. For its transparency and hardness, sapphire is used for smartphones and watches [6;7] and in the fields of photonics [8;9]. Moreover, several studies have demonstrated the possibility of producing channels and reservoirs inside sapphire to be used for possible hosting of chemicals and chemical reactions for microfluidic applications. [10-14].

Crystalline sapphire can be processed using several techniques. Typical onestep processing methods are: mechanical sawing/dicing [7; 15], dry etching [16-19], wet etching [20-22] and laser surface treatment [23-25]. Although all of the cited methods have been demonstrated to be effective, all methods have in common that material can only be removed starting from the surface towards the bulk. This is limiting the type of shapes/patterns achievable in and on sapphire.

Some processing methods can also be combined, yielding so-called twostep methods. In this paper, we present and discuss a two-step processing technique to make microstructures in/on sapphire substrates, which consists of femtosecond infrared laser irradiation of sapphire to locally amorphize the material, followed by removal of the amorphized sapphire in combination with anisotropic etching of crystalline sapphire by a mixture of sulphuric acid and phosphoric acid at $180{ }^{\circ} \mathrm{C}$.

When ultra-short laser pulses (in the range of femtoseconds to picoseconds) are focused inside the bulk of sapphire, the absorbed laser energy [26] induces a "microexplosion" which creates an amorphous (or partially amorphous) [27] voxel inside the crystalline sapphire. The amorphous material can be etched selectively using specific etchants. The most used etchant for this purpose is hydrofluoric acid (HF) [10-13; 27-29] due to its high selectivity with respect to the amorphized sapphire. That is, this acid has been proven to have an etch rate for the amorphous $\mathrm{Al}_{2} \mathrm{O}_{3}$ which is $10^{5}$ [12] times higher than the etch rate for the crystalline $\mathrm{Al}_{2} \mathrm{O}_{3}$. However, despite the high selectivity, critical issues arise with the use of hydrofluoric acid. The laser amorphization of sapphire, 
is often not carried out completely and, after laser irradiation, the modified material can exhibit discontinuities or irregular shapes [10].

Moreover, the high affinity of hydrofluoric acid for the amorphous phase implies that, after the etching, the empty structure, that remains, shows the same shape (contour/perimeter) of the amorphized material present before the etching. This obviously entails that, it is not possible to modify the morphology of the structures during the etching phase.

In this work, after laser irradiation, sapphire is etched in a mixture of sulphuric acid and phosphoric acid. This etchant, not only dissolves rapidly the amorphized sapphire, but also etches the crystalline sapphire anisotropically. The laser-induced modifications are used as a "seed" to produce unique shapes inside the bulk and/or on the surface of sapphire. To the best of our knowledge, laser-induced modifications were never used as guide for the anisotropic etching of sapphire.

The mixture of $\mathrm{H}_{2} \mathrm{SO}_{4}$ and $\mathrm{H}_{3} \mathrm{PO}_{4}$ shows a lower selectivity compared to conventional etchants for laser-modified sapphire (e.g. HF), but it also etches crystalline sapphire anisotropically. As a consequence, in contrast to what occurs when employing HF, the crystalline material is shaped during wet etching. In this work, we exploit the latter effect to change the initial shape of the laser irradiated structures. In fact, the laser modified material is used as a (selective) starting point to make microstructures terminated by the slowest etching planes of crystalline sapphire. The study presents structures created in the bulk and on the surface of the substrate analysing the effects of changing experimental parameters on the two-step processing method.

\subsection{CRYSTALLOGRAPHIC STRUCTURE AND ANISOTROPIC ETCHING OF SAPPHIRE}

Crystalline sapphire is an anisotropic material with several crystal planes. The crystal planes which are most commonly exploited in industrial applications are C, M, A, N and R-planes, see Figure 6.1 (a). However, it is important to note that many other planes exist, besides the cited main crystallographic planes [1]. Anisotropic etching is a subtractive manufacturing process in which etchants chemically react with crystalline materials, with a faster etch rate along specific crystal planes rather than other planes. This allows the fabrication of features with geometric characteristics such as sharp corners or flat surfaces. Anisotropic etching is typically used for highlighting of possible defects of a single crystal material, or to understand the crystallographic structure and 

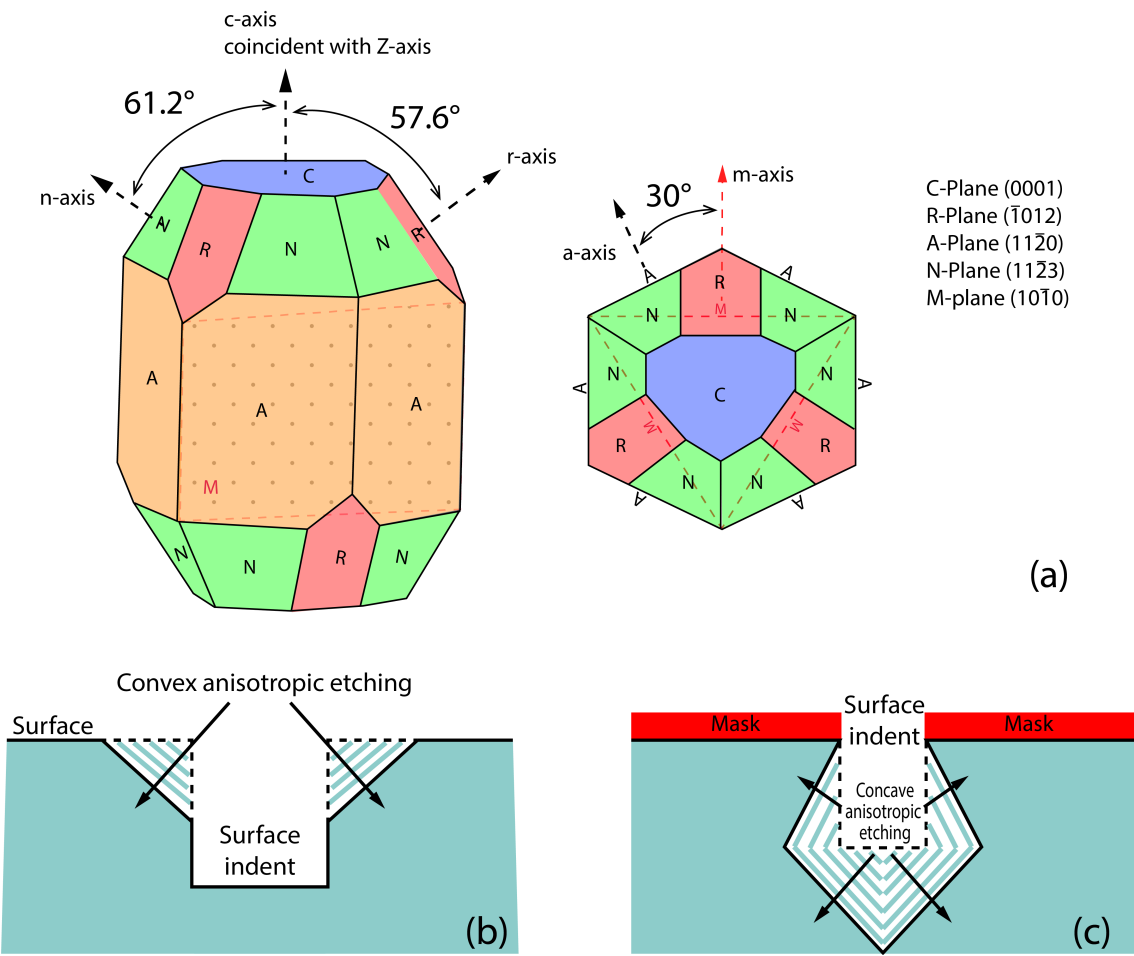

Figure 6.1: (a) 3D model (left) and top view (right) of the crystallographic diagram of sapphire showing the main crystal planes. (b) Schematic representation of convex anisotropic etching of rims of a surface indentation on the surface. (c) Schematic representation of concave anisotropic etching of a surface indentation.

symmetry. When in contact with the acid, in fact, crystalline materials undergo a phenomenon called decrystallization in which the crystalline structure is broken down. This phenomenon typically starts from the discontinuities of the exposed surfaces [30]. The anisotropic etchant used in this study, a mixture of sulphuric and phosphoric acid, was selected based on its known capacity of (anisotropically) etching sapphire [31]. Aota et al. [32] explained the main etching mechanisms of anisotropic etching of sapphire when using this mixture. These authors analysed the etching of sapphire independently in each of the acids composing the solution and observed that the sulphuric acid has a higher etch rate towards the crystalline sapphire than phosphoric acid. However, etching of the material in sole sulphuric acid produces a precipitate $\left(\mathrm{Al}_{2}\left(\mathrm{SO}_{4}\right)_{3}\right)$ which sticks to the surface and prevents further etching. 
Table 6.1: Etch rates for crystalline and amorphized sapphire.

\begin{tabular}{|l|c|}
\hline & Etch rate $(\mathrm{nm} / \mathrm{min})$ \\
\hline C-plane & 1.196 \\
\hline R-plane & 0.085 \\
\hline $\begin{array}{l}\text { Amorphized } \\
\text { sapphire }\end{array}$ & 532.080 \\
\hline
\end{tabular}

Even when the two etchants are used as a mixture, these same impurities deposit on the surface and behave as a protective mask for further etching. As a result, the inclination of the obtained exposed faces after the anisotropic etching depends on the composition of the etchant solution. Moreover, they showed that etching at high(er) temperatures increases the etching rate.

Two main mechanisms can be defined of anisotropic etching of a surface: "convex anisotropic etching" and "concave anisotropic etching". During convex anisotropic etching (Figure 6.1 (b)), the features, which are protruding, are quickly etched following the fast etching planes of the material. For example, Shen et al. [33; 34] showed that the fabrication of cone-shaped Patterned Sapphire Substrate (PSS) (used for high brightness light emitting diodes[2-5]) using convex anisotropic etching on cylindrical pillar structures in a mixture of sulphuric and phosphoric acid.

In concave anisotropic etching, the etchant directly interacts with the pit of an indentation, see Figure 6.1, (c). Concave anisotropic etching is obtained only if the surface of the material is protected (for example by a mask) to avoid the occurrence of the convex anisotropic etching on the edges [35]. Aota et al. [32] demonstrated concave anisotropic etching in a mixture of phosphoric and sulphuric acid by using a $\mathrm{SiO}_{2}$ mask to prevent the etching of the surface.

In this paper, laser treated areas (on the surface and in the bulk) are directly exposed to anisotropic etching. This implies that in all the structures analysed both concave and convex etching occur simultaneously.

Finally, the etch rates in the mixture of $\left(\mathrm{H}_{2} \mathrm{SO}_{4}+\mathrm{H}_{3} \mathrm{PO}_{4}\right)$ at $180^{\circ} \mathrm{C}$ were found experimentally for C-plane, R-plane directions, in crystalline sapphire, and for amorphized sapphire. The etch rates, in $\mathrm{nm} / \mathrm{min}$, are shown in table 6.1 . 


\subsection{EXPERIMENTAL SECTION}

\subsubsection{Materials}

The sapphire substrates used for this study were circular 2 inch wafers (Crystech, Germany) of $430 \mu \mathrm{m}$ thickness and oriented along C-axis (0001), i.e. having the C-plane parallel to the top and bottom surface. The chemical etchant used is a solution of $96 \% \mathrm{H}_{2} \mathrm{SO}_{4}+85 \% \mathrm{H}_{3} \mathrm{PO}_{4}(\mathrm{vol} \%$ ) in volumes respectively of $2850 \mathrm{ml}$ and $950 \mathrm{ml}$ (ratio of 3:1). The etchant was heated to a temperature of $180^{\circ} \mathrm{C}$.

\subsubsection{Laser set-up}

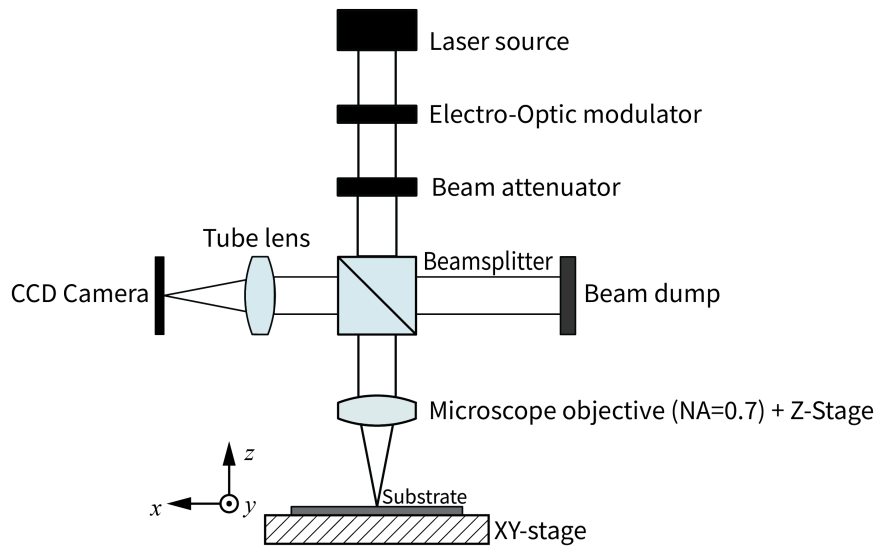

Figure 6.2: Experimental set-up.

The laser set-up that was used to tightly focus laser pulses on the surface and inside crystalline sapphire is shown in Fig. 6.2. The laser source used for this study is a fibre laser (Y-Fi, KMLabs, USA) emitting a linearly polarized beam at a central wavelength of $\lambda=1035 \mathrm{~nm}$. It has a full width at half maximum pulse duration of $230 \mathrm{fs}$ (measured with the autocorrelator pulse-Check by APE Berlin, Germany). The fluence profile of the beam is spatially nearly Gaussian with a beam quality of $M^{2}<1.2$.

The repetition rate of the pulses is controlled by an electro-optic modulator (360-80 by Conoptics, USA) and the pulse energy is set with a beam attenuator (Ultrafast Version, Altechna, Lithuania). 
The microscope objective employed (Leica Microsystems model 11101666, Germany) has a numerical aperture ( $N A)$ of 0.7 . The lens focuses the laser beam to a diameter of about $0.9 \mu \mathrm{m}$ (calculated). The same lens is used also for monitoring the process and to position the focal spot on the surface or inside the substrate, see Figure 6.2. To that end, a beam splitter is used to redirect the light which is reflected back from the specimen to a camera (Thorlabs DCC1545, USA) through a tube lens.

The objective is moved along the $\mathrm{Z}$-axis (focusing axis) using a linear stage (Aerotech ATS100, USA, resolution $100 \mathrm{~nm}$ ) allowing the positioning of the focus spot on top of the surface or inside the bulk of the material. The computerised mechanical stages ( $\mathrm{X}$ and $\mathrm{Y}$ axes) used to move the substrate during laser processing, are Aerotech ALS 130-150 (USA, resolution $50 \mathrm{~nm}$ ).

\subsubsection{Methods}
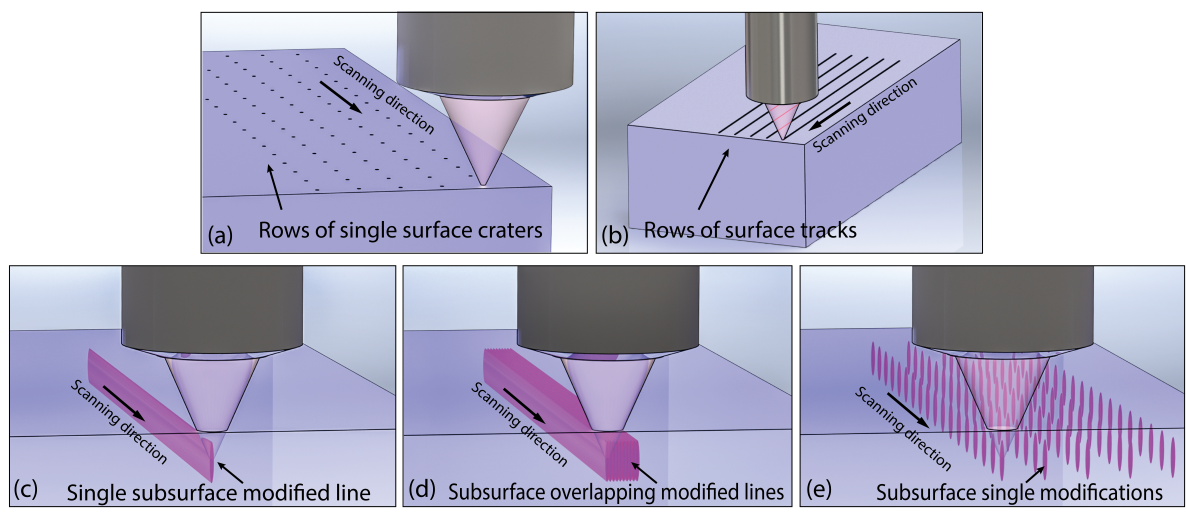

Figure 6.3: Schematic representing the way in which the various types of laser structures were produced and analysed in the study: (a) Single craters on the surface of the sample; (b) Tracks made by geometrically overlapping laser pulses on the surface of the sample; (c) Single laser-modified lines made of overlapping laser pulses produced $30 \mu \mathrm{m}$ below the surface of the sample; (d) Larger lines produced $30 \mu \mathrm{m}$ below the surface of the sample made by overlapping single laser-induced modified lines; (e) Single isolated modifications $30 \mu \mathrm{m}$ below the surface of the sample.

Simple structures were produced on the surface and in the bulk of the sample to study the influence of experimental laser parameters on the process of laser modification and selective anisotropic etching. To produce such struc- 
tures, the sample is moved with a constant velocity while the substrate is exposed to laser pulses emitted by the laser source.

The geometrical pulse-to-pulse overlap in percent is defined here as (6.1)

$$
O L=\left(1-\frac{v}{f \cdot D}\right) \times 100,
$$

where $v$ is the relative velocity between the laser beam and the substrate, $D$ is the diameter of the laser spot in the focus and $f$ is laser pulse repetition rate.

By changing the velocity (in the $x$ or $y$ direction as shown in Figure 6.2) and the pulse repetition rate, either single, separated, modifications (Figure 6.3 (a) and (e)) or lines of overlapping modifications (Figure 6.3 (b), (c), (d)) are produced.

The focus is positioned either on the surface of the sample (Figure 6.3 (a) and (b)) or $30 \mu \mathrm{m}$ below (Figure 6.3 (c),(d),(e)), by moving the microscope objective (attached to the z-stage, see Figure 6.2).

The latter value of processing depth, the energy per laser pulse and the pulse repetition rate were selected based on our earlier work [10]. All the laser-induced modifications are produced close to (about $5 \mathrm{~mm}$ ) an edge of the substrate for easy access. Starting from this edge, after the laser irradiation, the samples are grinded and polished using a Tegramin polishing machine (Struers, USA) to expose the cross sections of the modified material. The surface roughness after the last step of polishing is $R_{a}<5 \mathrm{~nm}$. This surface quality allows an easy characterization of the cross-sections.

After the polishing, the etching is carried out by submerging the substrate in a stagnant solution of $96 \% \mathrm{H}_{2} \mathrm{SO}_{4}+85 \% \mathrm{H}_{3} \mathrm{PO}_{4}$ in volumes respectively of $2850 \mathrm{ml}$ and $950 \mathrm{ml}$ (ratio of 3:1) heated to the temperature of $180^{\circ} \mathrm{C}$ in 3 subsequent rounds: $364 \mathrm{~min}, 385$ minutes (749 in total), 364 minutes (1113 in total). The etching periods reported in the figures indicate the cumulative etching time at each step.

\subsubsection{Analysis tools}

The analysis of the specimen after laser irradiation is performed with a high resolution Scanning Electron Microscope (JEOL7200F, Japan). The same substrates are also analysed at the very same positions before and after each etching step. Height profiles of the surface were obtained using a S-Neox (Sensofar Metrology, Spain) confocal microscope and a FlexAFM (Nanosurf AG, Switzerland) atomic force microscope. 


\subsection{RESULTS AND DISCUSSION}

The main objective of this research is to study a processing technique based on selective and anisotropic etching, using a mixture of $\left(\mathrm{H}_{2} \mathrm{SO}_{4}+\mathrm{H}_{3} \mathrm{PO}_{4}\right)$ at $180^{\circ} \mathrm{C}$, of leaser treated sapphire. This paper shows results obtained studying the etching behaviour on both surface and subsurface (bulk) laser-induced structures.
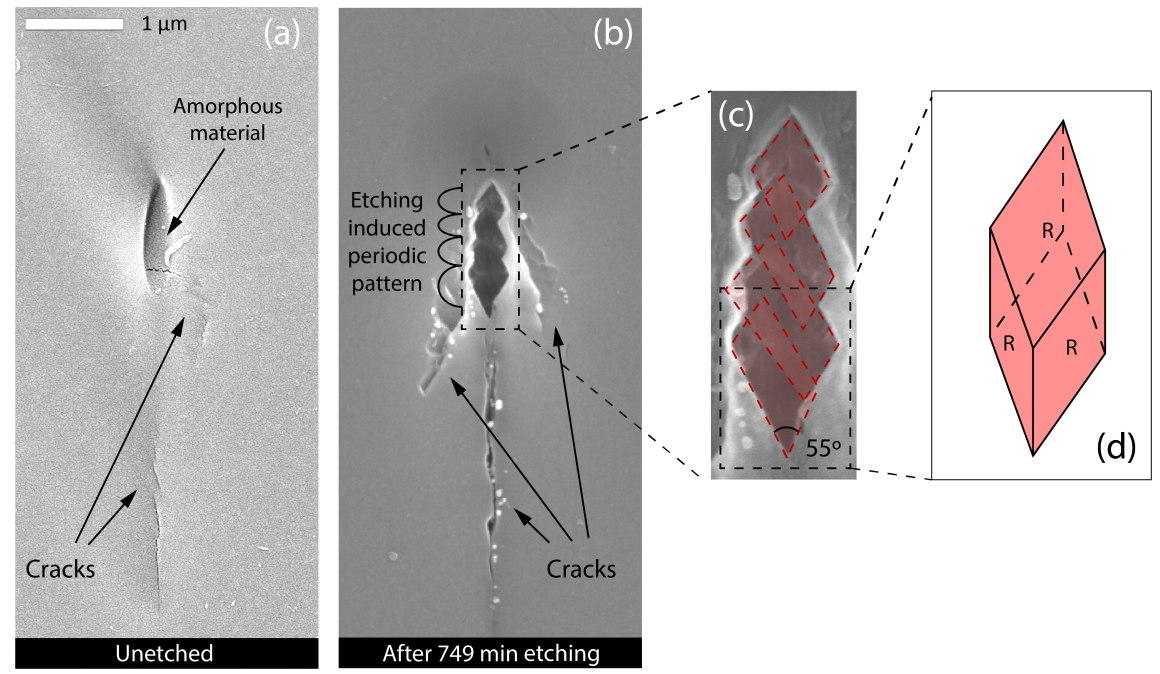

Figure 6.4: SEM micrographs of a typical cross-section of (a) a single-laser pulse induced modification after laser irradiation, (b) after 749 minutes etching in the micture of $\mathrm{H}_{2} \mathrm{SO}_{4}+\mathrm{H}_{3} \mathrm{PO}_{4}$ at $180^{\circ} \mathrm{C}$. A laser pulse energy of $94.5 \mathrm{~nJ}$ was used and the direction of the laser beam was from top to bottom in the micrographs. The C-plane is parallel to the horizontal direction of the images. Anisotropic etching causes (c) "periodic" structures bounded by R-planes. (d) 3D representation of the trigonal trapezohedron formed by the R-planes of the sapphire crystal composing the single features of the periodic patterns [1].

\subsubsection{Subsurface processing}

\subsubsection{Single-pulse induced bulk modifications}

Single laser pulse induced modifications were produced at about $30 \mu \mathrm{m}$ below the surface, by exposing the specimen to laser pulses at a repetition rate of $1 \mathrm{kHz}$ while moving the sapphire substrate at a velocity of $v=15 \mathrm{~mm} / \mathrm{s}$. In 
Figure 6.4 a cross-section of a typical modification induced by a single laser pulse is shown. The horizontal direction of the SEM micrographs is oriented parallel to the C-plane. The amorphized $\mathrm{Al}_{2} \mathrm{O}_{3}$ in the SEM micrograph of the cross-section before the etching (Figure 6.4 (a)) appears darker than the crystalline sapphire surrounding he modification. As can be observed from Figure 6.4 (b), etching the single modifications causes an "etching-induced periodic pattern". This type of pattern consists of repeating regular 3D shapes along the length of the single-pulse induced structure (Figure 6.4 (c)).

Our assumption for the formation of this pattern is that the slow etching R-planes (see Figure 6.1 (a)), which have an inclination with respect to the C-plane of $57^{\circ}[1]$ (Figure 6.1 (a)), will bound the etched structures. The six R-planes form all together a trigonal trapezohedron (Figure $6.4(\mathrm{~d})$ ). This is assumably the shape of the single feature composing the periodic pattern (the angle of $55^{\circ}$ measured at the base of the modification is very close to the $57^{\circ}$ inclination of the R-planes with respect to the C-planes).

In Figure 6.5 two sets of SEM micrographs are shown: the first set (Figure 6.5 (a) to (d)) shows single-pulse induced modifications made using a pulse energy of $94.5 \mathrm{~nJ}$; the second set (Figure $6.5(\mathrm{e})$ to $(\mathrm{h})$ ) is made at a higher pulse energy of $457 n J$. The region of amorphized sapphire is clearly discernible especially in Figure 6.5 (e) (unetched). The evolution with etching time of the visual cross sectional appearance is similar for both the pulse energies shown. The dimensions of the etching induced structures, as expected, increases with the higher energy per pulse. Cracks, which are typical for this type of process [27], are higher in number and bigger in size for the pulse energy of $457 \mathrm{~nJ}$ than for $94.5 \mathrm{~nJ}$. As can be observed from Figure 6.5, the amorphous material is fully removed after 364 minutes and the etching-induced patterns are visible throughout the etching process (Figure 6.5 (b) to (d) and Figure 6.5 (f) to (h)). Also, the crystalline material surrounding the cracks is widened by the anisotropic etching as can be observed most clearly after 1113 minutes of etching (Figure $6.5(\mathrm{~d})$ and $(\mathrm{h})$ ). The latter can be explained by the convex etching of the fast etching planes exposed on the rims of the cracks (see Figure $6.1,(b))$.

\subsubsection{Subsurface microchannels and large structures}

Subsurface channels were produced using the method described in section 6.3.3. Figure 6.6 shows the cross section of a channel produced using a pulse energy of $94.5 \mathrm{~nJ}$, a pulse repetition rate of $200 \mathrm{kHz}$ and a stage velocity $v=1 \mathrm{~mm} / \mathrm{s}$, at different etching times. 


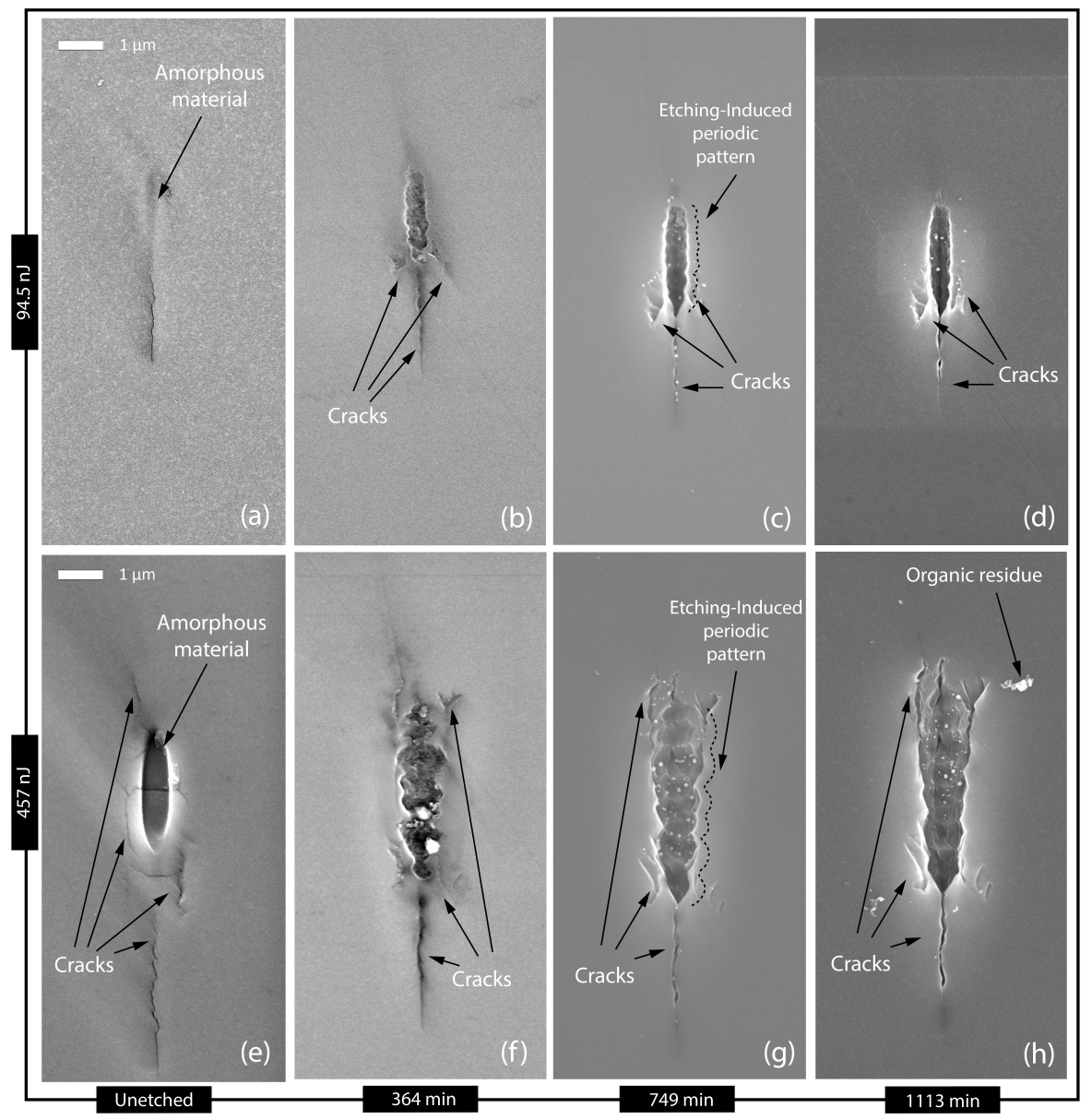

Figure 6.5: SEM micrographs of cross-sections (a,e) after irradiation and (b-d,f-h) after etching of single-laser pulse induced modifications obtained positioning the focal spot of the laser beam $30 \mu \mathrm{m}$ below the surface and using the pulse energies: $94.5 n \mathrm{~J}$ (top row) and $457 n \mathrm{~J}$ (bottom row). The direction of the laser beam was from top to bottom.

As can be observed from Figure 6.6, the obtained channels closely resemble those obtained in our earlier work [10] using stagnant HF (50\%) at room temperature as etchant. However, a difference with respect to HF as etchant is the outline of the contour of the cross-section of the irradiated channel upon using the anisotropic mixture. That is, the anisotropic etching "smoothens" the perimeter of the etched channel (Figure $6.6(\mathrm{~d})$ ). In case of HF, the "rough" 
contour was only due to the laser irradiation (and not due to HF-etching of the crystalline material).

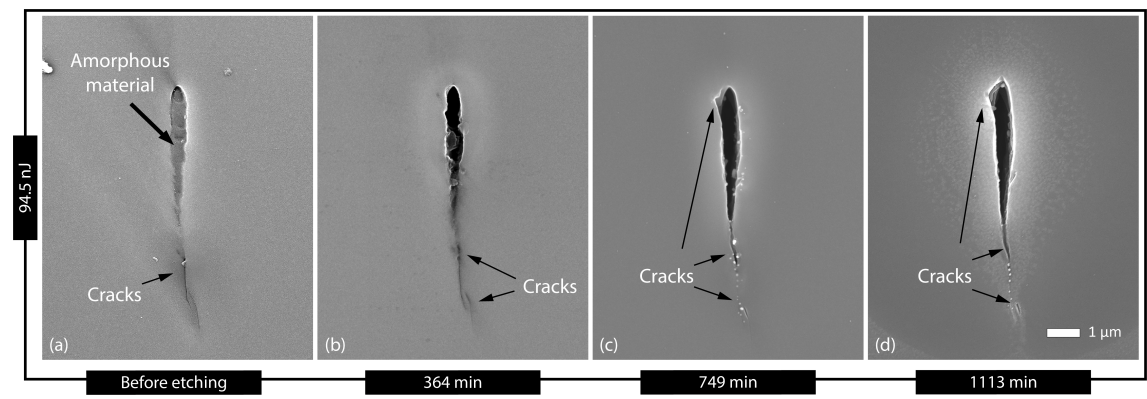

Figure 6.6: SEM micrographs of cross-sections (a) after irradiation and (b-d) after etching of irradiated lines produced positioning the focal spot of the laser $30 \mu \mathrm{m}$ below the surface of the sample using a pulse energy of $94.5 \mathrm{~nJ}$, a pulse repetition rate of $200 \mathrm{kHz}$ and a stage velocity of $1 \mathrm{~mm} / \mathrm{s}$. The direction of the laser beam was from top to bottom.

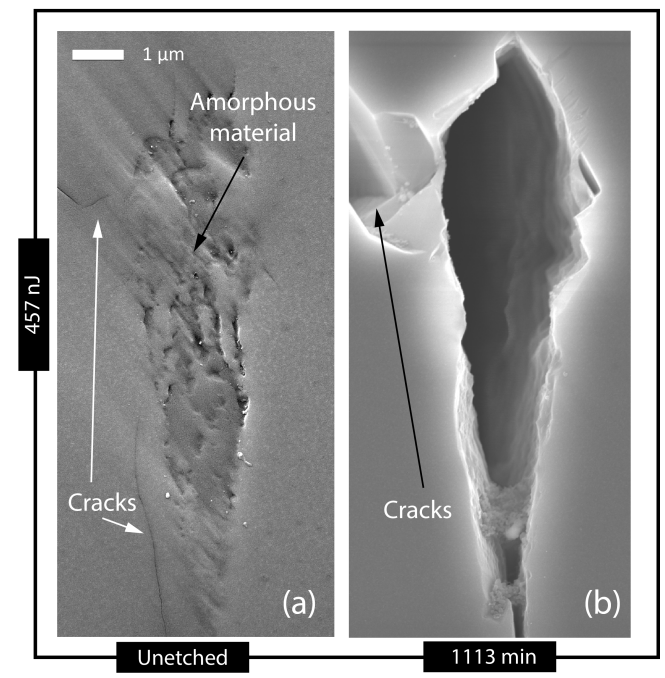

Figure 6.7: SEM micrographs of cross-sections (a) after irradiation and (b) after 1113 minutes etching (b) of a large structure produced by overlapping laterally 8 irradiated lines. The structure was produced positioning the focal spot of the laser $30 \mu \mathrm{m}$ below the surface of the sample, using a pulse energy of $457 \mathrm{~nJ}$, a pulse repetition rate of $200 \mathrm{kHz}$ and a stage velocity of $1 \mathrm{~mm} / \mathrm{s}$. The direction of the laser beam was from top to bottom. 
When the mixture of $\mathrm{H}_{3} \mathrm{PO}_{4} / \mathrm{H}_{2} \mathrm{SO}_{4}$ is employed, the contour is "terminated" by planes of crystalline sapphire (since crystalline sapphire etches slowly in this mixture), so partly a stack of trigonal trapezohedron units is formed. Similarly to the case of single laser-pulse induced modifications, cracks are subject to anisotropic etching, which proceeds along the cracks direction.

Figure 6.7 shows SEM micrographs of the cross-section of a structure produced, using a pulse energy of $457 \mathrm{~nJ}$, a pulse repetition rate of $200 \mathrm{kHz}$, at $30 \mu \mathrm{m}$ below the surface of the substrate and by overlapping (side by side) 8 modified lines to form a bigger structure. The cracks surrounding the structure are affected by the anisotropic etchant.

\subsubsection{Surface processing}

\subsubsection{Single laser-pulse induced craters}

Single laser-induced "craters" were produced on the surface of a sapphire substrate with a method similar to the method described in section 6.4.1.1. The stages were moved at a speed of $15 \mathrm{~mm} / \mathrm{s}$ while laser pulses were emitted with a repetition rate of $1 \mathrm{kHz}$ using a laser pulse energy of $94.5 \mathrm{~nJ}$. The focal spot was positioned on the surface of the sample. Differently to the laser-induced bulk modifications, the craters on the surface are mainly formed by laser ablation and vaporization of the material [36] rather than by amorphization. This implies that the mechanisms driving the etching of these structures are different. That is, during immersion of the surface-irradiated sapphire specimen in the wet chemical etchant mixture, mainly anisotropic etching of the crystalline material occurs. As a consequence, after etching of the craters, the shape of the remaining structures can be approximated with inverted tetrahedrons (Figure 6.8).

Figure 6.9 (a) shows a height profile of the surface obtained by confocal microscopy consisting of tetrahedral structures on the surface of the sample. The measurement was performed after 1113 minutes of anisotropic etching. The surface-edge angle of the tetrahedron was found to be equal to $5.3 \pm 0.3^{\circ}$, whilst the face of the tetrahedrons shows an angle of $8.5 \pm 0.1^{\circ}$ with respect to the surface of the substrate. The inverted tetrahedron shows symmetry (i.e. identical values of the inclination angles) on the 3 edges and faces.

Due to the reduced size and shape of the intermediate structures, the measurement in the centre of the tetrahedral shapes required the use of atomic 


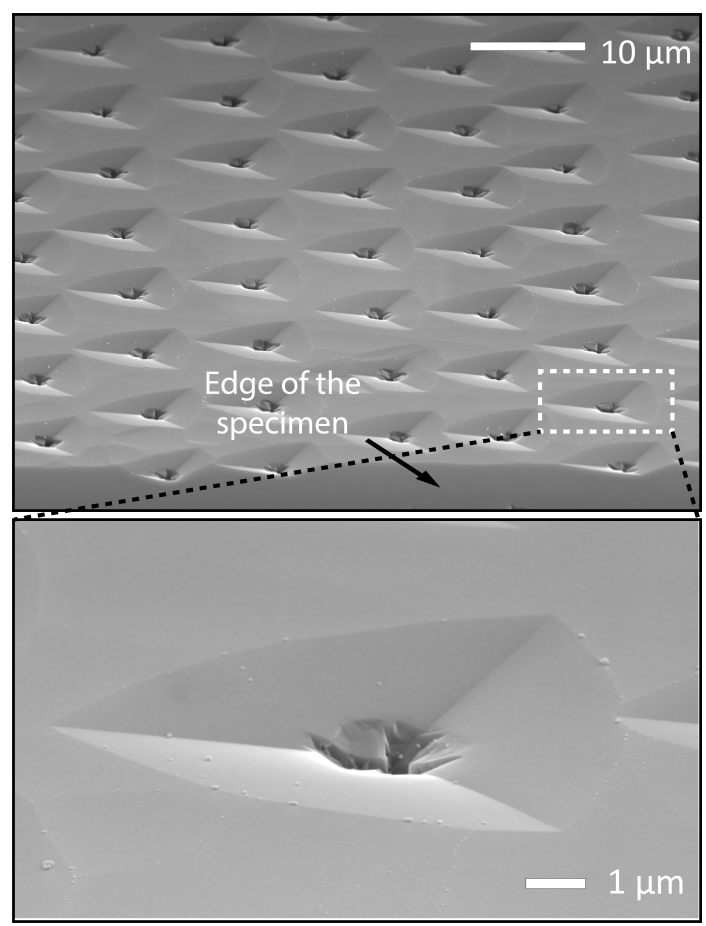

Figure 6.8: SEM micrographs $\left(60^{\circ}\right.$ tilted view) of a pattern of single-pulse induced modifications, after 749 minutes etching, produced on the surface of the sample using a pulse energy of $94.5 \mathrm{~nJ}$, a pulse repetition rate of $1 \mathrm{kHz}$ and a stage velocity of $15 \mathrm{~mm} / \mathrm{s}$.

force microscopy (AFM). Figure 6.9 (b) shows a height profile obtained with AFM of a cross-like structure appearing after 1113 minutes of etching.

One explanation for the tetrahedral shape of the structures could be (as for the single pulse induced modifications inside the bulk) that the slow etching R-planes (Figure 6.1 (a)) are exposed by the anisotropic etching. In this case, since the structure is formed on the surface, the shape would be given by the lower half of the trigonal trapezohedron which is, indeed, a tetrahedron. However, the considerable difference between the angles observed for subsurface single pulse induced modifications $\left(55^{\circ}\right.$, see figure $\left.6.4(\mathrm{~b})\right)$ and the inclination measured for single craters on the surface (about $5^{\circ}$ to $8^{\circ}$, see figure 6.9 (a)) suggests that different mechanisms determine the final shape of the single crater structures. Our assumption is that convex etching of the rim of the modification acts along faster etching planes than the concave etching of the pit of the modifications inside the bulk, which have lower inclination. 


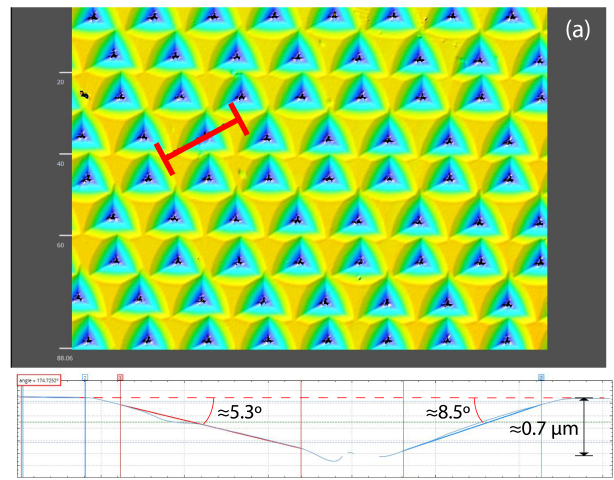

(b)

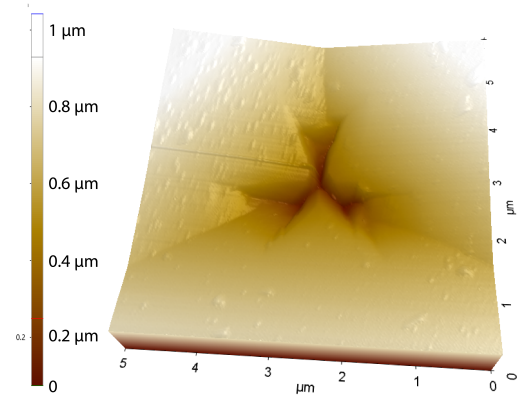

Figure 6.9: (a) Top: confocal microscopy image of an array of single laser-pulse induced craters after 1113 minutes etching. Bottom: profile of an etched crater along the edge and the face of the regular tetrahedral structure. (b) Height profile of the central area of a tetrahedral shape obtained by atomic force microscopy.
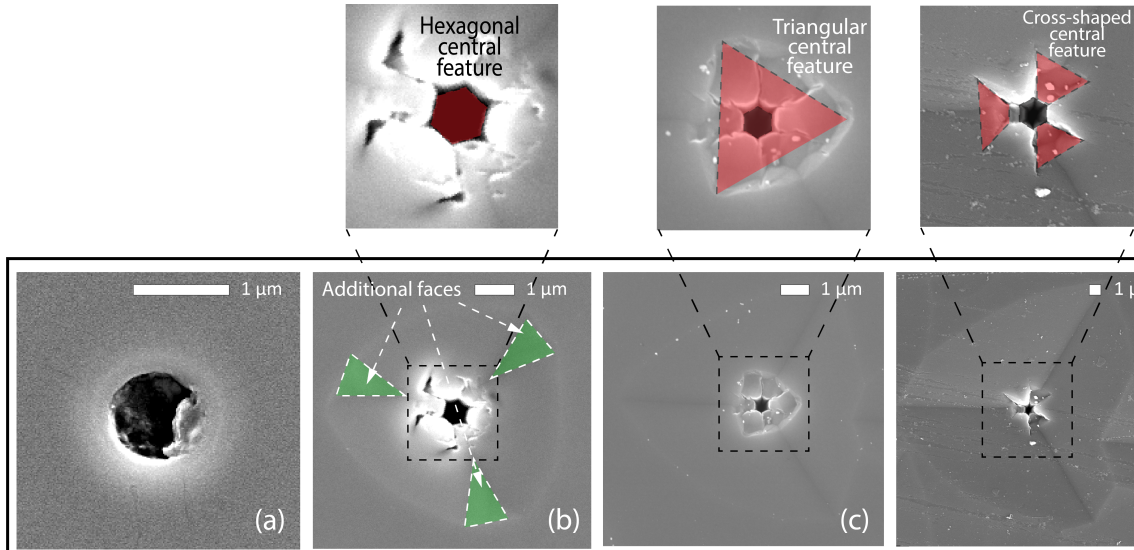

$364 \mathrm{~min}$

(b)
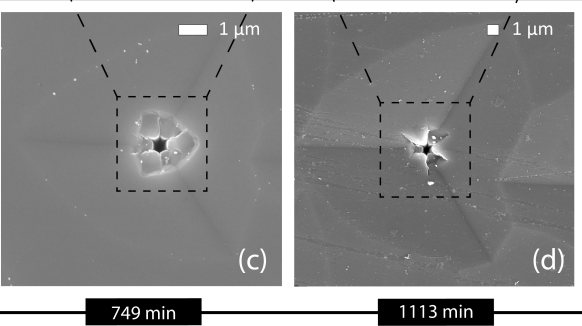

Figure 6.10: SEM micrographs (top view) of a single-laser pulse induced craters on surface (a) after irradiation and (b-d) after etching obtained moving the substrate with a velocity of $15 \mathrm{~mm} / \mathrm{s}$, a pulse repetition rate of $1 \mathrm{kHz}$ and a pulse energy of $94.5 \mathrm{~nJ}$. The top row shows details of the intermediate structures forming at each etching step in the centre of the craters.

In Figure 6.10 the evolution over time of the shapes can be analysed after various etching periods. 
Figure 6.10 (a) shows a top view of a typical laser ablated crater. The shape of the crater roughly equals the shape of the Gaussian fluence profile of the laser spot. Before assuming the final tetrahedral shape, after the first etching period (364 minutes, Figure 6.10 (b)), the structure shows more faces than the three of a typical tetrahedron. Superimposed on this shape, a hexagonal shape forms in the centre of the structure. The latter is caused by the fact that the plane perpendicular to the C-plane, which is directed towards the inside of the specimen (i.e. in vertical fashion with respect to the images in Figure $6.10(\mathrm{~b}-\mathrm{d}))$, etches faster than the other planes in the anisotropic etchant. This results in a "hole" in the sample and its edges have an hexagonal shape because of the lower etching speed for those planes parallel to the faces of the hexagon. In this case, the hexagonal shape and the faces perpendicular to the C-plane, suggest that A-planes (Figure 6.1 (a)) determine the shape of the hole.

After 749 minutes of etching (Figure 6.10 (c)), the additional planes disappear and a triangular (top view) shape rotated about $90^{\circ}$ forms in the centre. After 1113 minutes (Figure 6.10 (d)) a cross-like shaped structure evolves in the centre. An AFM measurement of this shape is shown in Figure 6.9, (b).

\subsubsection{Irradiated tracks}

An approach similar to the one used to create single craters on the surface of the specimen, was used to produce surface tracks. That is, while the focal spot was positioned on the surface of the sample, the substrate was moved at a $v=1 \mathrm{~mm} / \mathrm{s}$ exposing the surface to laser pulses using a repetition rate of $1 \mathrm{MHz}$ with an energy per pulse of $94.5 \mathrm{~nJ}$. This implies a geometrical overlap of adjacent pulses of $99.99 \%$. This high overlap ensures the uniformity of ablated tracks along their lengths.

Figure 6.11 shows the evolution of a single irradiated track evolving through all the etching periods. The structure formed after the etching shows a "plateau" in the centre (Figure $6.11(\mathrm{~b}, \mathrm{c}, \mathrm{d})$ ), which has an inclination of only $1.8^{\circ}$ with respect to the surface of the specimen. The width of the plateau increases throughout the whole etching process from about $1 \mu \mathrm{m}$ for 364 minutes up to about $3 \mu \mathrm{m}$ for an etching of 1113 total minutes.

The edges of the etched structures, characterized with confocal microscopy after 1113 minutes of etching, show angles of $11 \pm 0.2^{\circ}$ and $8.5 \pm 0.1^{\circ}$. This latter degree of tilting is identical to the inclination of the faces of the etched single modifications shown in section 6.4.2.1. 


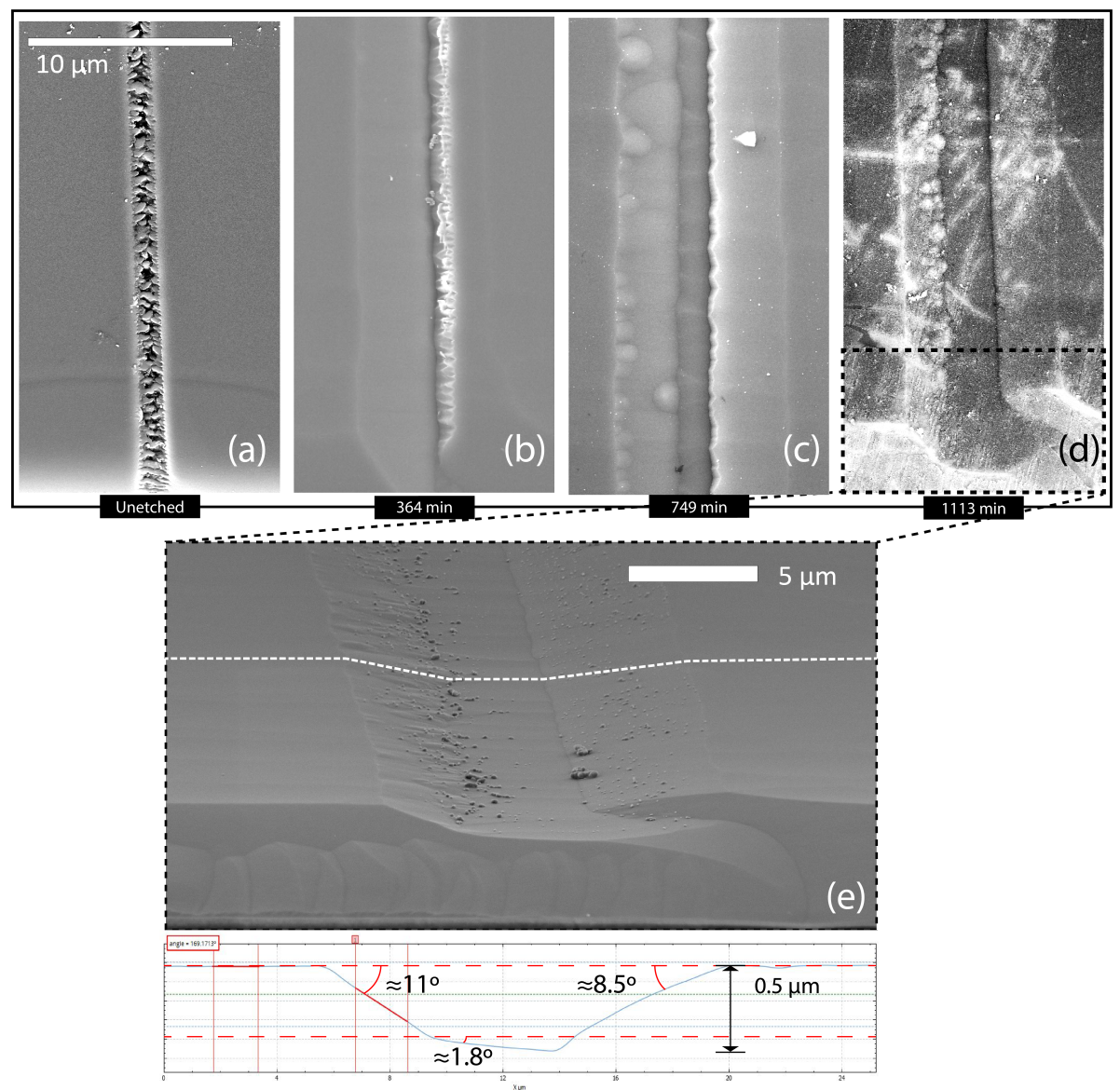

Figure 6.11: SEM micrographs (top view) of (a) a track on surface after irradiation and (b-d) after etching, obtained using moving the sample with a velocity of $1 \mathrm{~mm} / \mathrm{s}$, a pulse repetition rate of $200 \mathrm{kHz}$ and a pulse energy of $94.5 \mathrm{~nJ}$. At the bottom (e) a tilted view $\left(60^{\circ}\right)$ of the cross section of the track with a confocal measurement is shown.

\subsection{CONCLUSIONS}

A study has been performed on a new fabrication technique which combines laser modification of sapphire with selective wet etching of locally amorphized sapphire and anisotropic wet etching of crystalline sapphire $\left(\alpha-\mathrm{Al}_{2} \mathrm{O}_{3}\right)$. A series of different structures has been produced on the surface and in the bulk of sapphire to demonstrate the potential of the technique. The structures were analysed, before etching as well as after several etching periods. 
The first part of the investigation regarded subsurface single-pulse induced structures. After the complete etching of the amorphized part, the anisotropic etching of the crystalline sapphire of the modifications revealed empty structures showing an etching-induced periodic pattern. The edges of the pattern are defined by the R-planes of the sapphire crystal, resulting in an arrangement with repeating trigonal trapezohedrons. Subsequently, subsurface modified lines were studied.

Single lines and large structures (made by side overlapping of single lines) were produced below the surface with high pulse-to-pulse overlap. The resulting structures after etching in the anisotropic etchant show, in general, elliptical cross-sections as the ones obtained from our previous work using non-anisotropic etchant. However, the contour of the hollow structures shows less roughness. We assume that this is caused by the etching of the structures slowing down on the slow etching planes. Differently to non-anisotropic etching, the cracks, surrounding the modifications are etched and their morphology is modified. Next, to investigate the method for surface structures, single-laser pulse induced structures (craters) were produced on the surface of the sample. Anisotropic etching of such structures produces reversed tetrahedral shapes. The reason for such shape is the convex etching of the rim of the single craters along fast etching planes of the sapphire crystal. Finally, several intermediate superimposed structures have been observed forming in the centre as a function of etching time. Irradiated lines, written on the sample surface with a similar approach, show an inclination of the side faces of the rims which is identical to the inclination of the surface of the single tetrahedral structures. However, the etched lines also present a near-flat bottom with a plateau which becomes wider with increasing etching time. The subsurface void structures obtained using this technique could be employed for guiding fluids and hosting chemical reactions in possible microfluidic devices. Moreover, the results suggest that a much longer etching time could finally lead to the formation of structures which have extremely smooth walls. The structures on the surface could be employed for surface funcionalization in those applications that need particular microstructures oriented along specific directions, i.e. tribological applications.

\section{BIBLIOGRAPHY}

[1] E. R. Dobrovinskaya, L. A. Lytvynov, and V. Pishchik, "Application of Sapphire," in Sapphire, p. 95, Boston, MA: Springer US, 2009. 
[2] S. Kitamura, K. Hiramatsu, and N. Sawaki, "Fabrication of gan hexagonal pyramids on dot-patterned gan/sapphire substrates via selective metalorganic vapor phase epitaxy," Japanese journal of applied physics, vol. 34, no. 9B, p. L1184, 1995.

[3] K. H. Li, Y. F. Cheung, W. Y. Fu, K. K.-Y. Wong, and H. W. Choi, "Monolithic integration of gan-on-sapphire light-emitting diodes, photodetectors, and waveguides," IEEE Journal of Selected Topics in Quantum Electronics, vol. 24, no. 6, pp. 1-6, 2018.

[4] T. Kim, Y. H. Jung, J. Song, D. Kim, Y. Li, H.-s. Kim, I.-S. Song, J. J. Wierer, H. A. Pao, Y. Huang, et al., "High-efficiency, microscale gan light-emitting diodes and their thermal properties on unusual substrates," small, vol. 8, no. 11, pp. 1643-1649, 2012.

[5] I. Reklaitis, T. Grinys, R. Tomašiūnas, T. Puodžiūnas, L. Mažulè, V. Sirutkaitis, C. Lin, and C. Yang, "A new geometrical approach for rapid led processing by using femtosecond laser," Optics and Lasers in Engineering, vol. 74, pp. 17-21, 2015.

[6] G. Lin and Y. Huang, "High mechanical strength sapphire cover lens for smartphone screen," Crystal Research and Technology, vol. 53, no. 7, p. 1800049, 2018.

[7] D. Hayes, "Sapphire watch glass machining with diamond," Industrial Diamond Review, vol. 58, no. 577, pp. 55-6, 1998.

[8] A. Dutta, N. Kinsey, S. Saha, U. Guler, V. M. Shalaev, and A. Boltasseva, "Plasmonic interconnects using zirconium nitride," in 2016 Conference on Lasers and Electro-Optics, CLEO 2016, 2016.

[9] T. Baehr-Jones, A. Spott, R. Ilic, A. Spott, B. Penkov, W. Asher, and M. Hochberg, "Siliconon-sapphire integrated waveguides for the mid-infrared," Optics express, vol. 18, no. 12, pp. 12127-12135, 2010.

[10] L. Capuano, R. M. Tiggelaar, J. W. Berenschot, J. G. E. Gardeniers, and G. R. B. E. Römer, "Fabrication of millimeter-long structures in sapphire using femtosecond infrared laser pulses and selective etching," Optics and Lasers in Engineering, vol. 133, p. 106114, 2020.

[11] D. Wortmann, J. Gottmann, N. Brandt, and H. Horn-Solle, "Micro- and nanostructures inside sapphire by fs-laser irradiation and selective etching," in Proceedings of 2008 Conference on Quantum Electronics and Laser Science Conference on Lasers and Electro-Optics, CLEO/QELS, 2008.

[12] S. Juodkazis, K. Nishimura, H. Misawa, T. Ebisui, R. Waki, S. Matsuo, and T. Okada, "Control over the crystalline state of sapphire," Advanced Materials, vol. 18, no. 11, pp. 1361$1364,2006$.

[13] M. Hörstmann-Jungemann, J. Gottmann, and M. Keggenhoff, “3D-microstructuring of sapphire using fs-laser irradiation and selective etching," Journal of Laser Micro Nanoengineering, vol. 5, no. 2, pp. 145-149, 2010.

[14] R. Moser, N. Ojha, M. Kunzer, and U. T. Schwarz, "Sub-surface channels in sapphire made by ultraviolet picosecond laser irradiation and selective etching," Optics Express, vol. 19, no. 24, p. 24738, 2011.

[15] K. Matsumaru, A. Takata, and K. Ishizaki, "Advanced thin dicing blade for sapphire substrate," Science and Technology of Advanced Materials, vol. 6, no. 2, pp. 120-122, 2005.

[16] B.-J. Kim, M. A. Mastro, H. Jung, H.-Y. Kim, S. H. Kim, R. T. Holm, J. Hite, C. R. Eddy Jr, J. Bang, and J. Kim, "Inductively coupled plasma etching of nano-patterned sapphire for flip-chip gan light emitting diode applications," Thin solid films, vol. 516, no. 21, pp. 77447747, 2008.

[17] Y. P. Hsu, S. J. Chang, Y. K. Su, J. K. Sheu, C. H. Kuo, C. S. Chang, and S. C. Shei, “ICP etching of sapphire substrates," Optical Materials, vol. 27, no. 6, pp. 1171-1174, 2005. 
[18] C. H. Jeong, D. W. Kim, H. Y. Lee, H. S. Kim, Y. J. Sung, and G. Y. Yeom, “Sapphire etching with BCl3/HBr/Ar plasma," Surface and Coatings Technology, vol. 171, no. 1-3, pp. 280-284, 2003.

[19] H. Furuya, N. Okada, and K. Tadatomo, “Growth of $\{11-22\}$ GaN on shallowly etched r -plane patterned sapphire substrates," Physica Status Solidi (C) Current Topics in Solid State Physics, vol. 9, no. 3-4, pp. 568-571, 2012.

[20] M. Liu, Y. Hu, X. Sun, C. Wang, J. Zhou, X. Dong, K. Yin, D. Chu, and J. Duan, “Chemical etching mechanism and properties of microstructures in sapphire modified by femtosecond laser," Applied Physics A, vol. 123, no. 1, p. 99, 2017.

[21] S. Jiang, Z. Chen, X. Jiang, X. Fu, S. Jiang, Q. Jiao, T. Yu, and G. Zhang, “Study on the morphology and shape control of volcano-shaped patterned sapphire substrates fabricated by imprinting and wet etching," CrystEngComm, vol. 17, no. 16, pp. 3070-3075, 2015.

[22] T. V. Cuong, H. S. Cheong, H. G. Kim, H. Y. Kim, C. H. Hong, E. K. Sun, H. K. Cho, and B. H. Kong, "Enhanced light output from aligned micropit InGaN-based light emitting diodes using wet-etch sapphire patterning," Applied Physics Letters, vol. 90, no. 13, 2007.

[23] D. Nieto, J. Arines, G. M. O'Connor, and M. T. Flores-Arias, "Single-pulse laser ablation threshold of borosilicate, fused silica, sapphire, and soda-lime glass for pulse widths of 500 fs, 10 ps, 20 ns," Applied optics, vol. 54, no. 29, pp. 8596-8601, 2015.

[24] M. Shaheen, J. Gagnon, and B. Fryer, “Experimental study on $785 \mathrm{~nm}$ femtosecond laser ablation of sapphire in air," Laser Physics Letters, vol. 12, no. 6, p. 066103, 2015.

[25] T.-C. Chen and R. B. Darling, "Parametric studies on pulsed near ultraviolet frequency tripled nd: Yag laser micromachining of sapphire and silicon," Journal of Materials Processing Technology, vol. 169, no. 2, pp. 214-218, 2005.

[26] L. Capuano, D. de Zeeuw, and G. Römer, "Towards a numerical model of picosecond laser-material interaction in bulk sapphire," Journal of laser micro nanoengineering, vol. 13, no. 3, pp. 166-177, 2018.

[27] L. Capuano, R. Pohl, R. Tiggelaar, J. Berenschot, J. Gardeniers, and G. Römer, “Morphology of single picosecond pulse subsurface laser-induced modifications of sapphire and subsequent selective etching," Optics express, vol. 26, no. 22, pp. 29283-29295, 2018.

[28] S. Matsuo, K. Tokumi, T. Tomita, and S. Hashimoto, "Three-dimensional residue-free volume removal inside sapphire by high-temperature etching after irradiation of femtosecond laser pulses," Laser Chemistry, vol. 2008, 2008.

[29] S. Juodkazis and H. Misawa, "Forming tiny 3D structures for micro- and nanofluidics," SPIE Newsroom, pp. 4-6, 2007.

[30] L. Zhang, J. Sun, H. Zuo, Z. Yuan, J. Zhou, D. Xing, and J. Han, “Tridimensional morphology and kinetics of etch pit on the $\left\{\begin{array}{llll}0 & 0 & 0 & 1\end{array}\right\}$ plane of sapphire crystal," Journal of Solid State Chemistry, vol. 192, pp. 60-67, 2012.

[31] A. Reisman, "The etching of crystallographically determined orifices in sapphire," Journal of The Electrochemical Society, vol. 126, no. 6, p. 1004, 1979.

[32] N. Aota, H. Aida, Y. Kimura, Y. Kawamata, and M. Uneda, "Fabrication mechanism for patterned sapphire substrates by wet etching," ECS Journal of Solid State Science and Technology, vol. 3, no. 5, p. N69, 2014.

[33] J. Shen, D. Zhang, Y. Wang, and Y. Gan, "Afm and sem study on crystallographic and topographical evolution of wet-etched patterned sapphire substrates (pss): I. cone-shaped pss etched in sulfuric acid and phosphoric acid mixture (3: 1) at $230^{\circ} \mathrm{C}$," ECS Journal of Solid State Science and Technology, vol. 6, no. 1, p. R24, 2016. 
[34] J. Shen, D. Zhang, Y. Wang, and Y. Gan, "Afm and sem study on crystallographic and topographical evolutions of wet-etched patterned sapphire substrate (pss): Part ii. coneshaped pss etched in h2so4 and h3po4 mixture with varying volume ratio at $230^{\circ} \mathrm{c}$," ECS Journal of Solid State Science and Technology, vol. 6, no. 9, pp. R122-R130, 2017.

[35] E. J. W. Berenschot, H. V. Jansen, and N. R. Tas, "Fabrication of 3d fractal structures using nanoscale anisotropic etching of single crystalline silicon," Journal of Micromechanics and Microengineering, vol. 23, p. 055024, apr 2013.

[36] H. Mustafa, D. Matthews, and G. R. B. E. Römer, "Investigation of the ultrashort pulsed laser processing of zinc at $515 \mathrm{~nm}$ : morphology, crystallography and ablation threshold," Materials \& Design, vol. 169, p. 107675, 2019. 



\section{7}

CONCLUSIONS AND RECOMMENDATIONS

In this chapter, conclusions and results of earlier chapters are summarized and reviewed with respect to the research objectives defined in section 1.3. In addition, recommendations and suggestions for future research on the topic are presented.

\subsection{CONCLUSIONS}

As introduced in chapter 1 and 2, ultra-short pulsed laser micro- and/nanoprocessing and subsequent chemical etching of (synthetic) sapphire $\left(\alpha-\mathrm{Al}_{2} \mathrm{O}_{3}\right)$ is a technique which allows to create unique surface and bulk structures, which can not be achieved by other processing techniques. Employing a tightly focused laser beam, with a beam diameter in the order of $1 \mu \mathrm{m}$, combined with ultra-short laser pulses in the femto- to picosecond regime laser intensity levels can be reached up to $10^{18} \mathrm{~W} / \mathrm{cm}^{2}$. This high intensity allows to ablate the surface or modify the bulk of sapphire below the surface, at micrometer to nanometer precision. By overlapping single laser pulse-induced modifications, it is possible to produce virtually any 3D shape in the bulk or on the surface of sapphire. Combining ultra-short pulsed laser irradiation with subsequent chemical selective etching of the amorphized sapphire, using typically hydrofluoric acid (HF), allows flexible 3D surface and bulk machining of sapphire. This sapphire machining technique can be exploited for the microfabrication of a wide range of applications, such as microfluidic devices, texturized surfaces and microparts.

Chapter 2 presented and discussed this technique in more detail and showed that several types of structures can be created in sapphire such as channels, vertical cuts and cylindrical and cubic 3D structures. Although the technique has been studied before and various 3D structures in sapphire have been demonstrated, the method is still not exploited in industry due to several unresolved scientific and practical issues. These challenges include, but are not limited to: the formation of undesired laser-induced cracks surrounding the laser-induced amorphous region, the irregular and inhomogeneous distribution of amorphous material in the laser focal interaction zone and, last but not least, the etching of the channels which can be hard to control. To address 
these problems, first the phenomena and parameters governing laser-material interaction of subsurface processing of sapphire, and secondly the effect of etchants on both crystalline and amorphized sapphire need to be understood. Hence, three research objectives were formulated in section 1.3.

The first research objective of this thesis aimed at the implementation of a (numerical) model describing both laser energy absorption and thermal phenomena in bulk sapphire. The model, described in chapter 3, is based on a set of governing equations describing the free electron density, the free electron temperature, the lattice temperature and beam propagation of a collimated laser beam. Absorption phenomena included in the model are: free electron absorption, multiphoton absorption, tunneling ionization, avalanche ionization. The transfer of energy from the electrons to the lattice of sapphire was modelled using the well-known two temperature model (TTM).

The model was implemented in COMSOL Multiphysics and it allowed to simulate the laser-material interaction during picosecond pulse durations. It was found that the crucial physical phenomenon for obtaining material modification is the avalanche ionization. When an electron density in the order of of $10^{28} \mathrm{~cm}^{-3}$ is generated, avalanche ionization is triggered and the electron temperature steeply increases. Once the electrons transfer their kinetic energy to the lattice, the temperature of the latter finally increases. Moreover, a "shielding" effect was identified. That is, locations at which the laser energy is absorbed are also the locations at which free electrons are generated. In turn these free electrons absorb more laser energy, which "shield" lower regions of the material from the laser beam. This is in line with the experiments, in which the effects of a higher intensity in the top part of the modifications were observed.

In order to establish optimized laser parameters to obtain uniform amorphous structures in sapphire, experimental analysis was performed. Therefore, the second research objective aimed at the understanding of the influence of laser processing parameters on the morphology of the laser-induced amorphized volume and cracking inside bulk sapphire. In particular, the influence of the:

1. pulse duration,

2. laser pulse energy,

3. laser pulse repetition rate, 
4. spherical aberration, induced by the combined effect of the focusing objective to focus the laser beam,

5. the depth of the focal spot below the surface of the sapphire substrate, and last, but not least,

6. the geometrical overlap (pulse-to-pulse and line-to-line)

were studied. Chapter 4 studied the morphology of amorphizations induced by a picosecond pulsed infrared laser source, at various laser pulse energies (ranging from $4 \mu \mathrm{J}$ to $18 \mu \mathrm{J}$ ) and the depth of processing (focal position ranging from $0 \mu \mathrm{m}$ to $400 \mu \mathrm{m}$ below to surface of the substrate). It was found that, using the highest laser energies per pulse and at shallow focal depth below the surface (both contributing to high levels of intensity) severe cracking occurs. Moreover, the presence of a void inside the amorphized region was observed at higher laser intensities. The morphology of the modifications obtained in chapter 4 were in line with results when using femtosecond laser pulses. A qualitative study on the cracking phenomena was performed, showing that, for low levels of laser intensity, cracks do originate from the laserinduced modification, but these cracks are limited in length and resembled the cracks found in literature for femtosecond single pulse modifications. In addition, the shapes of the amorphized regions were related to calculated optical laser intensity profiles, which were obtained using the illumination point spread function (PSF). The optical model allowed to predict the shape of the single modifications in sapphire as function of the pulse energy and of the focus location (depth) below the surface of the substrate. Comparing the shapes obtained with the model to the shapes found in experiments, it was found that the laser intensity modification threshold above which sapphire amorphizes equals $2.5 \cdot 10^{14} \pm 0.4 \cdot 10^{14} \mathrm{~W} / \mathrm{cm}^{2}$. To further address the second research objective, more experimental parameters and conditions were studied in chapter 5 . That is, a study was performed on the fabrication of microchannels and stacks of microchannels inside the bulk of sapphire using infrared femtosecond laser irradiation and selective etching. The study included the effects of polarization of the light, pulse repetition rate, pulse energy and number of stacked lines on the morphology and appearance of the structures after irradiation and wet chemical etching. First the direction of laser processing - i.e. parallel or perpendicular to the polarization of the lightwas studied. It was found that, if the sample is irradiated along the direction perpendicular to the polarization of the light, the irradiated lines do not show a single-block/homogeneously amorphized cross-section, but rather a series 
of vertical amorphized parallel "nano-lines" propagating along the whole length of the channel. Homogeneous cross-sections could only be obtained at specific pulse repetition rates and pulse energies by irradiating the substrate in a direction parallel to the polarization. Next, moving the substrate with a fixed velocity, the effect of the pulse repetition rate on the obtained structures was studied, studying, in this way, also the geometrical pulse-to-pulse overlap. It was found that the most homogeneous and uniform cross-sections (of amorphized sapphire) were obtained at pulse repetition rates between $100 \mathrm{kHz}$ and $1 \mathrm{MHz}$. Below this range the amorphized structures do not show a single, constant, cross-section, but do show a fragmented "sponge-like" cross-section consisting of both amorphized and crystalline sapphire. When employing a pulse repetition rate above this range, the modified lines also show irregular cross-sections. In fact, they are interrupted (non-contiguous) and often contain a circular shape of modified material on top of the focal region which is shielding the lower/deeper located material and therefore not amorphized. This circular shape could be caused by the "shielding effect" observed in the simulation results of chapter 3 . The effect of pulse energy on the morphology of the structures after irradiation and selective wet chemical etching was also analysed in chapter 5 . It was found that, if a pulse energy over $234 n \mathrm{~J}$ for pulse repetition rates of $1 \mathrm{kHz}$ to $1 \mathrm{MHz}$ is used, the focus of the laser beam is "split" into multiple foci. The latter is most probably caused by the Kerr effect. Finally, the processing of stacks of micro-lines was studied, using the same technique, by varying the number of single lines composing the stacks. In general, the presence of cracks prevented the formation of large hollow structures and/or limited its size.

Etching of (amorphized) sapphire, leading to the final (void) structure in the bulk, is a critical step of the hybrid method. Studying the effect of etching parameters, including the etchant, is necessary to predict the final etched morphology. As mentioned at the start of this section, hydrofluoric acid is the most frequently employed chemical to etch amorphous sapphire. The use of a mixture of sulphuric acid and phosphoric acid $\left(\mathrm{H}_{2} \mathrm{SO}_{4}+\mathrm{H}_{3} \mathrm{PO}_{4}\right)$ at 180 ${ }^{\circ} \mathrm{C}$ to etch the structures obtained with this technique, results not only in the fast etching of the amorphized sapphire, but also in anisotropic etching of crystalline sapphire. Anisotropic etching is a type of etching which removes material faster along some crystal planes than along other planes. To analyse the impact of both the mentioned etchants on the process, the third research objective aimed at establishing experimentally the influence of hydrofluoric acid, as well as the mixture of sulphuric and phosphoric acid on the mor- 
phology of the laser-induced etched structures in sapphire. In chapter 4 and 5 hydrofluoric acid was employed to etch the amorphized material. In both chapters it was found that the dimensions of the modifications, delimited by the border between crystalline and amorphous material, before and after etching were unchanged. That is, the etching process completely removes the amorphous material and does not noticeably etch the crystalline material, leaving an "empty structure" in the bulk. In addition, the etching does not have any observable effect on the cracks surrounding the modification. With respect to the anisotropic etchant, chapter 6 discussed and analysed laser amorphization of sapphire with selective wet etching of amorphized sapphire and anisotropic wet etching of crystalline sapphire. A series of different structures were produced on the surface and in the bulk of sapphire to demonstrate the potential of the technique. The structures were analysed before etching and after several etching periods. The first part of the investigation analysed subsurface single-pulse induced structures. After the complete etching of the amorphized part, the anisotropic etching of the crystalline sapphire of the modifications revealed structures showing well defined geometrical shapes and an etching-induced periodic pattern: the edges of the pattern are stopping on the R-planes of the sapphire crystal, resulting in an arrangement with repeating trigonal trapezohedrons. Subsequently, single lines and large structures (made by side overlapping of single lines) were produced below the surface with high pulse-to-pulse overlap. The resulting structures after the etching in the anisotropic etchant show, in general, similar shapes as the ones obtained from the experiments made using HF (shown in chapters 4 and 5). However, the contour of the hollow structures shows less roughness. This is caused by the etching of the structures "stopping" on the slow etching planes of sapphire. Moreover, contrary to non-anisotropic etching, the cracks, surrounding the modifications are attacked by the etchant. Next, single-laser pulse induced structures (craters) were produced on the surface of the sample. Differently to the laser induced bulk modifications, the craters on the surface are mainly formed by laser ablation and vaporization of the material. This implies that the mechanisms driving the etching of these structures are different from the mechanisms occurring in the bulk. That is, during immersion of the surface-irradiated sapphire specimen in the wet chemical etchant mixture, mainly anisotropic etching of crystalline material occurred. After etching of the craters the resulting structures are inverted tetrahedrons. The reason for such shape to occur is, presumingly, the convex etching of the rim of the single craters along fast etching planes of the sapphire crystal which leaves those 
planes exposed. Intermediate superimposed structures have been observed to form in the centre at each etching step. Finally, irradiated lines made by highly overlapping single laser pulses were produced on the surface of the sample. The resulting structures show the same inclination as the surface single tetrahedrons, but also a plateau in the centre which becomes larger with the increase of the etching time.

\subsection{RECOMMENDATIONS}

The research reported in this thesis was focused on the implementation and optimization of a method of laser microfabrication based on laser irradiation of sapphire and etching of the irradiated regions in selective (and/or anisotropic) etchants. That is, the main focus of the research was on the study of the main (experimental) parameters and physical phenomena influencing the final morphologies obtained in the bulk and on the surface of sapphire, in order to optimize the method to make it exploitable in industry. Despite the results and insights reported in this thesis, still some aspects need to be further analysed to allow full industrial exploitation of the technique

- Model of laser-material interaction in sapphhire The model described in chapter 3 assumes a collimated (spatially) Gaussian beam propagating in the material. Future work on the model should include a realistic caustic beam propagation of a Gaussian focused beam inside sapphire to better compare the results of the experiments with the ones from the simulation. Another important step towards a realistic simulation would be the inclusion of anisotropic and temperature-dependent properties. The next phase for the model is certainly the simulation of physical phenomena and material transformation happening inside sapphire after the phase of thermalization. This is the stage which determines the final shape of the modifications and it is not included in the present model.

- Cracks Cracks are, in different extents, always present around the laserinduced modifications as aftermath of the laser irradiation, especially when larger structures are fabricated. Further study is needed to understand the physical origin of these cracks and to establish laser processing strategies to avoid or eliminate the cracks and especially to prevent the stress accumulation (causing the cracks) when overlapping irrradiated 
lines to form bigger features. A crack-free process would guarantee high quality of the obtained structures.

- Anisotropic etching Further research would be important to determine all the possibilities on the shapes obtainable with selective etching of amorphized sapphire and contemporary anisotropic etching of crystalline sapphire as discussed in chapter 6 . This method is still at the very initial phase of development. The use of substrates with different crystal orientation, for example, would allow to produce different shapes. Furthermore, new ways should be found for speeding up the (very slow) etching of the crystalline material.

- Applications Testing and discussion on the performance of microfluidic applications and functionalized surfaces, produced using the laser irradiation and wet selective (anisotropic) etching, was out of the scope of the thesis. However, this would be the most logical direction for the continuation of this thesis work. Microchannels and resorvoirs could be produced, for example, inside the bulk of sapphire for hosting chemical reactions. Furthermore, 3D structures could be built at the surface exploiting the combination of in-bulk and surface processing. Finally, the unique geometrical shapes achievable on the surface with anisotropic etching could be exploited in tribology applications. 

Being a PhD researcher is like diving into the ocean: you never know how deep it is, until you jump and figure it yourself.

I found myself lucky to have had the best people around me during this jump in the unknown, and I am and will be always thankful to each one of them.

First of all, I would like to thank my supervisor Prof. dr. ir. Gert-Willem Römer. Before joining the Laser Processing group, I was only a freshly graduated student with a lot of research dreams. He helped me becoming the laser-freak and, more in general, the researcher I am today. He was there in the moments when I needed help, he was there in the moments when I needed motivation, he was there to talk about pizza with pineapple, he was there to talk about music and guitars. The most important thing is that he was ALWAYS there during this hard path. I don't think many colleagues can say the same about their supervisors, and I will always be grateful to my boss Gert-Willem for this.

This thesis would not be that beautiful (or, at least, that is how it looks to me) without the fine (British-) German touch of dr. Matthias Feinaeugle, my mini-boss and second supervisor. A good supervisor, a good neighbour and, above all, a great friend, who was available at any time of the day, for listening and advising me on work and non-work related matters.

Special thanks to dr. Roald Tiggelaar, the first dutch person I met 5 years ago, my supervisor during the Master's thesis and, invaluable advisor during PhD time. From the first moment, I understood that your impressive knowledge of sapphire-processing combined with your even more surprising knowledge about football would be the perfect recipe for a long-lasting collaboration. I cannot be enough grateful for all the help I received from you during the last years.

A huge thank you goes to the people from Mesoscale Chemical Systems (MCS), Prof. dr. ir. Han Gardeniers and Erwin Berenschot. Apart from being fantastic collaborators for great part of my research, they were always there, ready for discussions and ready to help, in any possible way.

Thanks to dr. Ralph Pohl for the fruitful discussions and for the HUGE help in the building of the experimental setup. 
Before joining the Laser Processing group at the university, I had no-idea on how beautiful it is to stay in a multicultural environment. This discovery is, without any doubt, thanks to my office colleagues, my second family (as we literally call each other "fratello").

They are beautiful people (thanks again Gert-Willem for the nice selection process) and sharing my PhD time with them was one of the best parts of the path. Talking and laughing on a daily basis about our problems, doing experiments together in the lab up to late night or even just having together lunch or coffee (the best coffee in town). I will never forget our endless discussions up to 5 in the morning about the world's issues at our group dinners.

Many thanks to dr. Hasib, Bangladeshi fratello, friend from the longest time. Thank you for sharing almost every single day of $\mathrm{PhD}$ life with me and for being so friendly and so helpful in any possible way, from helping me in the movings, to helping me fixing my set-ups, my scripts and my experiments (and sometimes my life). I thank dr. Naveed, my Pakistani fratello, for the longest discussions possible about so many topics, for the ultra-high level sport matches (I was always losing), for the good time spent doing 1 million EBSDs, and, above all, for your infinite kindness. Thanks to Marek, German fratello, my brother in arms in the Laser4Fun project. I had countless good moments during the project meetings with and thanks to you. I could not have imagined a better partner. I thank Sietse, Dutch fratello, for being so funny and in a so "wrong" way. Your dry-wit humour lifted up the spirit in the daily routine and some of your jokes will stay fixed in my memory.

I met other people, in the university, which undoubtedly participated in making this thesis possible. I want to express my infinite gratitude to the lab technicians who helped me with building the experimental setups and for the analysis of the specimens: Leo, Nick, Martijn, Erik, Gerald and Ivo. I also thank the secretaries Martina, Belinda and Debbie for helping me so much on a daily basis. I extend my gratitude also to all the friends and colleagues populating the corridors of the Horst.

I thank the students I supervised during their Master's theses Daniël and Mark. Given the complexity of the topics I gave you, in the end I learned from you much more than you did from me.

Along the course of these incredible 4 years, outside the work environment, I could not have survived without having the support of my friends. Thank you Guido, you are part of $80 \%$ of the good stories of most of the inhabitants of Enschede. Thank you for the legendary nights and memories and thanks to Michela, as well, for taming you and bringing us il piccolo Alessandro, 
who brought a lot of joy in our Enschedese family. Thanks to Francesco for raising the nonlinearity of those same legendary nights. The time spent at your Trappartamento will always be one of the best parts of my life. Thank you Federico O.; you wrote it in your thesis, I am writing it in mine: you were the best housemate one could hope for, and a great friend. Many thanks to Kennet, the youngest, but sometimes the wisest of the group. Our friendship is as big as our rivalry in tennis and table-tennis. Thanks to Sara, colleague tennis player, destroyer of coffee machines with electric skateboards, who brought an important contribution to our group. Thank you Federico C. for being so important that it feels wrong that we only met so late in life. I am happy to have found you here and I know I will count on your friendship forever.

A special acknowledgement goes to all the people I met during this beautiful path: Raffaele, Himanshu, Fanny, Davide, Quentin, Gianmarco, Daniele, Michael, Lara, Federica, Martina, Marco, Roberta, Luca, Daniel, Kiko, Anna, Guim, Flavia, Matteo, Elena, Philip, Javi, Alvaro, Blanca and many, many others. Thanks to my historical friends back in Italy: Mario, Alessandra, Sasi, Chiara, Teresa and Enrico. They shared with me most of my life and stayed close even if far away.

Thanks to Andrea and Emanuele, my brothers (in this case also biologically). You are my best friends and always will be one of the biggest certainties of my life.

Grazie ai miei genitori, a cui è dedicata questa tesi. Nemmeno un libro intero pieno solo di ringraziamenti sarebbe abbastanza per esprimere quanto io vi sia grato. Dal primo giorno di scuola fino a quello del mio dottorato, voi avete creduto in me e mi avete spronato senza mai dubitare. Questa tesi è per voi, questo traguardo, il più importante della mia vita, è per voi.

Thank you Iris, love of my life, my person, my everything. You arrived in my life (with Punkie) and made it better from the very first moment. You cheered with me after my successes and pulled me up after every failure. You always believed in me and I feel like a little of this doctorate belongs to you as well. Coming to talk to you, that night in the city centre, was one of the best decisions I've taken in my life. Thanks to you, I am everyday a better man and I will never be able to express how much I owe you. Te quiero.

Finally, a special tribute goes to the city I live in: Enschede. Enschede gave me a home, a job that I love, a second family of beautiful people, and finally the love of my life. The feeling I get every time I arrive after a long trip to Enschede station is a warm welcoming sense of shelter and familiarity. Many 
people see this small city only as a step for reaching something bigger. But I think that the greatness of Enschede sits in this: it gives everybody a lot, asking very little in return. 